\title{
Macro- and microcirculatory derangements in borderline hypertension : relation to salt-sensitivity
}

Citation for published version (APA):

Draaijer, P. (1994). Macro- and microcirculatory derangements in borderline hypertension : relation to saltsensitivity. [Doctoral Thesis, Maastricht University]. Datawyse / Universitaire Pers Maastricht. https://doi.org/10.26481/dis.19940128pd

Document status and date:

Published: 01/01/1994

DOI:

10.26481/dis.19940128pd

Document Version:

Publisher's PDF, also known as Version of record

\section{Please check the document version of this publication:}

- A submitted manuscript is the version of the article upon submission and before peer-review. There can be important differences between the submitted version and the official published version of record.

People interested in the research are advised to contact the author for the final version of the publication, or visit the DOI to the publisher's website.

- The final author version and the galley proof are versions of the publication after peer review.

- The final published version features the final layout of the paper including the volume, issue and page numbers.

Link to publication

\footnotetext{
General rights rights.

- You may freely distribute the URL identifying the publication in the public portal. please follow below link for the End User Agreement:

www.umlib.nl/taverne-license

Take down policy

If you believe that this document breaches copyright please contact us at:

repository@maastrichtuniversity.nl

providing details and we will investigate your claim.
}

Copyright and moral rights for the publications made accessible in the public portal are retained by the authors and/or other copyright owners and it is a condition of accessing publications that users recognise and abide by the legal requirements associated with these

- Users may download and print one copy of any publication from the public portal for the purpose of private study or research.

- You may not further distribute the material or use it for any profit-making activity or commercial gain

If the publication is distributed under the terms of Article $25 \mathrm{fa}$ of the Dutch Copyright Act, indicated by the "Taverne" license above, 
MACRO- AND MICROCIRCULATORY DERANGEMENTS IN BORDERLINE HYPERTENSION

\author{
RELATION TO SALT-SENSITIVITY
}




\section{CIP-DATA KONINKLUJKE BIBLIOTHEEK, DEN HAAG}

Draaijer, Petra

Macro- and microcirculatory derangements in borderline bypertension: relation to salt-sensitivity / Petra

Draatjer. Masstricht : Universitaire Pers Maustricht. -

III.

Thesis Maustricht. - With Ref. - With summary in Dutch.

ISBN $90-5278-122-2$

Subject headings: borderline hypertension /

sall sensitivity / vascular characteristics.

Deze studie werd financieel ondersteund door ASTRA-pharmaceutica BV en Merck, Sharp \& Dohme BV.

\section{Bij de omslag}

Een symbolische weergave van de verschillende facetten van verhoogde bloeddruk. L. Cortenraad 


\title{
MACRO- AND MICROCIRCULATORY DERANGEMENTS IN BORDERLINE HYPERTENSION
}

\author{
RELATION TO SALT-SENSITIVITY
}

\section{Proefschrift}

ter verkrijging van de graad van doctor aan de Rijksuniversiteit Limburg te Maastricht, op gezag van Rector Magnificus, Prof. dr. H. Philipsen, volgens het besluit van het College van Dekanen, in het openbaar te verdedigen op vrijdag 28 januari 1994 om 14.00 uur

door

\section{Petronella Draaijer}

geboren te Voorburg op 28 januari 1963

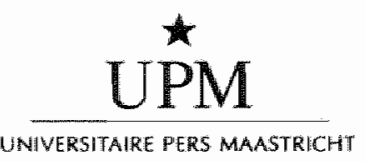




\section{Promotores:}

Prof. dlr. J.P. van Hooff

Prof. dr. P.W. de Leeww

\section{Co-promotor:}

Dr. K.M.L. Leunissen

\section{Beoordelingscommissie:}

Prof. dr. R.S. Reneman (voorzitter)

Prof. dr. W.H. Birkenhäger (Erasmus Universiteit Rotterdam)

Prof. dr. M.E. Safar (Université P\&M Curie, Parijs)

Prof. dr. H.A.J. Struijker Boudier

Prof. dr. H.J.J. Wellens 
aan mijn ouders

voor Erwin 



\section{Chapter 1}

Introduction ..... 1

General introduction

-Definition of borderline hypertension

-Pathophysiological considerations

Background of the study

-Relation between dietary sodium intake

and blood pressure - sodium-sensitivity concept

-Mechanisms of sodium-sensitivity

-Macro- and microcirculatory parameters in borderline

hypertension - relation to soditum-sensitivity

-Pharmacology and macro- and microcirculatory parameters

-Conclusion

-Aims of the study

Chapter 2

Subjects and methods ..... 25

Subjects

Design

Methods

-Sodium-sensitivity assessment:

- Nailfold capillary density

- Arterial compliance and distensibility

-Venous compliance

-Echo-Doppler cardiographic variables

-Renal haemodynamics

-Plasma volume

-Determinations in blood and urine

Statistical analyses

Chapter 3

Salt-sensitivity testing in borderline hypertensive patients ..... 39

Reproducibility and potential mechanisms

Chapter 4

Vascular distensibility and compliance in salt-sensitive and salt-resistant borderline hypertension ..... 57 
Chapter $5 \quad$ Nailfold capillary density in salt-sensitive and salt-resistant borderline hypertension ..... 73

Chapter $6 \quad$ Vascular compliance in salt-sensitive and salt-resistant borderline hypertensive patients ..... 83

Effect of treatment with enalapril or felodipine

Chapter $7 \quad$ Nailfold capillary density in salt-sensitive and saltresistant borderline hypertensive patients ..... 99

Effect of treatment with enatapril or felodipine

Chapter 8 Summary and concluding remarks ..... 107

Chapter $9 \quad$ Samenvatting ..... 113

Dankwoord ...... 119

Curriculum vitae ..... 123 


\section{CHAPTER 1}

\section{INTRODUCTION}

Part of this chapter has been published in Neth J Med 1991;39:158-169. 


\section{General introduction}

\section{Definition of borderline hypertension}

According to the definition of the WHO, borderline hypertension is defined as a blood pressure (systolic/diastolic) between $140 / 90$ and $160 / 95 \mathrm{mmHg}{ }^{1}$. Alternative$1 y$, borderline hypertension is often considered in the sense that blood pressure crosses the arbitrary limit of $140 / 90 \mathrm{mmHg}$ more often than not. In this respect, descriptions as labile and occasional hypertension are also used. These terms imply increased blood pressure variability. Such is, however, not the case, since blood pressure variability tends to increase with higher blood pressure and is not a characteristic feature of slight blood pressure elevations ${ }^{2}$. Terms as early or prehypertensive are also found in the literature to describe blood pressures above $140 / 90 \mathrm{mmHg}$. Early hypertension or pre-hypertension suggest a condition which will with certainty lead to established hypertension. But, it appeared from studies with a follow-up of up to 20 years, that only 20-30 per cent of borderline hypertensives develop established hypertension ${ }^{3}{ }^{4}$. Nevertheless, borderline hypertensive subjects seem to develop established hypertension twice as often as normotensive subjects ${ }^{50}$.

Thus, in practice, no worldwide uniformity in the definition of borderline hypertension exists. The term borderline hypertension has been applied to both persistent and non-persistent blood pressure elevation in the above mentioned range.

Borderline hypertension is a wide spread condition. Among young males the prevalence of borderline hypertension is approximately 10 to 20 per cent ${ }^{7}$, according to surveys held in the United States.

\section{Pathophysiological considerations}

The formula: arterial pressure $=$ cardiac output $\mathrm{x}$ total peripheral resistance, indicates the primacy of flow and resistance in the control of arterial pressure. Any condition that influences cardiac output or peripheral resistance will have its impact on arterial pressure, supposing that the other of the two factors does not change. As in established hypertension, no uniform mechanism leading to increased pressure is present in borderline hypertension. A wide range of abnormalities are encountered in borderline hypertension, considered as a more or less persistent blood pressure elevation above the $140 / 90 \mathrm{mmHg}$ limit.

Elevation of the resting cardiac output can be found in approximately 30 per cent of patients with borderline hypertension, while high vascular resistance seems to be the main pressure elevating mechanism in the remainder. A large proportion of patients exhibits increased resting heart rate 910 . The elevated cardiac output may be neurogenic in origin since the elevation can be abolished with autonomic blockade of 
the heart with propranolol and atropine". Furthermore, the enhanced stroke volume response to increased venous retum in these patients may indicate a sympathetically mediated increased inotropic state ${ }^{12}$. Increased plasma volume does not underlie the increased cardiac output since plasma volume appeared to be reduced in borderline hypertension. An inverse relation has been reported between plasma

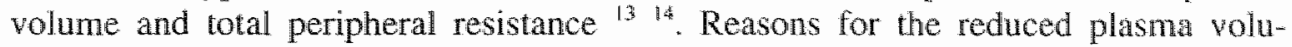
me are not apparent. An abnormal distribution of the extracellular volume between intravascular and interstitial volume may play a role, as was found in established hypertension ${ }^{15}$. The reduced plasma volume/interstitial volume-ratio may reflect an overall decrease in vascular capacity since treatment with vasodilators and alphaadrenergic blocking drugs leads to fluid retention and expansion of plasma volume 16.

In borderline hypertensive subjects with a high cardiac output, total peripheral resistance was found to be normal and thus inappropriately adjusted to the increased output "7. This 'hyperkinetic' high output state is believed to transtorm into a high resistance state in a later phase of the disease 18 . According to the theory of Guyton and Coleman, an elevation in cardiac output above the metabolic demands of the whole body, eventually triggers an autoregulatory response of higher vascular resistance, leading to higher blood pressures, pressor natriuresis and normal fllow and volume ${ }^{19}$. However, Julius and co-workers stated that in hyperkinetic borderline hypertensive patients both the oxygen consumption and the cardiac output are elevated, so that the stimulus for autoregulation is absent. Instead it was supposed that the transition from high output into high resistance occurs entirely through changes in structure and responsiveness of the cardiovascular system in the course of hypertension. Decreased left ventricular compliance and decreased chronotropic responsweness to sympathetic stimulation may explain the reduction in cardiac output ${ }^{17}$. While the movement from relatively normal to high vascular resistance may best be understood within the framework of Folkows's obserwation and his concept of vascular structural reinforcement 20 .

The hyperkinetic state as initial stage in the development of essential hypertension is not commonly appreciated. The hyperkinetic circulatory response may wear off as investigations are repeated. Moreover, it appears to be related to the invasiveness of the method used to determine cardiac dynamics ${ }^{2 !}$. There are also indications that the awareness of having hypertension may contribute to the hyperkinetic state 22 23. Taken together, the hyperkinetic state, as initial state in the development of hypertension may be partly dependent upon environmental factors.

In this respect nomokinetic borderline hypertension was not only seen in older subjects ${ }^{17}$, but also in youngsters ${ }^{24}$. The latter studies reported normal cardiac index and high total peripheral resistance in borderline hypertensive teenagers as compared to normotensive controls. The mechanism of the abnormal peripheral resistance is not completely elucidated. A fully neurogenic elevation of the resistance can be demonstrated only in selected cases ${ }^{25}$. Structural changes in the resistance arteries may also play a role. 
Apart from functional and structural changes at the level of resistance vessels, large arteries and veins also seem to be involved in borderline hypertension. A reduction in both venous ${ }^{26}$ and large artery compliance ${ }^{27}$ has been described in this stage of the disease. It has been suggested that a reduction in venous compliance may contribute to blood pressure elevation through centralisation of blood volume ${ }^{28}$. However, concerning measurements of cardiopulmonary blood volume, problems of validation must be resolved. Arterial compliance is an important determinant of the dynamic component of pressure and flow. Reduced vascular compliance may be the consequence of increased vascular tone, however, structural alterations in the composition of vascular walls may also be involved ${ }^{29}$.

Functional and structural alterations may not be restricted to large and medium-sized blood vessels, but may be also present in the microvasculature of borderline hypertensives ${ }^{30}{ }^{37}$. A considerable part of the elevated resistance in hypertension seems to be determined at microcirculatory level (eg vessels with an internal diameter of $100 \mu \mathrm{m}$ or less), as was demonstrated in experimental models of hypertension ${ }^{32}$. Increased microvessel tone and decreased vessel number seem to be the main mechanisms leading to the increased microvascular resistance in essential hypertension ${ }^{33}$.

The exact role of dietary sodium chloride in the pathophysiology of borderline hypertension is unknown. Only very severe sodium restriction that was started early in life was able to interfere with the development of high blood pressure in spontaneously hypertensive rats ${ }^{34}$, and in newborn infants ${ }^{35}$, suggesting that sodium per se is only a link in the development of hypertension. Indeed, an elevated state of sympathetic function seemed to be a prerequisite for sodium to act as a pressor substance, as was demonstrated in a large epidemiological study performed by Staessen and co-workers ${ }^{36}$. Increased sympathetic nervous activity may mediate renin release and increased plasma renin levels may be the link between sodium and blood pressure in borderline hypertension. Plasma renin levels in borderline hypertension, however, seem to be distributed in a similar fashion as in established hypertension, $\mathrm{eg}$ when $24 \mathrm{hr}$ urinary sodium excretion is related to upright renin levels, low, normal and high levels were found. But low plasma active renin levels were found in combination with low levels of plasma noradrenaline ${ }^{14}$, while high plasma renin levels were found in combination with elevated noradrenaline levels ${ }^{24}$ ${ }^{25}$. Since an individual susceptibility has been postulated as far as the blood pressure response to sodium is concerned, precisely these subjects with high renin levels may be the ones that are salt-sensitive. However, Sullivan divided a group of borderline hypertensive subjects into a sodium-sensitive and a sodium-resistant one and was not able to find evidence for a role of the renin-angiotensin-aldosterone system in the response of the blood pressure to sodium ${ }^{30}$. It was found, however, that during high sodium intake sodium-sensitive subjects had higher forearm vascular resistance ${ }^{37}$, lower venous compliance ${ }^{38}$ and lower capillary density ${ }^{30}$ than sodium-resistant subjects, suggesting that functional and structural properties of the vascular tree contribute to salt-induced elevation of blood pressure. Structural and functional 
properties of large arteries and veins as well as of capillaries and how they rellate to sodium-sensitivity will be the main interest of this thesis.

\section{Background of the study}

\section{Relation between dietary sodium intake and blood pressure - sodium-sensitivity concept}

A positive association between salt and blood pressure across populations was first described by Dahl and co-workers in $1960{ }^{39}$. They found a straight-line relationship between the average sodium intake of a population and the prevalence of hypertension in that population. Subsequently, the relationship between salt and blood pressure has gained considerable scientific attention. In transcultural studies weak positive relationships were described between blood pressure and salt intake (for review see rel. ${ }^{40}$ ). Studies performed within a particular society yielded a less clear picture ${ }^{41}{ }^{42}$. Recently, the results of the INTERSALT study were published, reporting a weak, but significant positive association between 24-hours urinary sodium excretion and systolic blood pressure within a population of 10.079 subjects 43. The weak associations that are in general observed between sodium intake and blood pressure, could well be a reflection of a strong effect of sodium on blood pressure in some subjects and the absence of an influence in others. Furthermore, the fact that normotensive subjects were found in populations consuming large amounts of sodium could also be explained by an individual susceptibility of the blood pressure to sodium intake ${ }^{44}$.

Moreover, it became clear that patients with essential hypertension differ markedly in their blood pressure response to changes in dietary sodium intake 4.5 46; apart from a decrease in blood pressure upon sodium restriction as was first reported by Ambard and Beaujard in $1904^{47}$, some patients display an increase in blood pressure during sodium restriction ${ }^{48}$.

The above mentioned epidemiological and clinical findings have led to the concept of sodium-sensitivity. Sodium-sensitivity is not a clear cut concept. It suggests an on/off phenomenon. However, no study has reported a clear bimodality in the blood pressure responses to a change in dietary sodium intake and the more gaussian distribution of the responses implicates the need of arbitrarily chosen cul-off points. There is no consensus concerning the pressure response upon a sodium load that defines sodium-sensitivity and severall different cut-off points are used. Neither is there uniformity in the methods used to assess sodium-sensitivity status. Diet methods are used, but also intravenous sodium loading followed by diuretics ${ }^{40}$. 


\section{Mechanisms of sodium-sensitivity}

Very important in the sodium-sensitivity concept seems to be a decreased renal capacity to excrete sodium. The subsequent pressure response upon high sodium intake seems to be accomplished by a combination of increased cardiac output and inappropriate adaptation of the total peripheral resistance. The increase in cardiac output upon high salt diet was found to be equal ${ }^{30}$ or greater ${ }^{5}$ in sodium-sensitive subjects than sodium-resistant ones. In the latter subjects, however, the increased cardiac output is accompanicd by a decrease in vascular resistance, while in sensitive subjects no change ${ }^{30}$ or even a rise ${ }^{37}$ in peripheral resistance has been described during high sodium intake. Moreover, dietary sodium intake may induce a reduction in vascular capacily, since a reduction in venous compliance has been described in sodium-sensitive hypertensive subjects on a high sodium diet ${ }^{38}$. The regulatory systems that could be involved in the hemodynamic changes induced by alterations in sodium intake include the following:

\section{Adrenergic nervous system}

Abundant evidence suggests that sodium retention and hypertension in sodiumsensitive subjects may be related to increased activity of the sympathetic nervous system. It was demonstrated in 2.450 subjects that were randomly selected from the population, that a high pulse rate, used as an index of high sympathetic tone, was a prerequisite for sodium to act as a pressor substance ${ }^{36}$. During high sodium diets, plasma noradrenaline levels usually decrease in normal subjects and sodium-resistant hypertensive patients, but levels tend to increase or do not change in sodium-sensitive patients $\$ 253$. Koolen and co-workers demonstrated that noradrenaline release decreased in salt-resistant hypertensive patients whereas it increased in salt-sensitive patients between low salt and high salt periods ${ }^{37}$. Moreover, it has been demonstrated that cumulative sodium retention during high sodium intake was greatest in subjects displaying an increase or only a slight decrease in plasma noradrenaline upon high sodium intake, suggesting that renal adrenergic activity was a factor in the impared sodium excretion in sodium-sensitive patients ${ }^{54}$.

Apart from increased catecholamine release and plasma levels, an enhanced pressor response to noradrenaline could contribute to the blood pressure rising effect of sodium in susceptible individuals. Koolen, however, did not find an increased pressor response to noradrenaline in the forearm vasculature of sodium-sensitive essential hypertensive patients ${ }^{37}$. In contrast, other investigators demonstrated an enhanced blood pressure responsiveness to infused noradrenaline during high salt conditions. A similar trend was seen in response to lower body negative pressure ${ }^{55}$ \$6. In the renal circulation an enhanced noradrenaline sensitivity may explain the increased renovascular constrictor response during upright position, that was found in borderline hypertensives during high sodium intake as compared to normotensive controls, since no difference on plasma catecholamine levels could explain the finding 5 .

Taken together, it is accepted that the sympathetic nervous system relates to sodium 
sensitivity. The nature of this relationship remains to be determined but may consist of facilitation of sympathatic transmission, elevation of plasma catecholamine levels, increased noradrenaline release, increased sensitivity and responsiveness of effector cells or increased central adrenergic activity but also cellular processes beyond receptor level may be involved.

\section{Renin-angiotensin-aldosterone system}

Conflicting data exist on the role of the renin-angiotensin system in the pathophysiology of sodium-sensitivity. Compared to sodium-resistant subjects, a blunted suppression of the renin-angiotensin system during high salt diet, with inappropriately high plasma renin activity ${ }^{58}$ as well as decreased plasma renin activity during low salt diet 49 have been described in sodium-sensitive stibjects. On the other hand, several investigators could not detect any differences in plasma renin activity or aldosterone concentration between sodium-sensitive and resistant subjects on a high and low sodium diet ${ }^{30} 52$. However, it is possible that local activation of the system, not reflected by measurement of renin activity in the plasma, may contribute to sodium-sensitivity. In this respect, inappropriate activation of intrarenal angiotensin II production could participate in the pathophysiology of a subgroup of sodium-sensitive essential hypertensive patients, called the 'non-modulators". Hollenberg and co-workers postulated the concept of non-modulation in normal and high renin essential hypertensive patients. They noticed that, although in normotensive subjects renal blood flow increases upon high sodium intake, in some patients with essential hypertension, no such increase was observed. Moreover, these hypertensive patients did not enhance their aldosterone output in response to acute volume depletion in a manner similar to that observed in normotensive subjects. Because the response of both the adrenal and the renal blood supplies with shifts in total body sodium or effective blood volume is primarily determined by angiotensin II, the above mentioned observations suggested that the underlying difficulty was an abnormality in the interaction of these tissues with angiotensin II ${ }^{59}$. Indeed, in comparison to nomotensive controls, non-modulators displayed a decreased sensitivity of the renal vasculature to angiotensin II during high sodium intake, while treatment with angiotensin converting enzyme inhibitors normalised the decreased sensitivity of the renal vasculature, suggesting an increased intrarenal angiotensin II production and subsequent down-regulation of angiotensin II receptors during high sodium intake ${ }^{60}$.

\section{Peripheral dopaminergic system}

It has become apparent that dopamine is an important neurotransmitter in the peripheral nerwous system. Physiological concentrations of dopamine may mediate renal vasodilation and natriuresis (DAl receptor). Direct DAl receptor stimulation as well as indirect DA2 mediated sympathoinhibition lead to dilation of peripheral blood vessels, while dopamine has an aldosterone suppressive action on the adrenals (DA2). Thus, dopamine acts as a hypotensive natriuretic substance "several investigators suggested a link between an impaired renal ability to mobilise 
dopamine upon high sodium intake, possibly through a decreased renal tubular uptake or conversion by a decarboxylase of dihydroxyphenylalanine (dopa), and the pressor action of salt in sodium-sensitive subjects ${ }^{62}$. The consequences of such a defective conversion would be a low dopamine-to-dopa ratio. Indeed, it was demonstrated that such a low ratio combined with high urinary dopa excretion may be characteristic for sodium-sensitivity ${ }^{64}$. Dopamine as hypotensive substance is counteracted by noradrenaline. Gill and co-workers suggested that a low urinary dopamine-to-noradrenaline ratio determined during high sodium intake may be a reliable index of salt-sensitivity ${ }^{65}$.

\section{Atrial Natriuretic Peptide}

Atrial natriuretic peptide (ANP) may be involved in sodium-sensitivity. ANP is synthesized in cardiac atria and released upon atrial stretch. A steeper rise in plasma ANP levels in response to high salt intake has been reported in sodium-sensitive hypertensives as compared to resistant ones 6667 . The finding of increased levels of ANP in salt-sensitive subjects fits with the concept that sodium-sensitive subjects on a high sodium diet gain more weight, retain more sodium and water, display a greater increase in cardiac output and thereby produce a greater rise in blood pressure than sodium-resistant subjects ${ }^{68}$. In this respect, a positive correlation was observed between the percent change in mean blood pressure and the percent change in plasma ANP level ${ }^{66}$. Alternatively, increased levels of ANP could be related to decreased venous distensibility and right atrial stretch in sodium-sensitive subjects on high sodium intake as was demonstrated by Takeshita et al. ${ }^{38}$.

Recently a brain natriuretic peptide, with characteristics similar to that of ANP, has been discovered ${ }^{69}$. The importance of this factor and its impact on sodiumsensitivity remain to be established.

Moreover, other, less defined, natriuretic substances may be involved in sodiumsensitivity. De Wardener and co-workers observed that plasma obtained from normal subjects on a high sodium intake inhibited $\mathrm{Na}^{*}-\mathrm{K}^{*}$-ATPase activity approximately 25 thes more than plasma from the same subjects on a low sodium diet. There appeared to be two ouabain-like substances with an ability to inhibit $\mathrm{Na}^{*}-\mathrm{K}^{*}$ ATPase, that were probably synthesized in the hypothalamus. Subsequently, an increase in the plasma's capacity to inhibit sodium transport was found to be present in essential hypertensive patients and it was postulated that increased levels of $\mathrm{Na}^{+}$$\mathrm{K}^{*}$-ATPase inhibition may be an important factor in the pathogenesis of saltsensitive hypertension ${ }^{70}$. The $\mathrm{Na}^{+}-\mathrm{K}^{+}$-ATPase inhibitor may lead to increased renal sodium excretion and may produce an increased intracellular sodium concentration 1! This may alter the process of sodium-calcium exchange, thereby leading to an increased intracellular concentration of free calcium. In vascular smooth muscle cells such a raised level of free cytosolic calcium could increase arteriolar tone, thereby mediating the pressor effect of sodium. Later studies demonstrated a direct relation between the salt-induced blood pressure rise and the salt-induced increase in free intracellular calcium concentration in circulating mononuclear cells of essential hypertensive patients ${ }^{72} 73$. However, it remains to be determined whether salt.- 
induced increases in white blood cells reflect corresponding increases in vascular smooth muscle cell's intracellular calcium concentration.

Taken together, many studies have been performed to unravel the etiology of sodium-sensitivity. The underlying mechanisms are complex, multifactoral and probably interrelated. This may explain the lack of a unifying scheme of pathogenetic and pathophysiologic events.

\section{Macro- and microcirculatory parameters in borderline hypertension . relation to sodium-sensitivity}

\section{Macrocirculation}

Borderline hypertension is associated, as was noted before, with an increased risk to develop established hypertension. Moreover, sodium-sensitive essential hypertensive subjects appeat to demonstrate a more severe course of the disorder ${ }^{74}$. Such could be related to a higher afterload for the heart and to atherosclerotic changes in the blood vessels, predominantly the large arteries. The latter serve two important purposes. Firstly, they conduct blood from the heart to the capillary beds and, secondly, they store a fraction of the ventricular outflow in their distensible walls in order to buffer the pulsatile dynamics generated by the heart. The latter function of large arteries may be quantitatively expressed by compliance. A reduction in systemic arterial compliance has been described in borderline 27 and established hypertension 75 . The observation that arterial compliance is reduced in young borderline hypertensive subjects as compared to age matched controls, shows that the decrease in compliance of large arteries begins early in the development of hypertensive disease. Furthermore, large arteries appear to age faster in borderline hypertensive subjects than in normals ${ }^{76}$. Since arterial distensibility decreases as the distensing pressure rises, it is possible that the reduced distensibility is explaned solely on the basis of arterial distension, the applied load shifting with increasing pressure from the extensible elastin to the relatively inextensible collagen component of the wall ${ }^{29}$. However, a $40 \%$ decrease in arterial compliance has been demonstrated in borderline hypertensive subjects displaying only a $14 \%$ increase in arterial pressure when compared to normotensive subjects of the same age ${ }^{27}$. Thus, arterial compliance clearly was reduced to a greater extent than would be expected from the increase in pressure alone, suggesting that other factors are involved such as structural or functional alterations of the arterial walls. Incleed, since at nearly matched pressure values, compliance is improved by direct smooth muscle dilation, a-blockade and angiotensin converting enzyme inhibition, but not by B-blockade, intrinsic alterations in the hypertensive wall may be involved in the reduction of arterial compliance ${ }^{n}$.

Alternatively, the question may be raised whether the alterations in arterial wall properties are really a result of the elevated blood pressure, or that they develop independently of the blood pressure rises. In this respect, a limited maximal 
vasodilator capacity was demonstrated in normotensive young men with a familial predisposition to hypertension at the level of the resistance arteries ${ }^{78}$. Similarly, structural changes in large arteries may precede the onset of blood pressure elevation.

Several studies have shown that arterial sliffness is dependent on dietary salt intake and that the relationship between arterial stiffness and salt intake is independent of, and additional to, the relationship between stiffness and mean arterial pressure 80. In animal studies it was found that a decrease in sodium intake may improve cardiac hypertrophy independently of blood pressure changes 81 and that an elevated sodium intake is associated with structural alterations in large arteries ${ }^{82}$. In this respect, it may be hypothesized that a more pronounced reduction in arterial compliance is related to the less benign course of the hypertensive process seen in sodium-sensitive subjects as compared to sodium-resistant ones, because reduced vascular stiffness may accelerate the detrimental effects of hypertension stuch atherosclerosis ${ }^{83}$. Furthermore, it was noted in cross-sectional studies that the correlation coefficient relating cardiac hypertrophy to blood pressure was relatively low, indicating that other factors than vascular resistance play a role in the development of cardiac hypertrophy. Moreover, cardiac hypertrophy correlates better with systolic than with diastolic blood pressure ${ }^{84}$. Therefore, reduced arterial compliance with its predominant impact on systolic blood pressure and pulse pressure, may be important for the development of cardiac hypertrophy. In women older than 55 years, reduced compliance and increased pulse pressure, were positively correlated with death from coronary heart disease, indicating that although the steady component of blood pressure is the principal risk factor of cardiovascular death in both sexes, the pulsatile component is an independent risk factor of cardiovascular death ${ }^{85}$.

Venous compliance is also reduced in borderline hypertensive subjects ${ }^{26}$. This may be of pathophysiologic significance since capacitance vessels are able to shift intravascular volume from the peripheral to the intrathoracic compartment, thus raising cardiopulmonary volume and cardiac output ${ }^{86}$. Pari of the decreased venous distensibility in borderline hypertension appeared to be caused by $\alpha$ adrenergic venoconstriction, but after phentolamine administration venous distensibillty values remained below these of normotensive controls ${ }^{26}$. Therefore, other factors such as structural alterations in the venous system may be involved. A small increase in the water and glycosaminoglycan content of veins has been found in human hypertensives ${ }^{87}$. Increased water and sodium logging ${ }^{88}$, increased glycosaminoglycan content ${ }^{89}$, less distensible collagen 90 and vascular smooth muscle hypertrophy ${ }^{91}$ have been encountered in the venous wall of experimental models of hypertension.

Venous compliance was significantly decreased during high sodium intake in sodium-sensitive hypertensive subjects but not in sodium-resistant ones ${ }^{38}$. The difference between the groups persisted after o-blockade with phentolamine. This may suggest that excess salt intake may cause structural changes in veins during a 
high salt diet in salt-susceptible patients.

In summary, vascular compliance seems to play a role in the pathophysiology of borderline hypertension. Moreover, the diversion in haemodynamic responses upon high sodium intake between sodium-sensitive and sodium-resistant subjects may be partly based upon differences in the effects of sodium on the venous and arterial walls. Limited information is available on the relation between sodium-sensitivity and vascular compliance during regular daily sodium intake. In the context of the more severe course of hypertensive disease in sodium-sensitive subjects, this information may be of value.

\section{Microcirculation}

Macrocirculatory alterations encountered in borderline hypertension, such as increased resistance, increased cardiac output, reduced total systemic compliance and decreased plasma volume may have impact on microvascular dynamics. The improvements in in-vivo microscopic techniques have allowed a critical study of the microcirculation in hypertension. It appeared in experimental models of hypertension, that a considerable part of the increased resistance that underlies the elevation of blood pressure is determined at microcirculatory level (vessels with an internal diameter less than $100 \mu \mathrm{m}){ }^{32}$. Microcirculatory studies in spontaneously hypertensive rats (SHR), and to a lesser extent, in human hypertensives, have revealed two mechanisms that predominantly raise microvascular resistance: (1) a decreased internal diameter of the arterioles; (2) a decrease in the total number of arterioles and capillaries (rarefaction).

Zweifach studied pressure-flow relationships in the microcirculation of the spinotrapezius muscle of young and mature SHR and Wistar Kyoto (WKY) control rats. He demonstrated a greater drop in pressure and a normal flow across the arteriolar branchings of the hypertensive rats, as early as 5-6 week of age, a difference that became more evident in the 13-14 week old mature hypertensive rats ${ }^{32}$. Since the increased resistance developed at an early age, the data suggested that hypertension is associated with a generalized effect on the muscular arterioles, an effect that becomes more pronounced with time. Some studies indicated that this effect on the muscular arterioles was able to protect the terminal vascular bed from the elevated systemic blood pressure ${ }^{32}{ }^{92}$. However, direct measurements of the capillary pressure in SHR skeletal muscle, demonstrated that the pressure elevation still exists in the capillary bed and even in the wenules ${ }^{93}$.

Several studies have demonstrated a higher vessel wall tone in skeletal muscle of the young as well as the mature SHR ${ }^{32}$. Such tone can be demonstrated by comparing the steady state diameter with that after maximal vasodilation. In the spinotrapezius muscle of the mature SHR the tone in the transwerse arterioles is 30$40 \%$ higher than in WKY controls, despite the fact that age-matched cohorts show almost identical diameters after maximal vasodilation ${ }^{32}$. This elevated tone is heterogeneously distributed throughout the microvascular network, and it varies 
cyclically during the vasomotor activity ${ }^{94}$. Apart from the SHR skeletal muscle, an elevated vascular tone was also demonstrated in the intestine ${ }^{95}$ and the cerebral cortex ${ }^{96}$ of the adult SHR.

Data that support a neurogenic origin of increased vessel tone in the SHR, include an elevated central sympathetic nerve activity ${ }^{97}$ and an increased density of the nervous plexus in the arterioles in this species 98 . An increased response to adrenergic blocking agents was also demonstrated in the SHR $"$ Moreover, an elevated sensitivity of the arterioles to noradrenaline ${ }^{100}$ and to oxygen ${ }^{101}$ has been demonstrated.

Initial studies in the SHR failed to show a difference in resting arteriolar diameters as compared to controls $90.10 \%$ whereas the above mentioned studies demonstrated an elevated vascular tone. Part of this discrepancy may be explained by the fact that the smallest arterioles tend to close during the development of hypertension and are not included in measurements of resting arteriolar diameter 104. Furthermore, the use of general anaesthetics during the experiments may have a depressant effect on vascular smooth muscle tone. Le Noble at al studied the cutaneous muscle microcirculation in adult SHR and WKY that were provided with dorsal microcirculatory chambers, so that the microvessels could be studied without the use of general anaesthetics. They demonstrated a diameter reduction of the first and second order arterioles in the adult hypertensive rats as compared to the normotensive controls. However, third and fourth order arteriolar diameters did not differ from those in normotensive rats ${ }^{105}$.

Considerable evidence has been accumulated to indicate that not only changes in vessel caliber, but also in vessel number contribute to the elevated resistance in the SHR. Prewitt and co-workers ${ }^{105}$ demonstrated in the gracilis muscle in rats of $6-8$ week of age, the age at which the pressure starts to rise, a diminished capillary density in the SHR as compared to the WKY, not only at rest but also after denervation and vasodilation. At this age there was no difference in arteriolar density between the two strains. At 12-14 week of age there was a reduction of arteriolar density under innervated and denervated conditions, but not after vasodilation. This is called functional rarefaction. At 16-18 week of age the SHR showed a diminished arteriolar density in rest, after denervation and after vasodilation: a state of anatomical or structural rarefaction. So, the development of rarefaction of arterioles proceeds from a state of normality at 5-6 week of age, via a state of functional rarefaction at 12-14 week of age to finally at 16-18 week of age, a state of functional and anatomical rarefaction, where there is a true reduction of the number of arterioles in the tissue. Prewitt demonstrated a $56 \%$ reduction in arteriolar density in the gracilis muscle of the SHR. In the cremaster muscle Hutchins reported a $50 \%$ reduction in number of perfused arterioles in young rats of 6 week of age ${ }^{103}$, as did Le Noble et al ${ }^{107}$. Rarefaction has allso been demonstrated in the skin 102 and the mesentery ${ }^{108}$ of the SHR. In the cerebral cortex the number of arterioles per unit area of brain surface was equal in SHR and WKY, at rest as well as during maximal vasodilation ${ }^{96} 109$. 
Green at al constructed a mathematical model of the microcirculation of the hamster cheek pouch and demonstrated that vessel rarefaction significantly influences tissue blood flow resistance to a degree comparable with vessel constriction ${ }^{110}$.

The rarefaction concept is at variance with the studies of Engelson and co-workers, who performed a quantitative comparison of the anatomical arrangement of arterioles in the skeletal muscle of mature (16-18 week) SHR and WKY. They reported a denser arteriolar network in the spinotrapezius muscle in the hypertensive rats "11. Morphological studies performed by Gray were also unable to confirm the rarefaction concept ${ }^{112}$.

Increased sympathetic tone has been considered as an important cause of rarefaction. However, cutting the nerves dilated the open vessels and increased capillary density, but did not change arteriolar density. The majority of the closed arterioles opened only after application of nitroprusside. Circulating agents as plasma noradrenaline or angiotensin could also contribute to the closure ${ }^{10 \%}$. Another possibility is that local autoregulatory mechanisms are responsible for rarefaction of microvessels. During the development of hypertension, the increasing blood pressure in the SHR tends to overperfuse the tissues. This may result in a wash-out of vasodilating substances 11: , but also in a diminished vascular growth due to an autoregulatory response to oxygen overload 107 .

In contrast to the large number of microcirculatory studies in the SHR, only few studies have been performed in the microcirculation of human essential hypertensives. Most of the investigations of the human microvasculature are performed by non-invasive methods and are therefore restricted to the skin, the bulbar conjunctiva and the retina. By way of exception, muscle biopsies have been used to investigate the microvessels in human hypertensives ${ }^{1 / 4}$.

Early studies in the bulbar conjunctiva of human subjects with moderate to severe hypertension have revealed capillary 115 and arteriolar 116 narrowing as well as elongation and tortuosities of these vessels. Harper demonstrated a $5 \%$ decrease in arteriolar diameter in the conjunctiva of essential hypertensives 1i?. Sullivan studied the conjunctival microvessels in young patients with borderline hypertension and found no reduction of arteriolar diameter in this early stage 3 . Henrich demonstrated a $37 \%$ decrease in the capillary density in the pectoralis major muscle and a $51 \%$ decrease in capillary density in the quadriceps muscle of essential hypertensives 114. A $20 \%$ reduction in arteriolar density has been found in the conjunctiva of hypertensive subjects ${ }^{11 \%}$. In borderline hypertensives, a decreased capillary and venous density has been demonstrated in the conjunctival microcirculation, whereas conjunctival arteriolar density did not differ from normotensive controls ${ }^{31}$. Moreover, in sodium-sensitive borderline hypertensives a decreased conjunctival capillary density was demonstrated during high sodium intake as compared to sodium-resistant subjects ${ }^{30}$, suggesting a relation between sodiumsensitivity and capillary density in borderline hypertension.

Direct measurements of capillary pressure have been performed in the nailfold of human essential hypertensives. Eichna found a $5 \%$ increase in capillary pressure in established hypertensives; an increase that did not reach statistical significance lis. 
Recently Tooke demonstrated a statistically significant increase in nailfold capillary pressure in established essential hypertension ${ }^{119}$, suggesting that the resistance elevation by increased tone and decreased density of microvessels is not sufficient to prevent a rise in blood pressure at capillary level.

Thus, microvascular abnormalities are present in borderline hypertension. This early stage of essential hypertension seems to be characterised by a decrease in capillary density, while arteriolar tone and density are still unaltered as compared to normotensive controls. Moreover, decreased capillary density may be connected to sodium-sensitivity.

\section{Pharmacology and macro and microcirculatory parameters}

Pharmacological treatment of hypertensive patients should aim not only to lower blood pressure, but also to improve the mechanical properties of the cardiovascular system. Angiotensin converting enzyme inhibitors can reverse structural arterial changes and increase arterial compliance $120121 \quad 122$, as do calcium-entry blockers ${ }^{123}$. Large artery compliance is not significantly modified by $\alpha-{ }^{124}$ and B- ${ }^{122}$ blocking agents. Dihydralazine does not improve large artery compliance ${ }^{125}$, while nitroglycerine in low doses has a beneficial effect ${ }^{126}$.

Venous tone is predominantly influenced by sympathetic activation and circulating catecholamines acting on adrenergic receptors and is not dependent on voltage-gated calcium-channels ${ }^{22}$. Therefore, alpha-adrenergic blocking agents may have impact on venous compliance, while calcium entry blockers will have little effect on the venous system 128129 . Angiotensin converting enzyme inhibitors act as venodilators ${ }^{128}$, although angiotensin II is not effective in constricting veins 130 . Possible explanations for this paradox may be that angiotensin II potentiates the effect of sympathetic stimulation ${ }^{131}$ or, alternatively, that increased levels of bradykinin, contribute to the venodilation ${ }^{27}$. Organic nitrates have a pronounced relaxant effect on veins, but, venous compliance is not necessarily improved by these agents, since venodilation may result in an increased unstressed venous blood volume, without altering the volumefpressure relationship ${ }^{132}$.

Limited information is available on the effects of antihypertensive drugs on microvessel rarefaction and angiogenesis. Since capillary growth seems to be induced by increased shear stress and blood/endothelial cell interaction or by increased capillary wall tension ${ }^{13}$, it may be expected that drugs inducing profound haemodynamic changes at microvascular level, may also influence capillary growth. The calcium-antagonist felodipine may alter microvessel dynamics, since increased small arteriolar and to a lesser extent, large arteriolar diameter was demonstrated in a study in striated muscle in the conscious spontaneously hypertensive rat by Messing and co-workers. In contrast, the ace-inhibitor enalapril did not influence arteriolar diameter in this experimental model 134 135. Furthermore, an adverse effect of ace-inhibitors on microvascular growth has been demon- 
strated in the one-kidney, one-clip hypertensive rat ${ }^{136}$. Long term treatment with hydralazine ${ }^{137}$ and prazosin ${ }^{133}$ leads an increased microvascular growth in spontaneously hypertensive rats. The possible effects of pharmacological agents on the human microcirculation remains to be elucidated.

\section{Conclusion}

Functional and/or structural alterations of the vasculature seem to be present in both the macro and microcirculation of borderline hypertensive subjects. Borderline hypertension, as an initial state of the hypertensive disease, represents an interesting model of the early alterations of the cardiovascular system that may eventually lead to established hypertension. Vascular compliance was found to be reduced in borderline hypertension. Arterial compliance is not only a main determinant of pulse pressure and systolic blood pressure, but may also be involved in ill effects of the hypertensive process such as cardiac hypertrophy and atherosclerosis. Venous compliance may contribute to the onset of hypertension by shifting intravascular blood volume from the peripheral parts of circulation towards the cardiopulmonary part. The reduction of the number of perfused capillaries in borderline hypertension may represent a consequence of the increased pressure, but, alternatively, it may represent a diminished microvascular growth, in time leading to blood pressure elevation.

The exact role of sodiumchloride in the pathophysiology of hypertension is not clear. During high sodium intake, however, sodium-sensitive borderline hypertensive subjects displayed lower arterial and venous compliance as well as lower conjunctival capillary density than sodium-resistant ones. The more severe course of the hypertensive process, seen in sodium-sensitive subjects may well be related to the effects of sodium on the macro- and microcirculation. However, whether macro and microvascular differences between sodium-sensitive and sodium-resistant subjects are still present under the conditions of normal daily sodium intake, is not known. The present study is an attempt to gain insight into some macro and microcirculatory variables during regular sodium intake in sodium-sensitive and sodiumresistant borderline hypertensive subjects. Moreover, the effects of pharmacological intervention will be studied.

\section{Aims of the study}

\section{Firstly, the sodium-sensitivity concept is studied.}

Chapter 3 describes a study performed in order to assess the reproducibility of sodium-sensitivity. In this study, sodium-sensitivity was arbitrarily defined as a difference in mean arterial pressure of at least $8 \mathrm{mmHg}$ between a low sodium regimen consisting of $20 \mathrm{mmol} / \mathrm{day}$ for one week and a high sodium regimen of 220 
mmol/day for one week. Moreover, factors of putative pathophysiologic importance, such as renal haemodynamics and blood pressure regulating hormones, were studied in order to assess whether a certain diversion of these factors between sodiumsensitive and resistant subjects after oral salt-loading was consistently present during both the initial investigation and the repeated study, that was performed approximately one year after the initial investigation. It was reasoned that a lack of reproducibility for a given variable would tend to diminish its impact in the pathogenesis of salt-sensitivity.

\section{Secondly, macro- and microcirculatory parameters in sodium-sensitive and sodium-resistant borderline hypertensive subjects were studied and compared to those of normotensive controls.}

Chapter 4 provides the results of a study on arterial and venous compliance in borderline hypertensive subjects and normotensive controls, who all had a regular sodium intake of approximately $120 \mathrm{mmol}$ per day. This study was performed in order to explore whether the borderline hypertensive subjects displayed reduced arterial and venous compliance as compared to normotensive controls. Moreover, it was assessed whether differences exist in vascular compliance between sodiumsensitive and resistant subjects.

Chapter 5 gives the results of a study of nailfold capillary density under the condition of regular sodium intake. Nailfold capillary density was compared between the sodium-sensitive and sodium-resistant borderline hypertensive subjects, as well as between the borderline hypertensive subjects and normotensive controls.

\section{Finally, the effects of antihypertensive therapy on the macro-and micro- circulatory parameters under study were investigated.}

Chapter 6 demonstrates the effects of long-term treatment with either the aceinhibitor enalapril, the calcium-antagonist felodipine or placebo on arterial and venous compliance in sodium-sensitive and resistant borderline hypertensive subjects.

Chapter 7 describes the effects of long-term treatment with enalapril and felodipine on nailfold capillary density. 


\section{References}

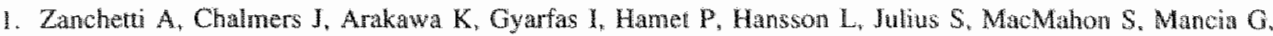
Menard J, Omae T, Reid J, Safar M. 1993 Gudelines for the managenuent of mill hypertension. Memoran dum from a WHOHSH meeting. ISH Hypertension mews 1993;jne:3-15.

2. Watson RDS, Stallard TY, Flin RM, Littler WA. Factors determining direct arterial pressure arid its variability in hypertensive man. Hypertension 1980;2:333-341.

3. Bohm R, van Baak M, van Hooff M, van Kemenade J, Rahn KH. Longerm study of the sympatheti: nervous system and the renin-angiotensin system in borderline hyepertension. Kidney Ini 1985:28:698.

4. Julius S, Schork MA. Borderline hypertension. A critical review. J Chr Dis 1971;23:723-754.

5. Sokolov M, Perloff D. The prognosis of essential hypertension treated conservatively. Circulation $1961,23,697-713$.

6. Pafferbarger RS. Thome MC. Wing AL. Chronic diseases in former college students. VIII characteristics in youth predisposig to hypertension in later years. Arn J Epidemiol 1968;88*25-45,

7. Hypertension detection and follow-up program cooperative group. The bypertension detection and followup program: A progress repont. Circ Res 1977; 40(suppl 1)1106-1109.

8. Roberts I. Blood pressure levels of persons 6-74 yrs. United states 1971-1974. Vital Health Stat $1977 ; \operatorname{ser} 11: 203-223$.

9. Julius S. Esler M. Autonomic nervous cardiovascular regulation in borderline hypertemsion. Am $J$ Cardiol $1975 ; 36: 685-696$.

10. Lund Johansen P. Hemodynamics in essential hypertension. Clin Sci Molec Med 1980;59:343.344.

11. Julius S, Pascual AV, London R. Role of parasympatic inhibition in the hyperkinetic type of borderline hypertension. Circulation 1971:44:413-418.

12. Eillis EN, Julius $\mathrm{S}$. Role of central blood volume in hyperkinetic borderline byperiension. Br Heart $\mathrm{J}$ $1973,35: 450-455$.

13. Julius $S$, Pascual AV, Reilly $K$, London $R$. Abnomalities of plasma volume in borderline hypertension. Arch Intern Med 1971:127:116-119.

14. de Leeuw PW, Kho TL Birkenlläger WH. Pathophysiologic features of hypertension in young men. Chest 1983 ; 2 february supplement:312-314.

15. Taraz RC, Frohlich ED, Dustan HP. Plasma volume in men with essential hypertension. N Engl J Med $1968.278 .762-765$.

16. Rushmer RF. Properties of the vascular system. Cardiovascular Dynamies, WB Saunders Company, Philadelphia, 1970 .

17. Julius $\mathrm{S}$. Transition from high cardiac output to elevaled vascular resistance in hypertension. An Heart $J$ 1988;1 16:600-606. 
18. Lund Johanswen P. Hemodynamic alterations in early essential bypertension: Recent advances. In Mild Hypertension, adied by Funz Gross and Toma Strasser. Kaven Press, New York, 1983: page $237-249$.

19. Guyton $A C$, Coleman TG. Quantiative analysis of the pathophysiology of hyperiension. Circ Res $196924 \cdot 25$ (supp 11$) \cdot 11-119$

20. Folkow B. Physiological aspects of primary hypertension. Whysiol Rew 1982:62:347-503.

21. Birkenhager WH. A critical interpretation of juvenile bordarline hypertension. I Hypertens 1991;94suppl6).\$2-\$9.

22. Rostrup M, Munda HH, Wertheim A. Eide IK. Awareness of high blood pressure increases arterial plasma catecholamines, platelet noradrenaline and adrenergic responses to mental stress. J Hypentens $1991: 9: 159-166$.

23. Rostrup M, Kjeldsen $\mathrm{SE}_{\text {, }}$ Eide $\mathrm{KK}_{\mathrm{w}}$ A waremess of bypertension increases blood pressure and sympathetic responses to cold pressior test. Am J Hypertens 1990;3:912-917.

24. Homan A, Roelandt JTRC, Boomsma F, Schalekamp MADH, Valkenburg HA. Haemodynamics, phasma noradrenaline and plasma renin in hypertensive and normotensive teenagers. Cli Scit 1981:61:169-174.

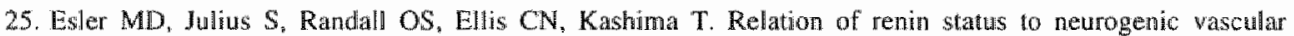
resistance in borderine hypertension. Am Candiol 1975;36:708-715.

26. Takeshita A. Mark A. Decreased venous distensibility in borderline hypertension. Hypertension $1979: 1: 202206$

27. Ventura HO, Messerli FH, Oigman W, Suarez DH, Dreslinski GR, Durn FG, Reisin E, Frohlich ED. Impanged systemic arterial complance in borderline hypertension. AM Heart J 1984;108:

$132-136$

28. Safar ME, Weiss YA. London GM, Frackowiak RF, Milliez PL. Cardiopulmonary blood wolume in borderline hypertension. Clin Sci Mol Med 1974:47:153-157.

29. London GM, Marchais SJ, Safar ME. Arterial compliance in hypertension, J Human Hypert 1989;3:53-56.

30. Stllivan JM. Prewitt RL, Rats. TH, Josephs JA. Connor MJ. Hemodynamic characteristics of sodium. sensitive subjects. Hypertension 1987,9:398-406.

31. Sullivan JM, Prewitt RL Josephs BS. Attenuation of the microcirculation in young patients with borderline hypertension. Hypertension 1983:5:844-851.

32. Zweifach BW, Kolwacheck S. De Lano PA. Chen PCY. Micropressurewhow relationships in a skeletal muscle of spontaneously hy pertensive rats. Hypertension 1981:3:601-614.

33. Draijier P. Le Noble JLML, Leunissen KML., Struylker Boudier HAI. The microcinculation and essential hypertension, Neth J Med 1991;39:158-169.

34. Wilczynski EA, Leenen FHH. Dietary sodium intake and age in spontaneously hypertensive rats: effects on blood pressure and sympathetic activity. Life Sci 1987;41:707-715.

35. Hofman A. Hazebrok A, Valkenburg HA. A randomized trial of sodium intake and blood pressure in newbon intants. JAMA 1983250:370-373. 
36. Stuessen I, Bulpit Cl, Thys L, Fagard R, Joossens IV, wan Hoof R. Amery A. Sympathetic tone and relation between sodium intake and blood pressure in the general population. Br Mod $J 1989,299: 1502,1503$.

37. Koolen MI van Brummeten P. Adrenergic activity and peripheral hemodynamics in relation to sodiumsensitivity in patients with essential hypertension. Hypertension $1984,6,820-825$.

38. Takeshita A, Ashihara $T$, Yamamoto $K$, Inaizumi $T$, Hoka $S$, Ito $N$, Nakamura M. Venous responses to salt loading in hypertensive subjects. Circulation 1984;69 nol:50-56.

39. Daht LK. Possible role of salt intake in the development of essential hypertension. in Cotter P. Bock KD (eds): Essential Hypertersion-an international symposium. Berlin, Springer-Verlag. 1960:53-65.

40. Eliott P. Observational studies of salt and blood pressure. Hypertension 199 ; 17 (suppl1):13-18.

41. Simpson FO, Wal-Manning HJ, Bolli P, Phelan LE, Spears GFS. Relationship of blood pressure to sodium excretion in a population sarvey. Clin Sci Mol Med 1978;55:5373 5375.

42. Ljungman $S_{n}$ Aurel $M$, Hartford $M$, Wikstrand J, Wilhelmsen L, Berglund $G$. Sodium excretion and blood pressure. Hypertension 1981;3:318-326.

43. Stamler J, Rose $G$, Elliot P, Dyer A, Marmot M, Kesteloot H, Stamler R. Findings of the international cooperative INTERSALT study, Hypertension 1991;17(supplI):19-115.

44. Sasaki N. The relationship of salt intake to hypertension in the Japanese. Geriatrics 1964; 19:735-744.

45. Brown WJ, Brown FK, Kristan 1. Exchangeable sodium and blood volume in notmotensive and hypertensive humans on high and low sodium intake. Circulation 1971;13:508-519.

46. Kawasaki T, Delea CS, Bartter FC, Smith $\mathrm{H}$. The effect of high sodium and low sodium intakes on blood pressure and other related variables in human subjects with idiopatic hypertension. Am J Med 1978;64:193. 198.

47. Ambard J, Beaujard E. Causes de I"hypertension aterielle. Arch Gen de Medicine 1904:1:520-533.

48. Longworth DL, Drayer JMM, Lieber MA. Laragh JU. Diwergene blood pressure responses duritg silnortlerm sodiun restriction in hypertension. Clin Pharmacol Ther 1980;27:544-546.

49. Sullwan JM, Ratts TE. Sodum sensitivity in human subjects. Hemodynamic and homonall contaties. Hypertension 1988:11:717-723.

50. Weinberger MH, Miller J2, Luft FC, Grim CE, Fineberg NS. Defintions and characteristics of sodiumsensitiwity and blood pressure resistance. Hypertension 1986:8(supp/II):11127-11134.

51. Fujita $T$, Henry WL, Barter FC, Lake CR, Delea CS. Factors influencing blood pressure in salt-sensitive patients whth hypartension. Am J Med 1980:69:334-344.

52. Campese VM, Romoff MS, Levitan D. Saglites Y, Friedlier RM, Massry SG. Abnormal relationship between sodion intake and sympathetic nervous activity in salt sensitive patients with essential hypertension. Kidney Int $1982 ; 21: 371-378$

53. Romoff MS, Keusch $G$, Campese VM, Wang MS, Friedlet RM, Weidmann P. Massiry SG. Effeet of sodium intake on plasma catecholamines in normal subjects. J Clin Endocrinol Metab 1979;48:26-31.

54. Gill JR, Gullner HG, Lake RC, Lakma DJ, Lan G. Plasma and urinary catecholamines in satl-gensitive idiopathic bypertension. Hypertension 1988;11:312-319. 
55. Abboud FM. Effects of sodrum, angiotersin and steroids on vascular reactivity in man. Federation Pitoc $074,33: 343-149$.

56. Skrabal $\mathbb{E}$, Herholz H, Neurrayr M. Hamberger L, Ledochowski M. Sporer H, Hortiagl H, Schwarz 5 . Schonitzer D. Salfsensitwity in humans is linked to entheded sympathetic responswyeness and to enhanced proximal tubular reabsorption. Hypertension $1984 ; 6: 152-158$.

57. Lawton W. Sinkey CA. Fit2 AE, Mark AL. Dietary sall produces abnomial renal vasoconstrictor responses to upright posture in borderline hypertentsive subjects. Hypertension 1988:11:529.536.

58. Oshima "T, Matscura $H_{\text {, Kido }} K$, Matsumoto $K$, Shingu $T$, Otsuki $T$, lnowe $\mathbb{I}$. Kajyana $G$. Factors detcrmining sodium chloride sensitivity of patients with essential hypertension: evaluation by multivariate analysis. J Hypertens $1989 \cdot 7: 223-227$.

59. Hollenberg NK, Williams GH. Sensitivity to sodium and non-modulation of renal and adrenal responsiveness to angiotensin II: Implications for the pathogenesis of essential hypertension. In 'Handbook of' Hypertension', Vol 8: Pathophysiology of hypentension-regulatory mechanisms. Eds Zancherti A, Tarazi RC. Enseviers science publishers b. $v_{\text {. }} 1986$ Chapter 25.

60. Hollenberg NK. Williams GH.The renal response to converting enzyme inhibition and the reatment of sodium-sensitive hypertension. Clin Exp Theory Prac 1987;A9(2\&3):531-541.

61. Carey RM, Siray HM, Ragsdale NV, Howell NL, Felder RA, Peach MJ, Chevalier RL. Dopamine-1 and dopartaine-2 mechanisms in the control of renal function. Am J Hypertens $1990,3: 595 \% 63$ S.

62. Shikuma R, Kambara $S$, Yoshimura M. Takashina $\mathbb{R}$, Yamasaki H, Takeda $K$, Takanashi H, ljichi $H$. Dopaminergic modulation of salt-sensitivity in essential hypertension. Jap J Kidney Dis 1984;26:417-423.

63. Lee MR. Salt, renal dopamine and essential hypertersion. Triangle 1987;26(1):11-21.

64. Gill JR, Grossman E, Goldstein DS. High urinary dopa and low dopamine-to-dopa ratio ifl salt-sensitive hypertension. Hypertension 1991:18:614-621.

65. Gill JR, Gullner HG, Lake CR, Lakatua DJ, Lan G. Piasma and urinary catecholamines in sall-sensitive idiopathic bypertension. Hypertension 1988;11:312-319.

66. Kohne: M, Yasumari K. Munakawa K, Kanayanka Y. Marsura 'T, Takeda T. Effects of high sodium and low sodium intake on circulating atrial natriuretic peptides in sall-sensitive patients with systemic hypertension. Am J Cardiol 1987,59:

$1212-1213$

67. Sowers IR, Zenel MB, Zemel P. Beck FW, Walsh MF, Zawada ET. Selt-sensitivily in blacks. Salt intake and natrimetic substances. Hypertension $1988: 12: 485-490$.

68. Fujita T, Andro $\mathrm{K}$. Ogats E. Systenic and regional hemodynamics in parients with salt-sensitive thypertension. Mypertension 1990;16;235-244.

69. Kichands AM, Crozier 1G, Holmes SI, Espiner EA, Yanddle TG, Frampton C. Brain natriuretic peptide; natritutic and endocrine effects an essental hypertension. J Hypertens 1993:11:

$163-170$

70. De Wardener HE, MacGregor GA. The relation of a circulating sodium transport inhibitor cthe natiuretic homone?) to hypertension. Medicine 1983;62 no5:310-326. 
71. Blanstein MP. Hamlyn JM. Sodium transport inhibicion, cell calcinn and bypertenswon: the natiuretic hormone Na-Ca exchange/hypertension hypothesis. Am J Med 1988,77,45-59.

72. Kurz TW, Monis RC. Sodium-calcium interactions and saltoensitive hypertension. Art I Hypettis $1990 ; 3: 1525-155 \mathrm{~S}$

73. Ashida T, Kawano $Y$, Yoshimi H. Kuramochi M, Omae T. Effects of dietary sat on soditumcalcium exchange and ATP-driven calcium pump in arterial smooth muscle of Dahl rats. I Hypertens 1992:10:1335. 1341

74. Campese VM, Kandaian $1-3$. Sall-sensitivity in hypertension. Implications for the kidney. I Am Soc Nephrol $1991: 2: S 53-\$ 61$

75. Simon AC, Safar ME, Levenson $\mathbb{A}$, London GM, Levy Bl. Chau NP. An evaluation of hrge artery compliance in men. Am J Physiol 1979;237(5):H550-H554.

76. van Merode T, Brands PJ. Hoeks APG, Reneman RS. Faster aging of the carotid artary bifureation ign borderline bypertensive subjects. I Hypertens 1993;11:171-176.

77. Yn FCF, Ting CT. Compliance changes in physiological and pathological states. J Hypertens $1992 ; 10($ suppi 6$) ; 531-533$.

78. Takeshita A, lnazumi T, Ashihara T, Yamamoto K. Foka S, Nakamura M. Limited maximal vasodilator capacity of forearm resistance vessels in normotensibe young men with a familial predisposifion to hypertension. Circ res 1982;50:671-677.

79. Awollo AP, Chen SG, Wang RP, Zhang CL, O'Rourke MF. Effects of anging on changing arterial compliance and left ventricular load in northern chinese urban community. Circulation $1983 ; 68(1): 50-58$

80. Awollo AP "Deng FQ. Effects of aging on arterial distensibility in populations will high and low prevalence of hypertension: Comparison between urban and rual communities in China. Circulation $1985 ; 7(2): 202-210$

81. Lindpaintmer $\mathrm{K}$. Sen $\mathrm{S}$. Role of sodium in hypertensive cardiac hypertrophy. Cinc Res 1985-57:610-617.

82. Tobian L. Salt and hypertension: Iessons from animal models that pate to humath hypertension. Hypertension $1991 ; 17$ (suppli): 152-158.

83. O"Rourke M. Arterial stitness, systolic blood pressure and logical tratment of arterial hypertension. Hypertersion 1990;15:339-347.

84. Tarazi RC. The role of the heart in hypertension. Clin Sci 1982:63:347s 359s.

85. 85. Kannel WB, Stokes J. Hypentension a cardiovascular risk factor. Handbook of hypertension, yolb, Epidemiology of typertension adited by Bulpit CJ. Amsterdam, Elsevier Science 1985:pp15i-34.

86. Shepherd $\mathrm{IT}_{\mathrm{T}}$ Aboond FM. The vemous system: The physiology of capacitance wessels. Handbook of Physiology, section 2, The cardiovascular system, wol Ill, Peripheral circulation and organ blond thow. Bethesda, Maryland: American physiological society, 1983,pp397-452.

87. Sinon G, Conklin DJ, Altman S. Abromal saphenous vein composition in human hypertension. Clin Exp Hypertens $1981 ; 3: 69-83$.

88. Simon G. Venous changes in renal hypertensive rats: Role of humoral factors. Blood Vessels $1978 ; 15: 311-321$ 
89. Sinon $G$, Alman $S$, Conklin DI. Venous wall electrolytes and the rosmines in hypertensive rats. Proc Soc Exp Biol Med $1980 ; 165-13-16$

90. Comper WD, Laurant TC. Physiological function of connective tisgue polysacharides. Physiol Rev $1978.98: 255 \cdot 315$

91. Greenberg 5, Pamer EC, Wiborn WM. Pressure-independent hypertophy of veins and pulmonary arteries of spontaneously hypertensive rats. Clin Sei Mol Med 1978;55(suppl):31-36.

92. Somnid-Schonbein $\mathrm{OW}$, Chien $\mathrm{S}$. The microcirculation in hypertension. Handbook of hypertension. Eds Zancheti A., Tarazi RC. Vol7: Puthophysiology of hypertension. Cardiovascular aspects. 1986, pp 465-489.

93. Bohler HO, Gore RW Hutchins PM. Comparisons of microvascular pressures in normal and trypertensive rats. Morowase Res 1977; 13:125-130.

94. Schmid-Schonbein GW, Zweifact BW, De Lano EA. Chen PCY. Microvascular tone in a skeletal muscle of spontaneously hypentensive rats. Hypertension $198790164-171$.

95. Dohlen HCH. Intestinal microvascular adaptation during maturation of spontaneously hypertensive rats. Hypertension $1983,5: 739-745$

96. Harper SI, Bohlen HC. Microwascular adaptation in the cerebral cortex of aduli spontaneously hypertensive wats. Hypertension $1984 ; 6 ; 408-419$.

97. Judy WV, Watanabe AM, Henry DP, Beseh HR, Murphy WR, Hockel GM. Sympathetic nerve actiwity: Role in regulation of blood pressure in the spontaneously hypertensive rat. Circ Res 1976;38(supplII);21-29.

98. Lee RMKW, Forrest JB, Garfield RE, Daniel EE. Uitrastructural changes in the mesenteric arteries from spontaneously hypertensiwe rats. Blood Vessels $1983 ; 20 ; 57-71$.

99. Herrich HA, Hertel RF. Microvascular hemodynamics in spontaneous hypertension, Microvascular aspects of spontaneous hypertension. Ed Henrich HA. Hans Huber Publishers. 1982,pp $21-39$.

100. Bohlen HG. Arteriofar closure mediated by hyperresporsiveness to norepinephrine in hypertensive rats. Am I Physiol $1979 ; 236: H 157-H 1164$.

101. Lombard JH, Hess ME, Stekiel WJ. Neurat and local control of arterioles in spontaneously hypentensive ras. Hyportension 198,$4 ; 6: 530-535$.

102. Hanck DW, Schaffer JI. Simpson JG. Comparisons of cutaneous microvessels from spontaneously bypentensive, normotensive Wistar-Kyoto and normal Wistar rats. Proc Soc Exp Bio Med 1980:164:453-458.

103. Huchins PM, Darnalh AE. Observations of a decreased number of small arterioles in spontaneously hypertensive quts. Circ Res $1974 ; 34 / 35$ (suppli):1161-1165. 104. Prewit RL. Stacy DL. Ono Z. The microcirculation in bypertension: Which are the resistance vessels?
News Physiol Sci 1987:2:139-141.

105. Le Noble JLML, Smath TL, Hutchins PM. Struyker Boudier HAJ. Microwascular alterations in adult conseious spontancously hypertensive rats. Hypertension $1990 ; 15: 415,419$.

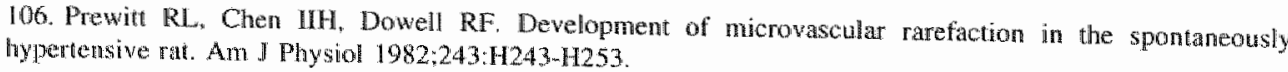


107. Le Noble JLML. Tangelder GJ, Slaaf DW, van Essen H. Renemair RS, Struyker Boudier HAd, A functional morphometric study of the cremaster muscle microcirculation in young spontaneously lyperiensive rats. J Hypertens 1990,8:741-748.

108. Henrich HA, Hertel RF, Assmann R. Stuctural differences in the mesentery microcirculation between nomotensive and spontameously hypertensive rats. Pflug Arch 1978,$375 ; 153,159$.

109. Werber AH, Fitch-Burke MPC. Harrington DG. Shah J. No rarefaction of cerebral arterioles in hypertensiwe rats. Can J Pharmacol Toxicol 1989:68:476-479.

110. Green AS, Tonellaio PI, Lui J, Lombard $\mathrm{JH}_{4}$ Cowley AW j. Microvascular ranehation and lissue vascular resistance in hypertension. Am J Physiol 1989,256:H126-1H31.

111. Engelson ET, Schnid-Schonbein GW. Zweifach BW. The mucrovisculature in skelletal musele II. Ateriolar network anatomy in nomotensive and spontaneously hypentensive rass. Microwasc Res $1986: 31: 356-374$

112. Gray SD. Lack of capillay rarefaction in skeletal muscle of spontaryeously hypertensive rats. Eds Ruscher W, Clough D. Hypertensive mechanisms. Schattauer, Stutgart-New York. 1982 pp 204-207.

13. Johnson PC. Review of previous studies and current theories of alutoreguliation. Circ, Res 1964: 1415 (SupplI):2-17.

114. Henrich HA, Romen W, Heimgatner W, Hartung E, Baumer F. Capillary rarefaction characteristics of the skeletal muscle of hypertensive patients. Klin Wochenschr 1988;66:54-60.

115. Lack A, Adolph W, Ralsion W, Leiby G, Winsor A, Griffth G. Biomicroscopy of conjunctival vessells in hypertension. Am Heart J $1949 ; 38: 654-664$.

116. Lee $\mathbb{R E}$, Holge EA. Peripheral vascular hemodynamics in the balbar conjuncriva of subjects with hypertensive vascular disease. J Clin Invest 1951;30:539-546.

117. Harper NH, Moore MA, MarrMC, Watt LE, Hutchins PM. Arteriolar ranefaction in the corjunctiva of thuman essential hypertensives. Microwasc Res 1978,16:369-372.

1 18. Eichna LW, Bordly S. Capillary blood pressure in man. Direct measurements in the digits of nomal and hypertensive subjects during vasoconstriction and vasodiation wariously induced. J Clin lnvest $194221: 711$ 729.

19. Tooke JE, Willans SA Wasserman S. MacGregor GA. Capillary pressume dyramics in essential hypertension. J Hypertens 1989;vol7(suppl6):S402-\$403.

120. Safar ME, Levy BI, London GM. Arterial structure in hypentersion and the effects of angoterusin converting enzyme inhibition. J Hypertens 1992;10(suppl5):551-557.

121. De Luca $N$, Rosiello $G$, Lamenza $F$, Ricciardelli $B$, Marchegiano $\mathbb{R}$, Volpe $M$, Marell $C$, Trimarco $B$. Reversal of cardiac and large artery structural abnomalitics induced by longrem anthypertensive treatment with trandolapril. An $₫$ Cardiol 1992;70,52D-59D.

122. Simon AC. Levenson JA, Bothier JD, Safar ME. Effects of chronic administration of enataprit and propanolol on the large arteries in essential hypertension. J Cardiovase Pharmacol 1985,7,856-861.

123. Levenson JA, Simon AC, Bouthiar T, Marek BC, Safar ME. The effect of acule and chronic ricatiping therapy on forearm arterial haemodynamics in essential hypertemsion. Br $\mathrm{J}$ Clin Pharmac 1985:20:1075-1135: 
124. Levenson IA, Simon AC, Bowher JC, Denetos A, Safar ME. Post-synaptic alphablockade and brachial artery compliance in essential hypertention. I Hypertens $1984,2.37-41$.

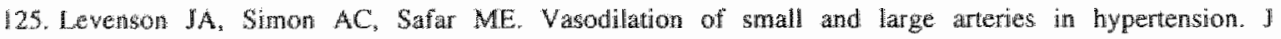
Cardiovase Pharmacol 1985;7:\$1 15-\$120.

126. Levenson $J_{A}$, Simon AC. Safar ME, Gitelman RC. Effect of intravenous nitroglycerin on arterial compliatce and baroneflex sensitwity in hypertension. Oxford workshop on baroreceptors and bypertension. edited by Sieight P. Oxford: Oxford University Press, $1980, p p 510520$.

127. Shepherd JT, Vanhoute PM. Veins and their control. WB Saunders Company, London-PhiladelphiaToronton. 1975 .

128. Robinswon BF. Differences in response to dilator agents in blood vessels of different types: Physiological buses for selectivity. IHperteris 1989,7(suppl4),5147.515\%.

129. Gascho JA. Apollo WP. Effects of nifedipine on the venodilatory response to nitroglycerin. Am $\mathrm{J}$ Cardiol $1990 ; 65: 99-102$

130. Collier JG, Nachev $C$. Robirson BF. Effect of catecholamines and other vasoactive substances on superficual hand veins in man. Clin Sci $1972 ; 43: 455-467$.

131. Benjamin N, Siedelin P, Webb DJ. Angiotensin II augments sympathetic wasoconstriction in foreann resistance vessels and veins in man. I Physiol 1988;400:56P.

132. Kooman IP, Winen IAG, Draijer $P$, van Bortel LMAB, Gladzwa U, Peltenburg HG, Smuyker Boudier HAJ, wan Hoof JP, Leunissen KML. Complance of the peripheral vemous system in patients treated with chronic intermittant hemodialysis. Kidney Int 1992:41:1041-1048.

133. Dawson JM, Hudlicka $\mathrm{O}$. The effects of long term administration of prazosin on the microcircullation in skeletal muscles. Cardiovascular research 1989,23:913-920.

134. Messing MWJ, van Essen H, Struyken Boudier HAJ. Microvascular actions of calcium channel antagonists. Eur J Pharmacoll 1991;198:189*195.

135. Messing MWI, wan Essen H, Struyker Boudier HAJ Inhibition of anglotensirn converting enzyme does not intluence atteriolir tone in surated musche of conscious spontaneously hypertensive rats. Acta Clin Belg $1991: 46252-253$

136. Wang DH, Prewit RL. Captopril reduces aortic and microvasculat growth in hypertensive and noratotensive rats. Hypertension $1990 ; 15 ; 68-77$

13\%. Huthins PM, Marhthurn TH, Maultsby SI, Lynch CD, Smith TL, Dusseau IW. Long-term microwascular response to hydralazine in spontaneously hypertensive rats. Hypertension $1988 ; 12: 74-79$. 


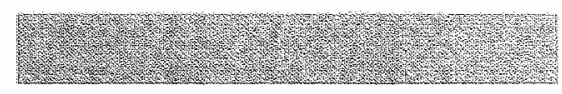

\author{
SUBJECTS AND METHODS
}




\section{Subjects}

The study described in this thesis was performed in a group of forty-five previously untreated borderline hypertensive male patients. Borderline hypertension was defined as a diastolic blood pressure of $90-95 \mathrm{mmHg}$ and a systolic blood pressure of 140 $160 \mathrm{mmHg}$ " measured on at least two occasions. All subjects were 20 to 45 year old males and non-smoker. The patients were recruited with the aid of general practitioners, blood banks and local advertising. Besides the slight increase in blood pressure, all subjects were in good health. Secondary hypertension was excluded on the basis of medical history, physical examination and laboratory test results.

The study was approved by the hospital's ethics committee and informed consent was obtained from all the participants before they entered the study.

Ten normotensive age and sex matched control subjects were studied to provide normal values of the parameters under study. The control subjects were recruited from the hospital's personnel.

\section{Design}

The study consists of two parts. The sodium-sensitivity status of the 45 borderline hypertensive subjects was determined in the first part of the study. To gain insight into the mechanisms underlying the pressor response, not only the blood pressure was studied during low and high sodium intake, but also renal blood flow, glomerular filtration rate, urinary dopa and dopamine excretion and plasma renin activity, plasma aldosterone and atrial natriuretic peptide levels. The second part of the study starts, after stratification into sall-sensitive and salt-resistant, with approximately one month of placebo therapy. Then basall values of micro- and macrocirculatory variables such as nailfold capillary density, arteriall and venous compliance, cardiac output and cardiac mass, renal blood flow, glomerular filtration rate, plasma vollume, and determination of plasma renin activity, plasma aldosterone and atrial natriuretic peptide levels took place in the borderline hypertensive subjects. These determinations were also performed in the normotensive controls. After this initial investigation, borderline hypertensive subjects were randomly assigned to three treatment stategies, viz. enalapril $10 \mathrm{mg} / \mathrm{day}$, felodipine $5 \mathrm{mg} / \mathrm{day}$ or placebo. After three and six months of treatment all measurements of the initial investigation were repeated. Then treatment was stopped. Three months later a final investigation took place. The week preceding the investigations of the second part of the study, the subjects used a diet containing $120 \mathrm{mmol}$ sodium/day and $70 \mathrm{mmol}$ potassium/day. 
All measurements were performed in a temperature controlled room of approximately $24^{\circ} \mathrm{C}$. The subjects entered the laboratory at $8.00 \mathrm{am}$. A light breakfast had been consumed at approximately $7.00 \mathrm{am}$. There was an acclimatisation period of at least 15 minutes before starting with the measurements.

\section{Methods}

\section{Sodium-sensitivity assessment}

The sodium-sensitivity status of the borderline hypertensive subjects was assessed in an outpatient setting. They consumed at random order a low sodium diet, containing 20 mmol sodium per day or a high sodium diet containing 220 mmol sodium per day during one week, with the alternative diet during the following week. The potassium content of both diets was $70 \mathrm{mmol}$ per day. The diets were prescribed and guided by a dietician. The investigator was not aware of the order in which a subject used the high and low salt diets. Blood pressure was measured at the end of each week, with the patients in supine position after at least 15 minutes of rest. Systolic and diastolic pressure were measured every five minutes for half an hour and the average of these blood pressure values was determined. The mean arterial pressure was calculated as the sum of the diastolic pressure and one third of the pulse pressure. An arbitrarily chosen cut-off point of $8 \mathrm{mmH}$ ig difference in mean arterial pressure between the end of the high sodium and the end of the low sodium diet, was taken as an index of sodium-sensitivity. In addition, body weight was measured at the end of each diet period.

Adherence to the diets was estimated by measuring the sodium and potassium excretion (Ion-selective electrode) in a 24 -hour urine collection obtained on the last day of each regimen. The excretion of dillydroxyphenylalanine (dopa) and dopamine was also measured in this 24 hours urine, that had been collected in bolles contai. ning $10 \mathrm{ml} 6 \mathrm{~N} \mathrm{HCl}$ to ensure the stability of dopamine and dopa. HPLC-methods were used to quantify the latter two substances ${ }^{2}$; inter-assay coefficients of variation were less than $5 \%$ for both dopa and dopamine measurements.

According to the above mentioned definition of sodium-sensitivity, 17 borderline hypertensive patients were called salt-sensitive and 28 salt-resistant. At the end of the high sodium period, the urinary sodium excretion of the sodium-sensitive group was $255 \pm 45 \mathrm{mmol} / 24 \mathrm{hr}$ (median 258, range 155-314) and the potassium excretion was $82 \pm 23 \mathrm{mmol} / 24 \mathrm{hr}$ (median 83, range 50-140). Alt the end of the low sodium diet, the sodium and potassium excretion were respectively $25 \pm 27 \mathrm{mmol} / 24 \mathrm{hr}$ (median 14, range 2-110) and $75 \pm 19 \mathrm{mmol} / 24 \mathrm{hr}$ (median 72 , range 45-119) in this group. In the sodium-resistant group, the sodium excretion after the high salt period was $227 \pm 44 \mathrm{mmol} / 24$ hr (medan 227 , range $155-327$ ), while the potassium excreti- 
on was $70 \pm 21 \mathrm{mmol} / 24 \mathrm{hr}$ (median 71 , range 34-122). The sodium and potassium excretion at the end of the low salt period was $32 \pm 20 \mathrm{mmol} / 24 \mathrm{hr}$ (median 28 , range 2-84) and $58 \pm 19 \mathrm{mmol} / 24 \mathrm{hr}$ (median 57 , range 16-93). In all subjects the difference in sodium excretion between the high and low salt period was at least $150 \mathrm{mmol} / 24$ hr. Apart from the potassiurn excretion at the end of the low salt diet, that was significantly higher in the sodium-sensitive group than in the sodium-resistant group ( 75 ys $58 \mathrm{mmol} / 24 \mathrm{hr}, \mathrm{p}=0.02$ ), no significant differences in sodium and potassium excretion between the end of the high and low salt diets were found.

The difference in mean arterial pressure at the end of the low and high salt diets was $12 \pm 5 \mathrm{mmHg}$ for the sensitive and $-2 \pm 7 \mathrm{mmHg}$ for the sodium-resistant group $(p \leq 0.0001)$. The weight gain after the high sodium diet as compared to the low sodium diet was $1.7 \pm 1.3 \mathrm{~kg}$ for the sodium-sensitive group and $0.9 \pm 1 \mathrm{~kg} \quad(p=0.08)$ for the sodium-resistant group.

\section{Nailfold capillary density}

Nailfold capillary density was studied using an intravital video microscope (Leitz orthoplan), chained to a television camera (Philips LDH 0402), a video recorder (Sony betamax SL-HF 950) and a television monitor (Sony PVM-122CE, fig.1).

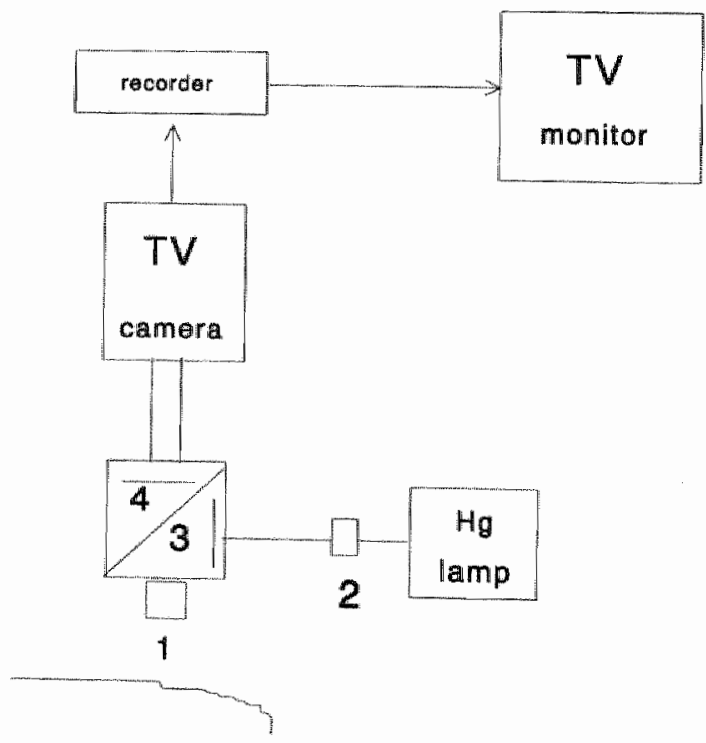

Pigure 1. Outline of the microscopic system. 1: objective lens 2 : filters 3: polarizer 4: $50 \%$ mirror. 
The skin temperature was monitored during the experiment. The subjects were in sitting position with the investigated hand at heart level. The 4 th finger of the left hand was studied. Incident illumination was achieved using a Leitz ploemopak 2.1 system with a polarizer cube. Light was provided by a mercury vapour lamp (100W: calflex heat reflection filter, DC power supply). Five percent and $30 \%$ grey filters were used in the experiments. The objective used was a Leitz PL-fluobar 10x with a numerical aperture of 0.30 (interpixel distance $1.25 \mu \mathrm{m}$ ).

The capillaries in 3 microscopic fields $\left(0.54 \mathrm{~mm}^{2}\right)$ were studied. These fields included the distal row of capillaries and were located in the median of the finger as well as adjacent to this central field. The capillaries were brought into focus. The camera was rotated in such a way that the distal row of capillaries, adjacent to the nail, was positioned perpendicularly to the right side of the TV screen. One specific capillary was placed in the upper right corner of the video screen as an identification marker of this field. Subsequently, all capillaries (not only the distal row) in the field were brought into focus and videotaped for off-line analysis. Then an arterial occlusion test was performed by applying a suprasystolic pressure of 4 minutes duration to the finger by inflating a finger cuff positioned just distally from the metacarpal-phalangeal joint. A period of 4 minutes arterial occlusion was chosen to oblain vasodilation not only through the mechanism of myogenic vasodilation, but also through an additional metabolic vasodilatory stimulus, in order to obtain optimal recruitment of capillaries that were not perfused during basal conditions ${ }^{3}$. After 4 minutes of occlusion, the marker vessel was repositioned in the upper right comer of the television screen and subsequently the cuff was deflated. Immediately after deflation, the capillaries in the same field as before the occlnsion, were brought into focus and videotaped again. A total of three microscopic fields were studied. A period of ten minutes of rest was attended between the measurement, to ensure that the previous hyperaemic response had subsided. Off-line, the video images were analysed and the number of capillaries per field was counted by one investigator who was not aware of the sodium-sensitivity status of the subjects. The intrabserver variability of this method was approximately $3 \%$.

Capillary density was defined as the number of capillaries per microscopic lield $\left(0.54 \mathrm{~mm}^{2}\right)$. The mean number of capillaries per field before and after arterial acclusion was subsequently calculated.

\section{Arterial distensibility and compliance}

Distensibility and compliance measurements were performed on the carotid, femoral and brachial arteries using a non-invasive ultrasound wall movement detector system, with the subjects in supine position. This system, developed by Hoeks et al has been described in detail ${ }^{4}$. In brief, it consists of a conventional ultrasound imager (Ultramark-V, ATL, Bothell, USA), with a 7.5 megahertz transducer, a dataacquisition system and a personal computer. The transducer was positioned on the 
skin surface, perpendicularly above the artery under study (fig. 2). An ultrasonic gel was used to optimize signal transduction. Subsequenty, the arterial diastolic diameter (Dd), with a precision of approximately $10 \mu \mathrm{m}$, and the arterial wall distension $(\Delta D)$, with a precision of less than $10 \mu m$, were recorded during 5 seconds (fig. 3).

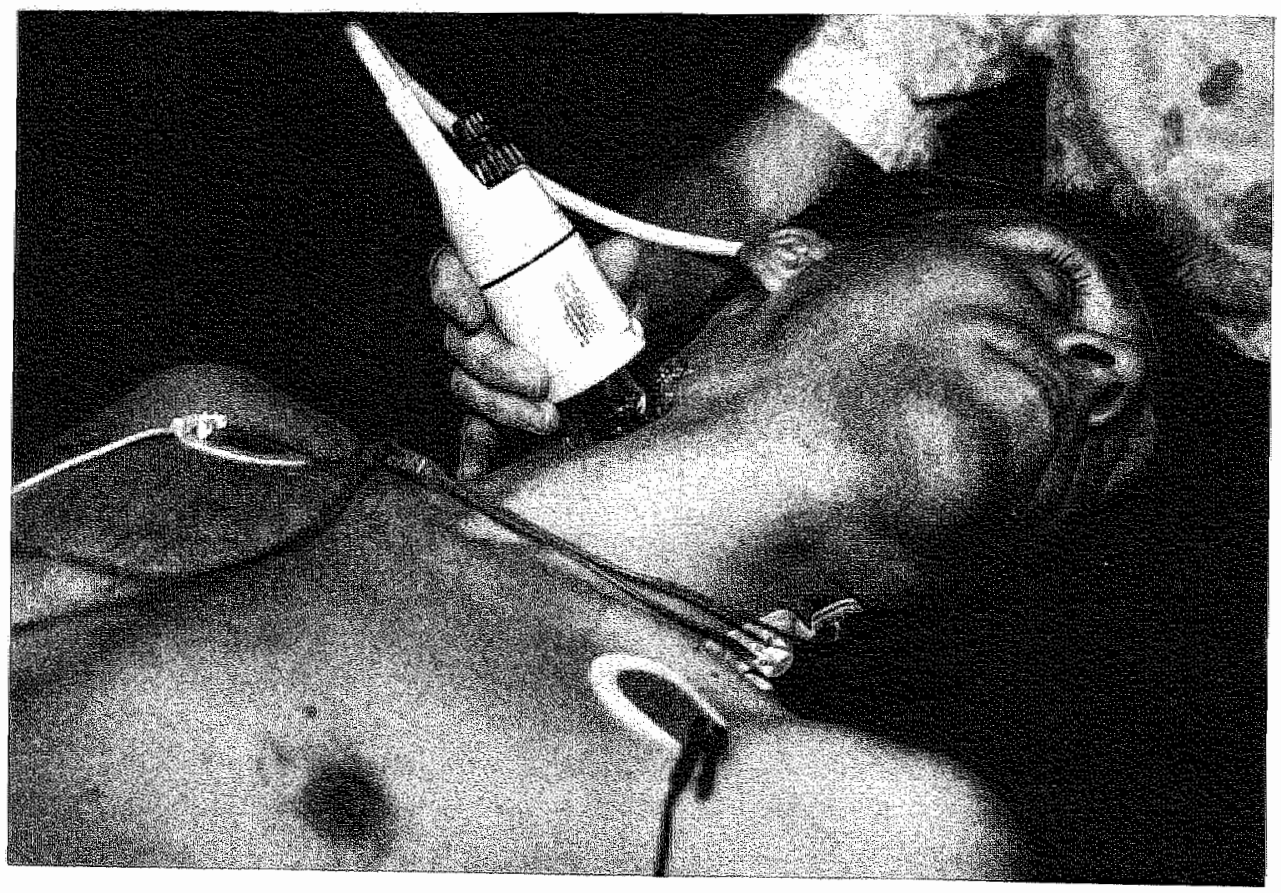

Figure 2: Measumement of the carotid artery. 


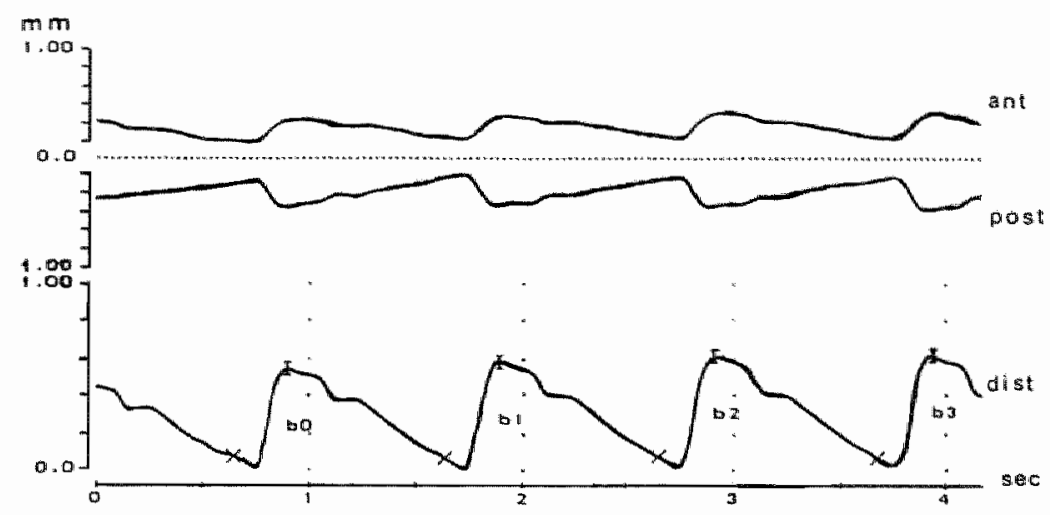

Figure 3. Upper panel: movement of the anterior and the posterior wall of an antery during 5 consecutive cardiac cycles. Lower pand: Arterial distension, the distance between anterior and posterior walll.

Simultaneously with the vessel movement registration, blood pressure was measured every 2 minutes with an automated device (Dinamap, Tampa, USA). The averages of these blood pressures and pulse pressures $(\triangle \mathrm{P})$ were calculated.

From the arterial diameter, the change in diameter during the heart cycle (distension), and the pulse pressure, arterial distensibility and compliance were calculated according to the following equations:

$$
\begin{array}{lll}
\mathrm{DC} \text { (distensibility coefficient) } & =(2 \Delta \mathrm{D} / \mathrm{Dd}) / \Delta \mathrm{P} & 10^{-3} / \mathrm{kPa}(1) \\
\mathrm{CC} \text { (compliance coefficient) } & =(\pi \mathrm{Dd} \mathrm{DD}) / 2 \Delta \mathrm{P} & \mathrm{mm}^{2} / \mathrm{kPa}
\end{array}
$$

This means that $\mathrm{CC}$ can be calculated by multiplying $\mathrm{DC}$ and the cross sectional area of the vessel lumen 5 .

The intraobserver variability of the diameter measurements, was determined and appeared to be less than $10 \%$ in the carotid artery and between $10 \%$ and $15 \%$ in the femoral and brachial arteries ${ }^{6}$. All measurements were performed by the same experienced investigator.

A critique on the vessel wall movement detector method is that pulse pressure was measured in the brachial rather than in the carotid and femoral artery. The calculations of distensibility and compliance as performed in this study are only valid, if brachial pulse pressure is representative for that of the carotid and femoral artery. We assume that, in the groups under study, a systematic error is made by using 
brachial artery pulse pressure in the calculations of carotid and femoral artery distensibility and compliance. The reason for using brachial artery pulse pressure instead of local pulse pressure is that non-invasive methods to assess local pulse pressure in these arteries are scarce. Applanation tonometry may be a candidate ", but technical difficulties and problems of reproducibility must be resolved.

\section{Venous compliance}

Venous compliance was measured by strain gauge plethysmography (Periflow, Janssen Scientific Instruments, Beerse, Belgium) with direct intravenous pressure measurements.

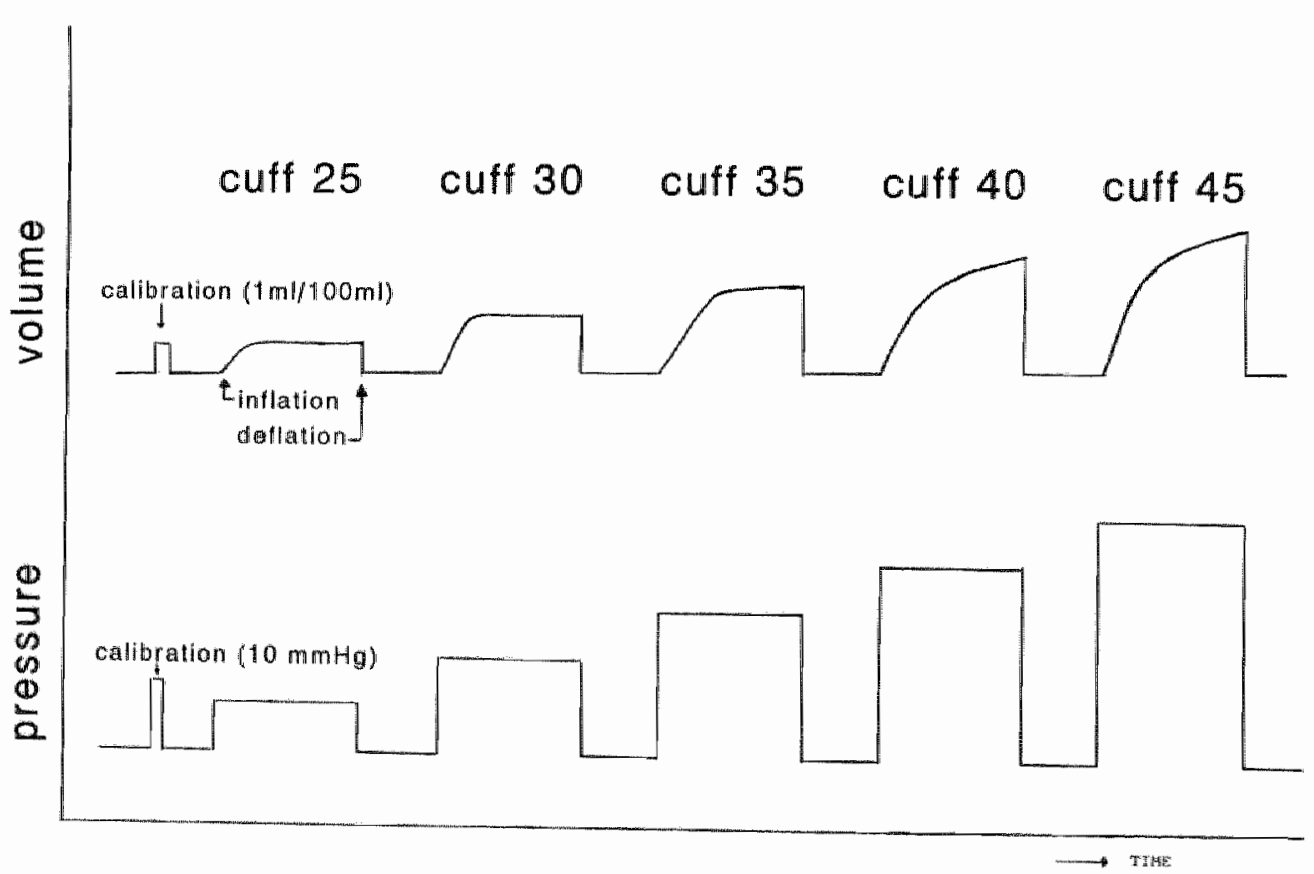

Figure 4. Tracing of an experiment. Change in intravenous blood pressure and the concomitant change in armil volume. 
The patients were in supine position. An antecubital vein was cannulated (Ventlon, internal diameter $1 \mathrm{~mm}$ ) and the canula was connected to a pressure dome (HewlettPackard), that was positioned at right atrial level, approximately $5 \mathrm{~cm}$ under the sternal angle. Venous pressure was displayed on a Hewlett-Packard monitor as well as graphically. An inflatable cuff was applied to the upper part of the cannulated arm, and a mercury-filled strain-gauge was positioned around the forearm at onethird of the forearm length from the lateral epicondyl. The plethysmograph and the pressure monitor were subsequently calibrated and a stabilisation period of 15 minutes was attended. The arm cuff was inflated at a cuff pressure of $25 \mathrm{mmHg}$ and was kept inflated during 3 minutes. This time interval was chosen to obtain stabilized values for arm volume and intravenous pressure. Hereafter the cuff was deflated for 2 minutes to prevent accumulation of interstitial fluid due to capillary filtration. The change in arm volume and intravenous pressure were both measured after cuff deflation (fig.4), in order to exclude the effect of capillary filtration on the obtained volume pressure ratio. Subsequently, the procedure was repeated at stepwise increasing cuff pressures of $30,35,40$ and $45 \mathrm{mmHg}$, thereby obtaining 5 volume-pressure ratios. These ratios were used in a linear regression analysis to obtain the volume-pressure relationship and thereby an estimate of venous compliance, since venous compliance is defined as the slope of this relationship ".

The coefficient of variation of this technique for repeated measurements was $8.1 \%$ 9 .

\section{Echo-Doppler cardiographic variables}

The measurements were performed using a Hewlett Packard sonos 100 echoDoppler cardiograph, with the subjects in the partial left lateral decubitus position. Parasternal B-mode short and long axis images were obtained to provide reference points for subsequent $\mathrm{M}$-mode investigation (3,5 $\mathrm{MHz}$ transducer). Left ventricular internal diameter (LVID), interventricular septum (IVS) and posterior wall thickness (LVPW) were measured distally to the tips of the mitral valve at the onset of the QRS complex on the ECG, during three consecutive cardiac cycles. Average values were determined. Left ventricular mass (LVM) was calculated according to formula of Devereux:

LVM $=1.04 *\left((I V S+\text { LVID }+ \text { LVPW })^{3}-\right.$ LVID $\left.^{3}\right)-13.6$. The reliability of this method has been amply demonstrated ${ }^{10}$ 1!. Left ventricular hypertrophy was considered to be present when the left ventricular mass index exceeded $125 \mathrm{~g} / \mathrm{m}^{2}$ 12

In order to obtain cardiac stroke volume, ascending aortic blood flow velocity was measured using a continuous wave Doppler system with a 10 megahertz transducer, positioned at the apex, while the aortic diameter was determined by means of Bmode echocardiography, positioned at the third or fourth intercostal space at the left sternal edge. Cardiac output was calculated by multiplying stroke volume with heart rate. It has been shown, that when performed by a skilled investigator, the results of 
this method correlate well with other (invasive and non-invasive) techniques ${ }^{13}$. In our clinic, the intra- and interobserver variability of this method to assess stroke volume has been established to be $9 \%$ and $11 \%$, respectively ${ }^{14}$. Cardiac output, stroke volume and left ventricular mass were normalized for body surface area.

\section{Renal haemodynamics}

Effective renal plasma flow (ERPF) and glomenlar filtration rate (GFR) were measured through the determination of the clearance of ${ }^{131}$ I-hippuran and ${ }^{125} \mathrm{I}$ thalamate at the end of each regimen ${ }^{15}$. Renal blood flow was calculated according to the formula: $\mathrm{RBF}=\mathrm{ERPF} / 1$-hematocrit $(\mathrm{ml} / \mathrm{min})$. In our laboratory the interday coefficient of variation is $6.6 \pm 4.6 \%$

\section{Plasma volume}

Plasma volume was measured in the two hypertensive groups using the radioiodinated serum albumin method (1-125 albumin) ${ }^{16}$. The measured plasma volume was compared to a theoretical plasma volume determined on the basis of age and weight ${ }^{17}$. The inter-day coefficient of variation is $5.8 \pm 3.8 \%$ in our lab.

\section{Determinations in blood and urine}

Blood samples were taken in order to determine plasma renin activity (PRA), plasma aldosterone (ALD) as well as atrial natriuretic peptide (ANP) concentration, with the patient in sitting position. Radioimmunoassay techniques were used to quantitate these variables 181920 .

The PRA inter-assay variability was approximately 14 percent. The inter-assay coefficient of variation of the aldosteron assay was between 8 and 10 percent and of the ANP assay approximately 10 per cent.

As was already mentioned, all subjects used a diet containing 120 mmol sodium and 70 mnol potassium per day in the week preceding the investigations. Compliance with these diets was estimated by measuring the sodium and potassium excretion (Ion-selective electrode) in 24 hours urine collection obtained on the last day of each regimen. 


\section{Statistical analyses}

All data analysis was done using programmes of SPSS-pct. Data are presented as mean values \pm standard deviations. The level of significance was $p<0.05$.

\section{Comparisons between the sodium-sensitive and sodium-resistant borderline hyperten- sive subjects}

The Kolmogorov-Smirnow goodness of fit test was used to verify whether variables were normally distributed. Whether variables follow the same distribution in the salt-sensitive and the salt-resistant subgroups was evaluated using the KolmogorovSmirnow test for 2 independent samples. In case of normally distributed data, statistical analysis of the differences between the two hypertensive groups was performed with Student's unpaired t-test. Otherwise non-parametric tests for 2 (KruskallWallis) independent samples were used.

\section{Comparison between the two hypertensive groups and the normotensive control group} In case of normally distributed data statistical analysis of the differences between the two hypertensive and the normotensive groups were performed by means of multiple regression analysis. Otherwise, the differences were analysed using nonparametric tests for 3 independent samples (Mann-Whitney).

\section{Analysis of treatment effects in sodium-sensitive and sodium-resistant borderline hypertensive subjects}

Firstly data were checked for normality. Because no great discrepancies were found in the data, repeated measurements multivariate analysis of variance was used to value treatment effects. Separate analyses were made for both sodium-sensitive and sodium-resistant groups. Each measure was analysed for one within-factor consisting of four repeated measurements and for one between-factor consisting of the three treatment categories. Tests of significance were made multivariately and univariately for all parameters. Since a multivariate approach should probably not be used in case of small groups ${ }^{2}$, only univariate test values were reported, unless large discrepancies existed between the uni- and multivariate approaches, then both values were given. The averaged univariate tests were corrected for sphericity if necessary 22. In a specific case, namely in the analysis of the effects of treatment on arterial distension, distension was analysed for the same factors as above, but with one within-factor added viz. mean arterial pressure. This 'doubly' multivariate analysis of variance was done to ascertain the elimination of confounding effects of blood pressure on the relation between type of treatment and arterial distension. 


\section{References}

1. Gross F, Pisa Z, Strasser T, Zancheti A. Management of arterial hypertension. WHO publication, 1985.

2. Kagedal B, Goldstein DS. Catecholamines and their metabolites. I Chromatogr 1988,429:177-234.

3. Johnson $\mathrm{PC}$, Burton $\mathrm{KS}$. Henrich $\mathrm{H}$. Henrich U. Effect of occlusion duration on reactive hyperemia in sartoritus muscle capillaries. Am I Physiol 1976; vol230 no3:715-719.

4. Hoeks APG, Brands PJ, Smeets $\mathbb{P}$ AM, Reneman RS. Assessment of the distensibiliny of superticial arteries. Ulrasound in Med Biol 1990: vol 16, No 2:121-128.

5. Hoeks APG, Brands PJ, Reneman RS. Assessment of the arterial distension wave form using Dopples signal processing. J Hypertens 1992;10(suppl6):S19-522.

6. Kool MJF, wan Merode T, Hoeks APG, Van Bortel LMAB. Reproducibility of a newily developed vessel wall movement detectur system. Abstrat European society of Hypertension. Fifh meeting, Milan, Italy* 7thIoth June 1991 .

7. Kelly $R_{*}$ Hayward $C$, Ganis I, Dealey $J$, Avolio A, $O^{3}$ Rourke M. Noninvasive registration of the arterial pressure pulse waweform using high-fidelity applanation tonometry. J Vascular Med Biol 1989m, wol1, no 3:142149.

8. Rothe CF. Venous systern: physiology of the capacitance vessels. In: Handbook of phystology, 1983, sect 2 Candiovascular system. Anerican Physiological Society, Bethesda. Vol 3. Peripheral circulation and blood fllow: Chapter 13; pp $397-452$

9. Kooman JP, Wijnen JAG, Draijer P, Van Bortel L, Gladzwa U, Peltenburg H, Struyker Boudier HAT, Van Hooff IP, Leunissen KML. Compliance and reactivity of the peripheral venous system in patients treated with chronic intermittent haemodialysis. Kidney International 1992:41:1041-1048.

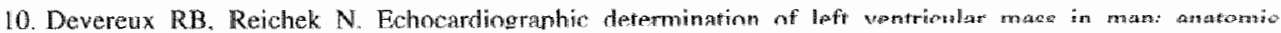
validation of the method. Cinculation 1977:55:613-618.

11. Devereux $\mathbb{R} B$, Alonsio DR, Lutas EM at al... Echocardiographic assessment of left ventricular bypertrophy: comparison to necropsy findings. An I Cardiol 1986;57:450-458.

12. Casale $P N$, Devenesux $R B$, Milner $M$. Walue of echocardiographic left ventricular mass in predicting cardiowacular morbid events in bypentensive men. Am Intern Med 1988;105:173-178.

13. Schuster AH, Nandi NC. Doppler echocandiographic measurement of cardiac output: Cormparison with a non-golden stmdund. Am J Cardiol 1984,53:257-259.

14. Lewnissen KML. Menheene PPCA, Cherex EC, Van der Berg BW, Noordzij TC, Van Hooff JP. Plasma alphahuman atrial natriuretic peptide and volume status in chronic heamodialysis patients Nephrol Dial Transplant $1989: 40,382-386$.

15. Donker AM, van der Hem GK. Sluirew WJ, Beekhuis H. A radio-isotope method for simultaneous detemination of the glomerular filtration tate and the effective renal plasma flow. Neth J Med 1977,20:97103.

16. Keyes J, Carey J, Mosses D. Beierwaltes W. Manual of nuclear medicine procedures. 2nd Edition CRS Press Cleveland 1973:95-98. 
17. Dagher FI, Lyons JH, Finlayson DC, Shatasai J. Moore FD. Blood Voltme Measunements: A critcal study. Prediction of normal values: Controlled measurements of sequential changes: Choice of a bedside method. Advanc Surg 1965; 1:69-109.

18. Haber E. Koerner T, Page LB, Kliman B, Purnode A. Application of a tadiommunoassay for angiotensin 1 to the plnysiologic measurements of plasmat remin activy iry normal human subjects. I Clin Endoer $1969: 29: 1349-1355$

19. Kubasik NP, Warren K, Sine HE. Evaluation of a mesw commencial radioassay kit for aldosterone using iodinated tracer. Clin Biochem 1979;12(2):59-61.

20. Rosmalen FMA, Tan A. Tan HS, Benrad T. A sensitive radioimmunoassay of atrit natruretic pepide in human plasma using a tracer with an immobilized glycoril agent. Clin Chem Acta 1987:165:33 -340.

21. Stevens I. Applied multivariate statistics for the social sciences. Lawrence Erlbaum Assaciates, hnc. Publishers. Hillsdale, New Jersey. Chapter 13.7: Sthould we use the univariate or the multivanate approdch? p454-p456.

22. Levine G. A guide to SPSS for analysis of variance. Lawrence Erlbaum Associates, Inc. Publishers. Hillsdale, New Jersey. Chapter; Correction for bias in tests of repeated factors, p2 $7 \times$ p 30 . 



\section{CHAPTER 3}

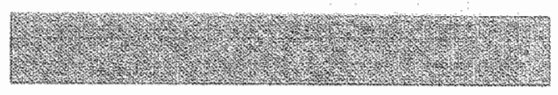

\section{SALT-SENSITIVITY TESTING IN BORDERLINE HYPERTENSIVE PATIENTS}

Reproducibility and potential mechanisms

P Draaijer, PW de Leeuw, JMC Maessen", JP van Hooff, KML Leunissen.

Departments of medicine and dietetics" of the university hospital in Maastricht, The Netherlands.

(submitted for publication) 


\section{Abstract}

The reproducibility of dietary sodium-sensitivity testing was examined by studying the effects on blood pressure of low sodium intake $(20 \mathrm{mmol} / \mathrm{day})$ and high sodium intake (220mmol/day) in 10 borderline hypertensive males on two separate occasions. A difference in mean arterial pressure of $8 \mathrm{mmHg}$ between the high salt and the low salt regimen was arbitrarily chosen to define sodium-sensitivity. In addition, the reproducibility of changes in renal haemodynamics and in humoral factors such as plasma renin activity, plasma aldosterone, atrial natriuretic peptide and urinary dopa and dopamine excretion upon the alteration in sodium intake were studied. As far as changes in blood pressure are concerned, there was perfect agreement between the two tests, since in the second investigation, all subjects were classified in the same category as before. The sodiwm- induced changes in plasma atrial natriuretic peptide and in renal excretion of dopa and dopamine were repeatedly and consistently different between the sodium-sensitive and the sodium-resistant group. No evidence was found for a role of renal haemodynamics or the renin-angiotensinaldosterone system in the pathophysiology of sodium-induced blood pressure elevations in sodium-sensitive subjects.

\section{Introduction}

The concept of sodium-sensitivity emerged from observations on the relationship between dietary sodium-chloride and blood pressure, pointing to a wide variability in the individual responses of the blood pressure to dietary sodium :

Various approaches have been employed for the characterisation of sodium-sensitivity, such as the evaluation of the blood pressure response to modifications of dietary sodium intake ${ }^{2}$ or to intravenous sodium and volume expansion ${ }^{3}$. In addition, several putative mechanisms underlying sodium-sensitivity have been explored. For instance, it has been suggested that sodium-sensitive hypertensive subjects display a defective renal haemodynamic adaptation to alterations in dietary sodium intake ${ }^{4}$. On the other hand, sodium-sensitivity may also be related to blunted modulation of renin release upon sodium loading, leading to sodium retention and increased pressure ${ }^{5}$. Elevated levels of plasma ANP, that have been found in sodium-sensitive subjects on a high sodium intake, may then be considered the consequence of sodium and volume retention ". Finally, an abnormal dopaminergic control of urinary sodium excretion may be involved in sodium-sensitivity ${ }^{7}$. In this respect, Gill and co-workers suggested that the ratio between urinary dopamine and dopa may be a marker of sodium-sensitivity ${ }^{8}$.

Information on the reproducibility of sodium-sensitivity testing is, however, scarce. Moreover, little is known about the consistency of changes in the mechanisms that 
are putatively involved in the pathogenesis of sodium-sensitivity.

Therefore, the aim of the present study was to test the reproducibility of both the changes in blood pressure and the concomitant changes in body weight, renal blood flow, glomerular filtration rate, plasma renin activity, aldosterone, plasma atrial natriuretic peptide and 24 hours urine excretion of dopa and dopamine when dietary sodium intake was changed from 20 to 220 mmol of sodium per day. The repeated measurements were performed approximately one year after the initial investigations.

\section{Patients and methods}

Ten borderline hypertensive males were included in the study. All were between 20 and 45 years of age and non-smokers. None of them used antihypertensive medication in the three months preceding the experiments.

The subjects, the method for the assessment of the sodium-sensitivity status as well as the techniques used in the present study were discussed in detail in chapter 2 . In brief,

sodium-sensitivity status of the borderline hypertensive patients was assessed by means of a diet method. They consumed in random order a low sodium diet, containing $20 \mathrm{mmol}$ sodium per day or a high sodium diet containing 220 mmol sodium per day each during one week, with the alternative diet during the following week. Blood pressure and body weight were measured at the end of each diet period. An arbitrarily chosen cut-off point of $8 \mathrm{mmHg}$ difference in mean arterial pressure between the end of the high sodium and the end of the low sodium diet, was taken as an index of sodium-sensitivity.

Compliance with the diets was estimated by measuring the sodium excretion (Ionselective electrode) in a 24 hours urine collection obtained on the last day of each regimen. The excretion of dihydroxyphenylalanine (dopa) and dopamine was also measured in this 24 hours urine, that had been collected in bottles containing $10 \mathrm{ml}$ $6 \mathrm{~N} \mathrm{HCl}$ to ensure the stability of dopamine and dopa. HPLC-methods were used to quantify the latter two substances ${ }^{9}$.

In addition, effective renal plasma flow (ERPF) and glomenular filtration rate (GFR) were measured through the determination of the clearance of ${ }^{131}$ I-hippuran and ${ }^{125} 1$ thalamate at the end of each regimen ${ }^{10}$. Renal blood flow was calculated accorm ding to the formula: $\mathrm{RBF}=\mathrm{ERPF} / 1$-hematocrit $(\mathrm{ml} / \mathrm{min})$.

Blood samples were taken on the last day of each diet, in order to determine plasma renin activity (PRA), plasma aldosterone (ALD) as well as atrial natriuretic peptide (ANP) concentration, with the patient in sitting position. These variables were determined using radioimmunoassay techniques 111213.

Approximately one year after the initial experiments the subjects entered the second study in which the above described protocol was repeated in the same way. 


\section{Data analysis}

Data are presented as mean \pm standard deviation. The Kolmogorov-Smirnow goodness of fit test was used to verify whether variables were normally distributed. Whether variables follow the same distribution in the salt-sensitive and the saltresistant subgroups was evaluated by means of the Kolmogorov-Smimow test for two independent samples. In the case of normally distributed data, statistical analysis was performed with Student's unpaired t-tests. Otherwise, Kruskall-Wallis tests for two independent samples were used. The level of significance was $\mathrm{p}<0.05$.

Reproducibility of changes in certain parameters upon high sodium intake $(\Delta x)$ are presented by plotting the differences in $\Delta x$ between the two measurements ( $\Delta x 1$ $\Delta \times 2)$ against their mean $((\Delta \times 1+\Delta \times 2) / 2)$. This approach, suggested by Bland and Altman ${ }^{14}$, is more appropriate as indicator of reproducibility than the productmoment correlation coefficient between the results of the two measurements. Correlations between variables were evaluated by linear regression analysis.

\section{Results}

Table 1 shows the used abbreviations.

Table 1

\begin{tabular}{|c|c|}
\hline USED ABBREVGAT & \\
\hline SS & Sodium-sensitive borderline hypertensives \\
\hline$S R$ & Sodium-resistant borderline hypertensives \\
\hline LS & Low sall intake \\
\hline HS & High salt intake \\
\hline Syst $\mathbb{P}$ & Systolic pressure $(\mathrm{mmHg})$ \\
\hline dias $\mathrm{P}$ & Diastolic pressure $(\mathrm{mmHg})$ \\
\hline MAP & Mean arterial pressure (mmHg) \\
\hline RBF & Renal blood flow (m//min) \\
\hline GFR & Glomerular filltration rate (m//min) \\
\hline PRA & Plasma yenin activity $(\mathrm{ng} / \mathrm{m} / \mathrm{hr})$ \\
\hline Ald & Plasma aldosterone concentration (ng/) \\
\hline ANP & Atrial natriuretic peptide (pg/ml) \\
\hline$U_{\text {Sin }}$ & Urimary sodium excretion (mmol/24hr) \\
\hline $\mathrm{U}_{\mathrm{k}}$ & Urinary potassium excretion (mmol/24hr) \\
\hline DOPA & Dihydroxyphenylalanine (nmol/24hr) \\
\hline DA & Dopamine (nmol/24hr) \\
\hline
\end{tabular}




\section{Blood pressure, heart rate and body weight}

Table 2 shows the general characteristics of the investigated groups before the start of the study. According to the definition used in this study, 4 subjects were found to be sodium-sensitive and 6 sodium-resistant.

Table 2

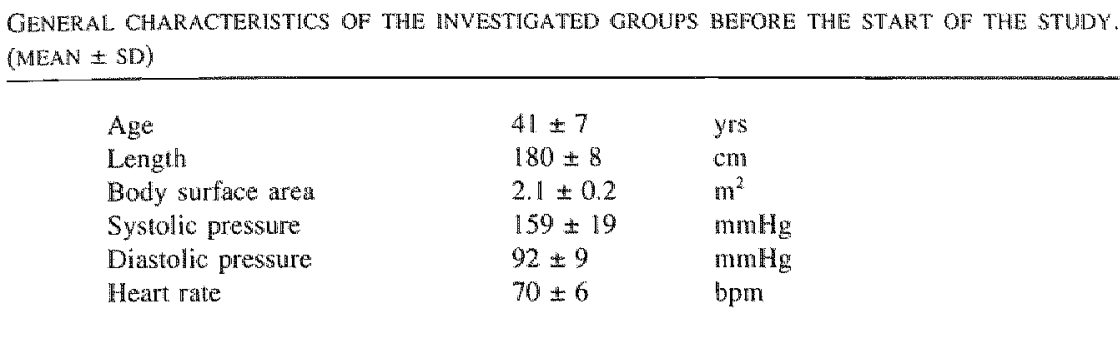

The results of both sodium-sensitivity tests are given in Table 3. The average difference in mean arterial pressure between the two diets ( $\triangle \mathrm{MAP}$ ) was $11 \pm 3$ (range $8 \leftrightarrow 14$ ) $\mathrm{mmHg}$ and $-5 \pm 7$ (range $-14 \leftrightarrow 5$ ) $\mathrm{mmHg}$, in the sodium-sensitive (SS) and the sodium-resistant (SR) group, respectively. The sodium-sensitive group displayed a significant increase in systolic blood pressure during high salt intake, while the diastolic pressure changed only marginally. On the other hand, systolic pressure was not so much affected by sodium intake, while diastolic pressure fell significantly after high sodium intake, in the sodium-resistant group. Heart rate was not modified in the sodium-sensitive group (low salt diet (LS):71 \pm 6 , high salt diet (HS):67 7 bpm, ns), whereas it increased upon sodium intake in the resistant group (LS:72 \pm 9 , $H S: 76 \pm 10$ bpm, $p \leq 0.05$ ). Body weight increased more during high salt than during low salt diet in the sodium-sensitive group, but not in the sodium-resistant group. Although, in general, blood pressure values tended to be lower during the second assessment than during the first on either diet, the categorisation of sodium-sensitivity status was confirmed during the second assessment in all subjects. The average difference in MAP between high salt and low salt diet was $11 \pm 3$ (range $8 \leftrightarrow 15$ ) mmHg in the sodium-sensitive group and $0 \pm 6$ (range $-10 \leftrightarrow 7$ ) mmHg in the sodiumresistant group. The changes in systolic and diastolic pressures followed a similar pattern as during the initial investigation. In figure 1 the two consecutive determinations of sodiun-sensitivity status by repeated evaluation of the change in mean arterial pressure when sodium intake is increased from 20 to 220 mmols per day are drawn in a simple scatterplot. 


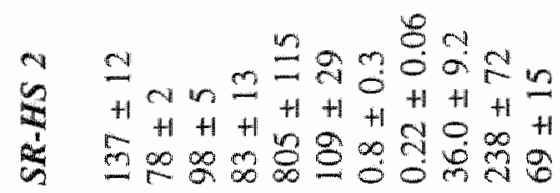

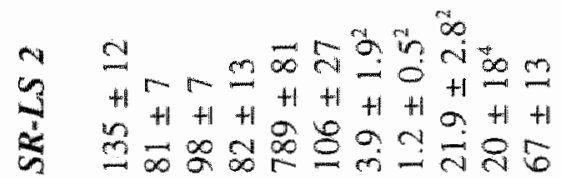

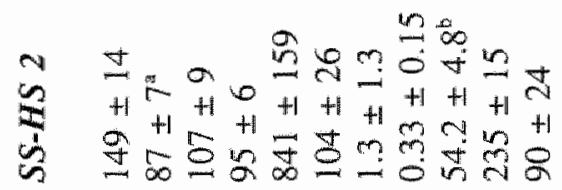

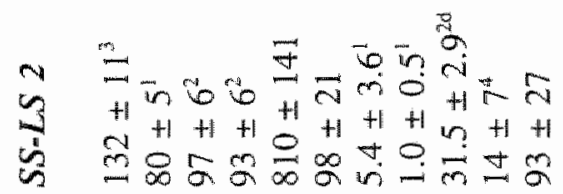

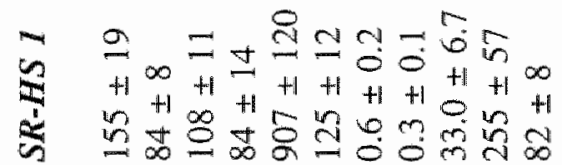

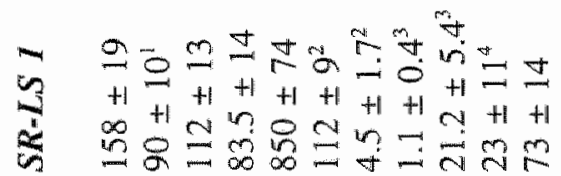

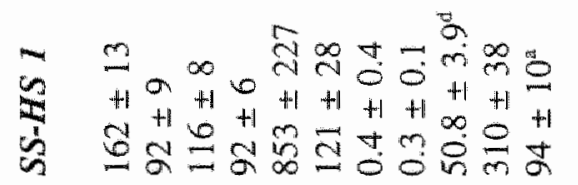

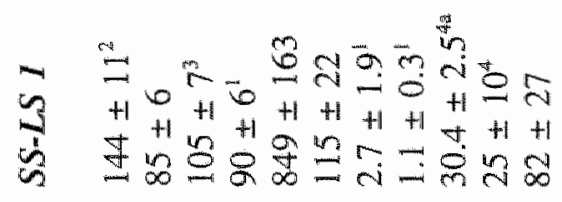

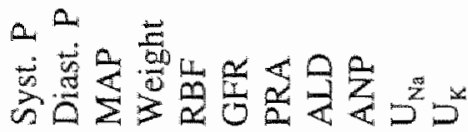

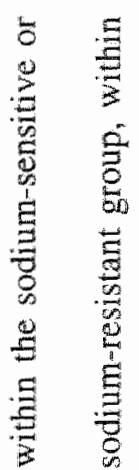

.5

.

2

$\begin{array}{ll}8 & \\ 8 & 8 \\ 9 & 8 \\ 8 & 0\end{array}$

ن

용

b.

क $\because=0$

\& 83

$\Xi \mathbb{v}_{1} D$

ㅁํำ

- $\dot{B} \ddot{0}$

동용

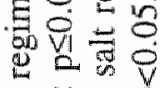

ॠ

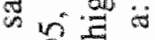

대용

IV

모용

$-1 \stackrel{\infty}{\square}$

政蛋

온일

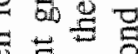

됴 00

通.

要跑

的 8

造导导

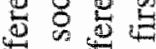

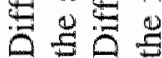




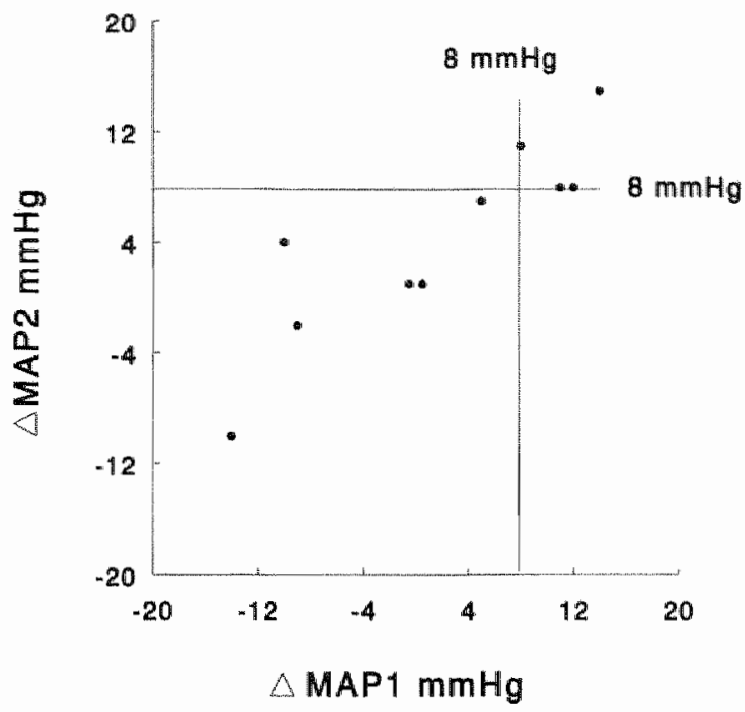

Figure 1. Sodium-sensilivity assessment. Differences in mean arterial pressure between the salt regimens in the first and second investigation (n=10). The right apper and left lower quadrant represent reproducilbility of sodhum-sensitivity and sodium-resistance, respectively.

Heart rate was not significantly modified by sodium intake in either of the groups (SS: LS:75 \pm 4 HS:72 \pm 5 , SR: LS: $66 \pm 6$ HS:65 $\pm 9 \mathrm{bpm}$ ). Weight gain upon high sodium intake was again larger in the sodium-sensitive than in the sodium-resistant group ( $2 \pm 1$ versus $1 \pm 0.5 \mathrm{~kg}, \mathrm{p} \leq 0.05$ ).

\section{Renal haemodynamics}

During the first investigation, renal blood flow and glomerular filtration rate did not change significantly in the sodium-sensitive group upon high sodium intake. RBF tended to increase in the resistant group, while there was a significant increase in GFR upon high salt diet.

Renal blood flow displayed a tendency to increase upon high sodium intake in both groups during the repeated study, as did glomerular filtration rate, but the differences were not statistically significant. In figure 2 a Bland-Altman analysis of the differences in $\triangle \mathrm{RBF}$ during the first and the second investigation is depicted. The mean of the differences was $13 \mathrm{ml} / \mathrm{min}$, with a standard deviation of $133 \mathrm{ml}$. 


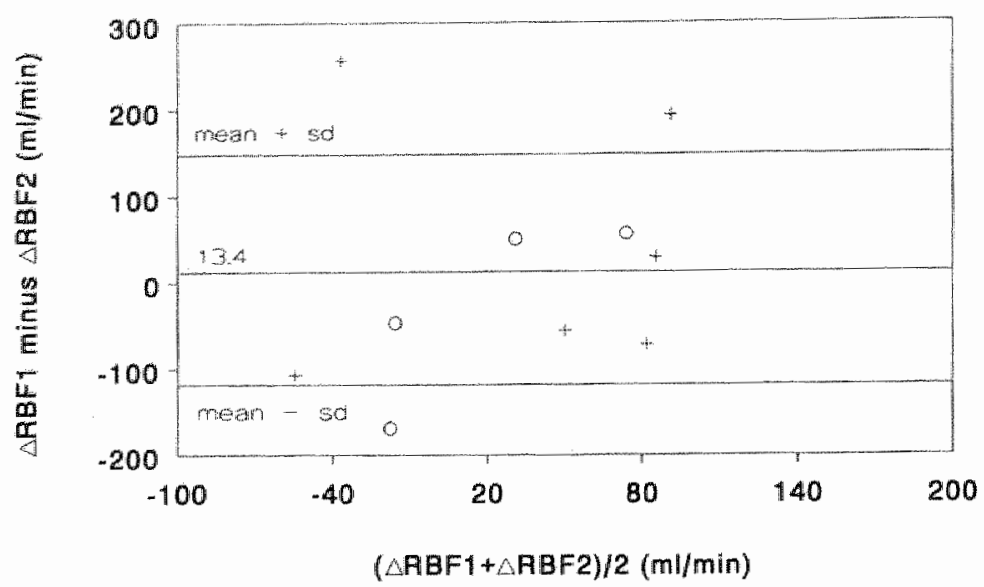

Figure 2. Reproducibility of the assessment of renal blood flow. o-signs represent siodium-sensitive subjects, +-signs sodium-resistant ones.

\section{Plasma renin activity, aldosterone and atrial natriuretic peptide}

As expected, plasma renin activity was significantly higher after the low salt diet than after the high salt diet in both groups during the initial investigation. The change in PRA upon the alteration in sodium intake ( $\triangle P R A$ ) was not significantly different between the groups (SS: $2.3 \pm 1.5$, SR: $3.9 \pm 1.8 \mathrm{ng} / \mathrm{ml} / \mathrm{hr}, \mathrm{p}=0.2$ ). Plasma aldosterone decreased significantly and similarly in both groups upon high salt intake. Atrial natriuretic peptide increased significantly during the high sodium diet in the two groups. However, the sodium-sensitive group displayed significantly higher ANP-levels on either diet. Furthermore, the increase in ANP upon high sodium intake ( $\triangle A N P$ ) was larger in the sensitive group $(20.4 \pm 5.5$ versus $11.8 \pm 5.3$ $\mathrm{pg} / \mathrm{ml}, \mathrm{p}=0.04)$ and $\triangle \mathrm{ANP}$ correlated significantly with $\triangle \mathrm{MAP}(\mathrm{r}=0.63, \mathrm{p}=0.027$, (1ig.3).

Plasma renin activity was reduced upon high sodium intake by $4.1 \pm 2.8 \mathrm{ng} / \mathrm{m} / \mathrm{hr}$ in the sensitive group and, similarly, by $3.2 \pm 2.0 \mathrm{ng} / \mathrm{ml} / \mathrm{hr}$ in the resistant group ( $p=0.55$ ), during the second investigation. As shown in figure 4 , the mean difference in $\triangle P R A$ between the first and the second investigation was $-0.28 \mathrm{ng} / \mathrm{ml} / \mathrm{hr}$, with a standard deviation of 2.5. Aldosterone decreased, as in the initial investigation, significantly and in a similar fashion upon high salt intake in both groups. Changes in atrial natriuretic peptide were comparable to those of the first investigation $(\mathrm{fig} .5)$ 


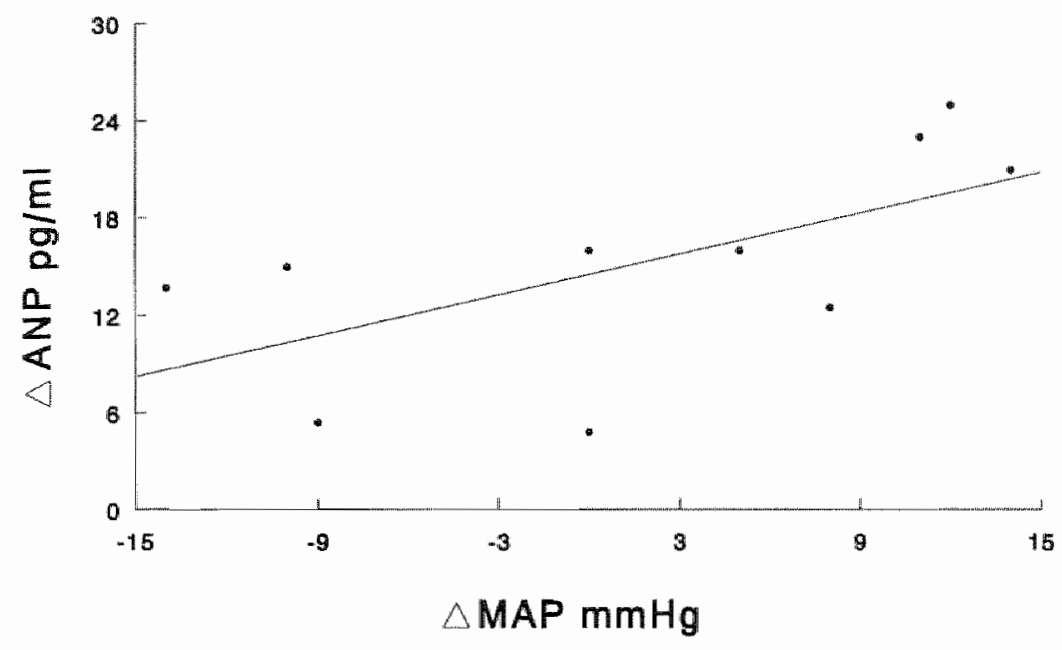

Figure 3. Correlation between the change in mean arterial pressure upon high sodium intake and the concomitant change in plasma ANP levels.

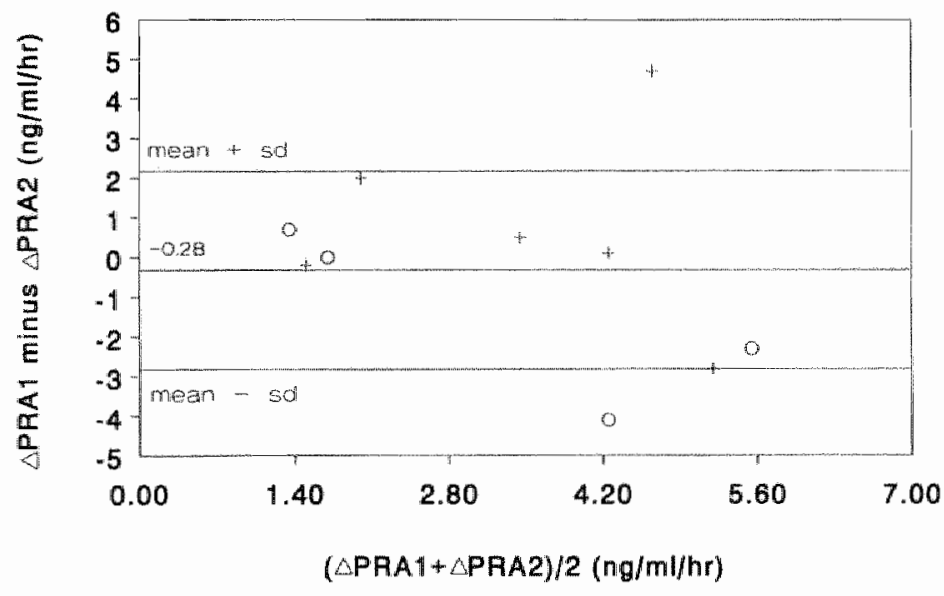

Figure 4. Reproducibility of the assessment of plasma renin activity. O-signs represent sodium-sensitive subjects, \#-signs sodium-resistant ones. 


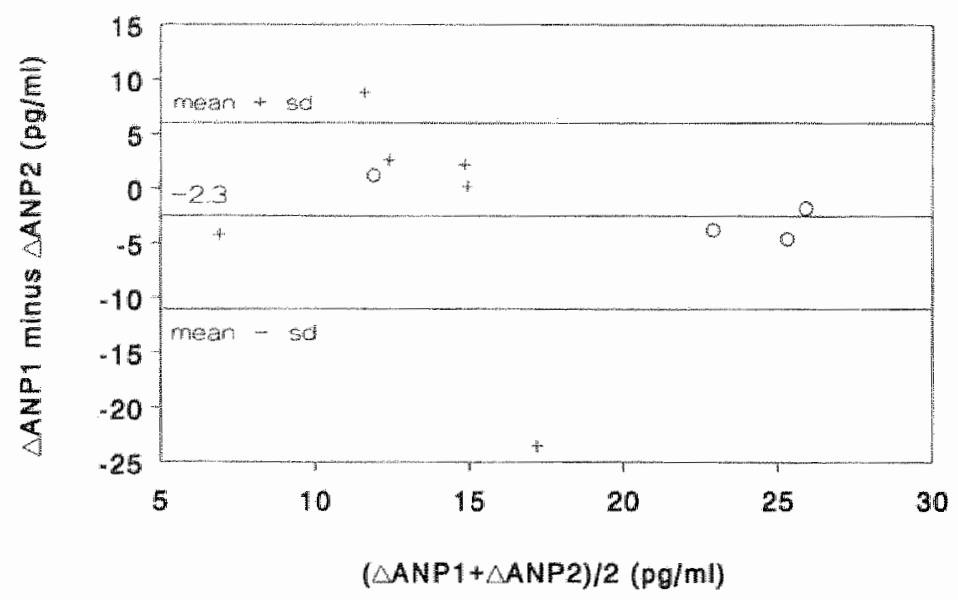

Figure 5. Reproducibility of the assessment of atrial natriuretic factor. o-signs represent sodium-sensitive subjects +-signs sodium-resistant ones.

\section{Renal excretion of dopa and dopamine}

Twenty-four hour urinary dopa excretion increased significantly upon the change from low to high sodium intake in the sodium-resistant group, but not in the sodium-sensitive group (fig. 6). Overall, urinary dopa levels tended to be higher in the sodium-sensitive group than in the sodium-resistant group on either diet, although no statistical significance was reached. Dopamine excretion in both groups increased during high sodium intake, but to a statistically significant degree only in the sodium-sensitive group (fig. 7). The calculated dopamine-to-dopa ratio was not significantly modified by sodium intake in the sodium-sensitive group (fig. 8). In contrast, this ratio fell significantly in the resistant group upon high sodium intake. Moreover, the ratio tended to be lower in the sodium-sensitive group as compared to the resistant one.

As in the first investigation, urinary dopa excretion increased significantly upon high sodium intake in the sodium-resistant group, but not in the sodium-sensitive group, during the second investigation (fig. 6). In the sodium-sensitive group the urinary dopa levels again tended to be higher than in the sodium-resistant group. The dopamine excretion tended to increase during high salt intake in both groups (fig. 7), but no statistical significance was reached. As in the initial study, dopamine-todopa ratio was not significantly altered by sodium-intake in the sodium-sensitive group, while it was significantly reduced in the resistant group (fig. 8). The ratio was again lower in the sensitive group than in the resistant one during the low salt period (SS: $5.7 \pm 2.5$ ys SR: $11.1 \pm 4.2, \mathrm{p}<0.05$ ). 


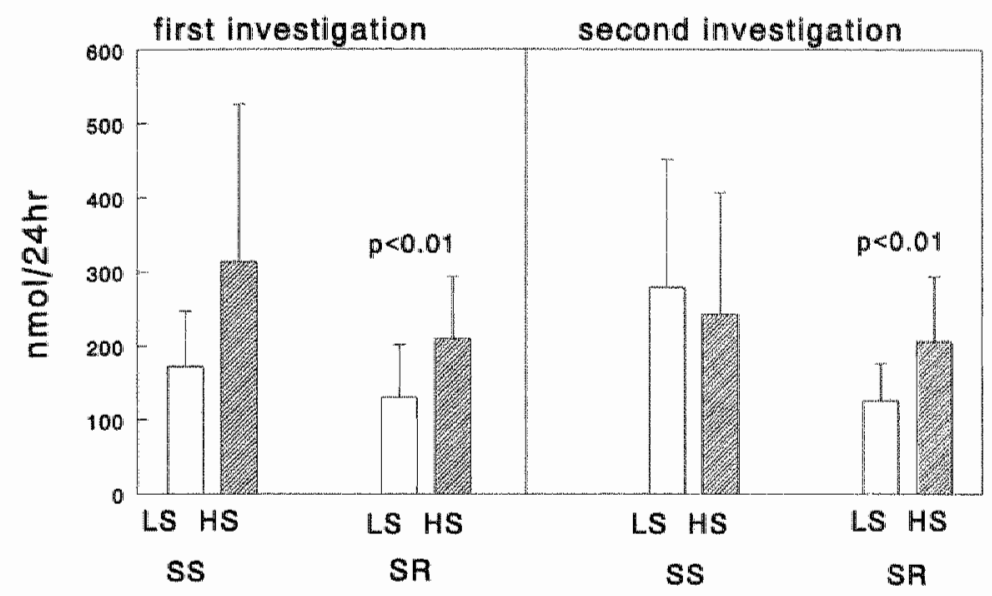

Figure 6. Urinary DOPA excretion

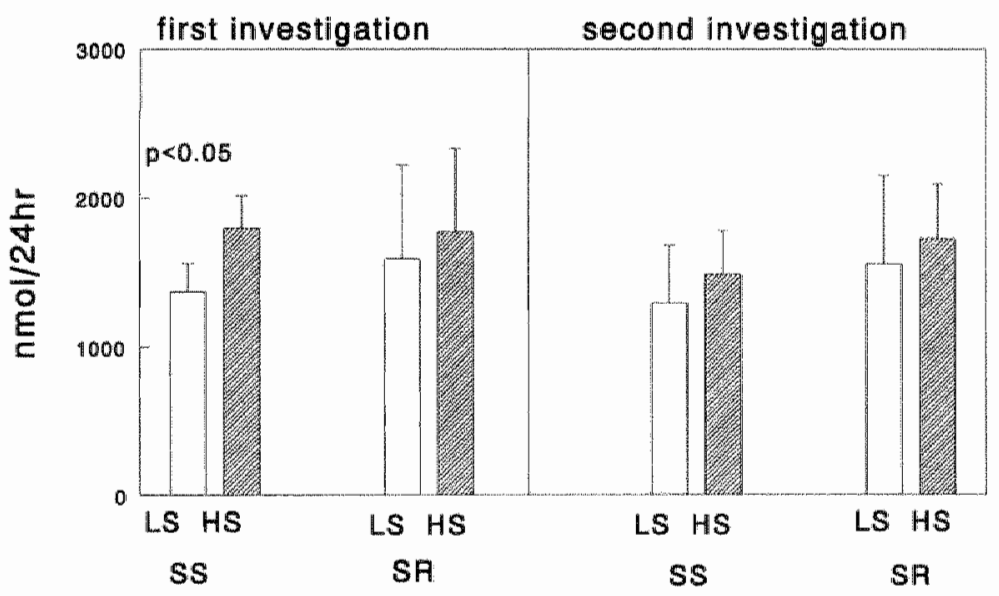

Figure 7. Urinary dopamine excretion 


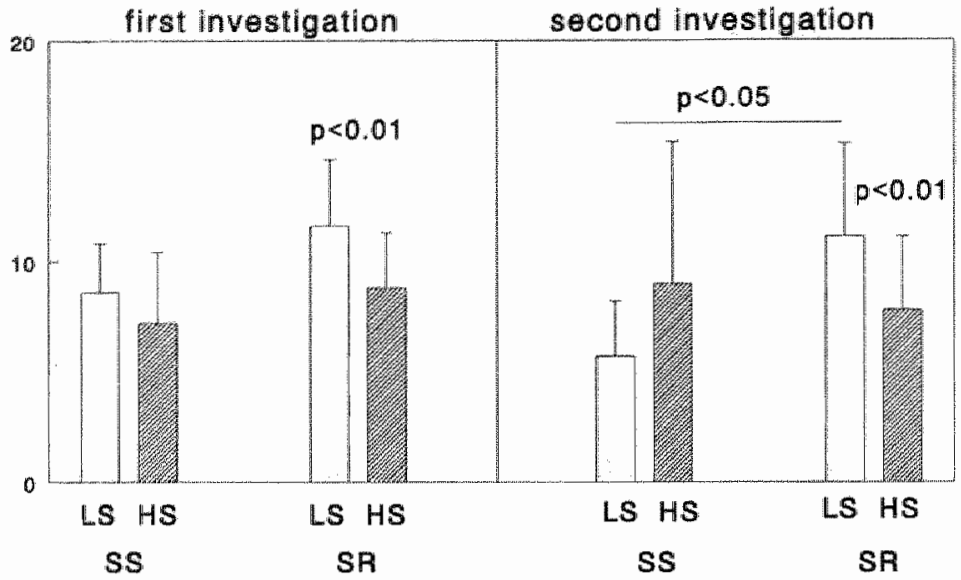

Figure 8. Dopamine-to-DOPA ratio.

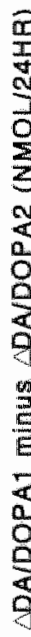

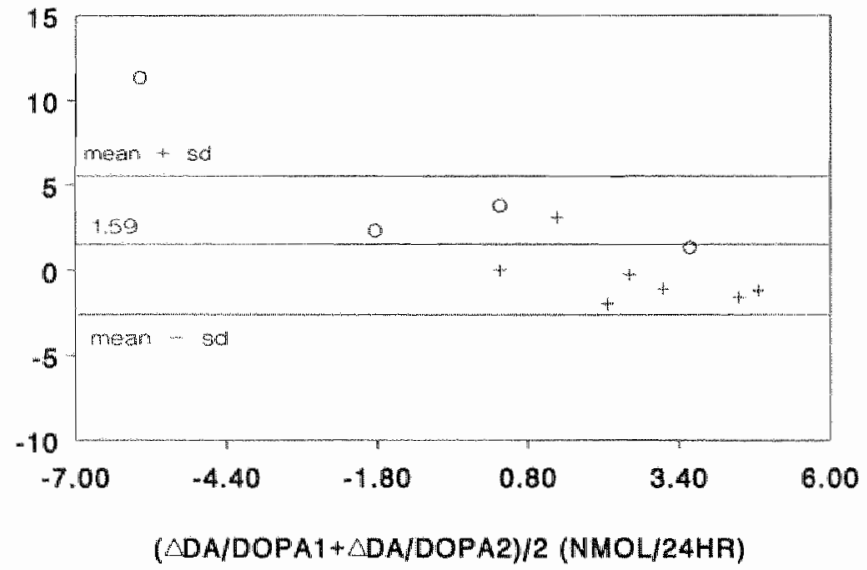

Figure 9. Reproducibility of the assessment of dopamine-to-dopa ratio. C-signs represent sodimm-sensitive subjects, +-signs sodium-resistant ones. 
In figure 9 the reproducibility of the change in dopamine-to-dopa ratio $(\Delta d a / d o p a)$ is depicted. During the Iow salt period of the second investigation, there were significant correlations between on the one hand urinary dopa excretion and dopamine-todopa ratio with on the other hand $\triangle M A P\left(U_{\text {dop }}\right.$ and $\triangle M A P: r=0.66, p=0.019$ and da/dopa and $\triangle \mathrm{MAP}: \mathrm{r}=-0.65, \mathrm{p}=0.021$ ).

\section{Urinary sodium and potassium excretion}

No significant differences were present in electrolyte excretion between the two groups, except for a higher potassium excretion at the end of the high salt diet in the sensitive group. During the first investigation $n_{\mathrm{y}}$ the difference in sodium excretion between high salt and low salt regimens was $286 \pm 34 \mathrm{mmol} / 24 \mathrm{hr}$ in the sodiumsensitive and $232 \pm 63$ mmol/24hr in the resistant group $(p=0.2)$. During the second investigation, these differences were $229 \pm 14 \mathrm{mmol} / 24 \mathrm{hr}$ in the sodium-sensitive group and $218 \pm 71 \mathrm{mmol} / 24 \mathrm{hr}$ in the resistant group $(\mathrm{p}=0.45)$.

\section{Discussion}

The reproducibility of dietary salt-sensitivity testing was examined in borderline hypertensive males by repeatedly studying the effects of low salt versus high salt intake on blood pressure. Furthermore, factors of putative pathophysiologic importance were studied in order to assess whether a certain diversion of these factors between sodium-sensitive and resistant subjects after oral salt loading was consistently present during both the initial and the second study. We reasoned that a lack of reproducibility for a given variable would tend to diminish its impact in the pathogenesis of sali-sensitivity.

According to the criterion for sodium-sensitiwity as defined in this study, a perfect agreement between the first and the second assessment was found with respect to categorisation of subjects (fig. 1). These data are in accordance with the results of studies on the reproducibillity of dietary salt-sensitivity testing as reported by Sullivan et al. demonstrating agreement between test and retest in 18 of 19 essential bypertensives ${ }^{2}$ and by Sharma et al. classifying 14 out of 15 normotensive subjects in the same category after restudy ${ }^{15}$.

Acquaintance with the protocol may explain that, overall, blood pressure values were somewhat lower during the second investigation. In the sodium-sensitive group differences in mean arterial pressure between the high and low salt regimens averaged $11 \mathrm{mmHg}$ in both investigations, whereas the resistant group displayed an average difference of $-5 \mathrm{mmHg}$ in the first and of $0 \mathrm{mmHg}$ in the second study. These results resemble those of Gill and co-workers, who demonstrated, while using 
the same $8 \mathrm{mmHg}$ criterion to define sodium-sensitivity as we did, a difference in mean arterial pressure between high and low salt diet of $12 \mathrm{mmHg}$ in sodiumsensitive and of $0 \mathrm{mmHg}$ in sodium-resistant hypertensive subjects 9 . High salt intake predominantly and consistently increased systolic blood pressure and to a lesser extent diastolic pressure in sodium-sensitive subjects. In contrast, systolic pressure was not much influenced by dietary salt whereas diastolic pressure tended to decrease in the resistant subjects. The tendency of the systolic pressure to rise during high salt intake in sodium-sensitive individuals may be explained by decreased large artery distensibility and compliance in these subjects as compared to sodium-resistant ones. We recently demonstrated such a difference in large artery compliance under conditions of normal sodium intake ${ }^{16}$.

Weight gain upon high salt intake was greater in sodium-sensitive subjects than in resistant ones, in both the initial and the second study, like was demonstrated before by Fujita and co-workers ${ }^{17}$. Furthermore, sodium-sensitive subjects tended to have higher body weights than resistant subjects, which corroborates the idea that sodiumsensitivity is more common in obese than in lean subjects ${ }^{18}$.

Hollenberg et al noted that the normal increase in renal blood flow upon high salt intake did not occur in a salt-sensitive subset of essential hypertensive patients. In these patients, called non-modulators ${ }^{19}$, the absence of such a modulatory influence of sodium on renal haemodynamics is thought to contribute to their sodiumsensitive response upon high sodium intake. However, neither in the initial study nor in the repeated one, did we find evidence for a difference in renal haemodynamic behaviour between sodium-sensitive and sodium-resistant subjects. Neither was this the case when two subjects with plasma renin levels below $2.5 \mathrm{ng} / \mathrm{ml} / \mathrm{hr}$ during low sodium intake were omitted from the analysis. Nevertheless, with a mean difference of $13 \mathrm{ml} / \mathrm{min}$ between the first and second assessment, reproducibility of the changes in renal blood flow upon high sodium intake were not that bad. Therefore, according to the results of this study, the behaviour of the renal vascular bed is a less likely determinant of sodium-sensitivity.

A blunted responsiveness of the renin-angiotensin-aldosterone system during sodium depletion in sodium-sensitive subjects has been described ${ }^{20}$. Plasma renin activity during low salt diet was lower in the sodium-sensitive group than in the sodium resistant group, during the first study. This difference, however, was not statistically significant and was not reproduced during the second investigation. Moreover, plasma aldosterone was not significantly different between both groups on either diet. Thus, also the renin-angiotensin aldosterone system may not be of prime importance for sodium-sensitivity. However, it is possible that local activation of the system, not reflected by measurement of blood PRA might contribute to sodiumsensitivity.

Atrial natriuretic peptide levels were significantly and reproducibly higher in the sodium-sensitive group than in the sodium-resistant one, both during low sodium and during high sodium intake. Moreover, the increase in ANP upon high sodium intake was significantly greater in the sodium-sensitive group. Kohno et al. also reported a steeper rise in plasma ANP levels in response to high salt intake in 
sodium-sensitive hypertensives ". The finding of increased levels of ANP in saltsensitive subjects fits with the concept that sodium-sensitive subjects on a high sodium diet gain more weight, retain more sodium and water, display a greater increase in cardiac output and thereby produce a greater rise in blood pressure than sodium-resistant subjects ${ }^{21}$. The positive correlation between the change in plasma ANP level and the change in mean arterial pressure, that was found in our study, may be a reflection of this mechanism (fig. 3). Alternatively, increased levels of ANP could be related to decreased venous distensibility and right atrial stretch in sodium-sensitive subjects on high sodium intake as was demonstrated by Takeshita et al. ${ }^{22}$.

In keeping with the results of Gill and co-workers, we found that in sodiumsensitive subjects urinary dopa levels tended to be higher and the dopamine-to-dopa ratio lower than in sodium-resistant ones, while dopamine excretion was comparable in both groups ". Urinary dopa excretion significantly rose and dopamine-to-dopa ratio significantly fell during the high salt diet in the sodium-resistant group during both the initial and the repeated study, a pattern that was also found in the normotensive control subjects studied by Gill et al.. In contrast, our data show that these variables do not appreciably change during modifications of sodium intake in the sensitive subjects. This finding appeared to be well reproducible. It may be speculated that in sodium-sensitive subjects urinary dopa levels already tend to be elevated during low salt intake in order to overcome decreased renal excretional capacity of sodium. When sodium intake subsequently increases, further increments of dopa excretion may be limited. The significant positive correlation between urinary dopa excretion and the blood pressure response upon high sodium intake and the significant inverse correlation between dopamine-to-dopa ratio and this response, that were found only during low sodium diet may favour the hypothesis that already during low salt intake the dopa-dopamine system is of importance in the renal sodium handling.

In conclusion, sodium-sensitivity testing of borderline hypertensive patients proved to be quite reliable in our hands. Our data indicate that plasma ANP levels reproducibly rise more upon high sodium intake in sodium-sensitive than in sodiumresistant subjects. In sodium-resistant patients, we found at both occasions a significant increase in urinary dopa excretion and a fall in dopamine-to-dopa ratio during high salt intake. These changes were consistently absent in the sodiumsensitive subjects in both the investigations. No compelling evidence was found to support the hypotheses that alterations in the regulation of renal haemodynamics or the renin-angiotensin-aldosterone system underlie the sodium induced blood pressure rise.

Taken together, atrial natriuretic peptide, urinary dopa excretion and the dopamineto-dopa ratio qualify as potential candidates for a role of pathophysiologic importance in the phenomenon of sodium-sensitivity, since they change consistently along with blood pressure during sodium challenge. Whether such changes are primary or a epiphenomenon is a matter for future research. 


\section{References}

1. Sullivar IM. Salt sensinwity. Definition, conception, methodology, and long-term issues. Hypertension 199177 suppll):16!-168.

2. Sullivan IM, Prewitt RL, Ratts TE, Josephs JA, Conmor MI Hemodynamic characteristics of sodiumgensitive human subjects. Hypenterssion $1987,9: 398 \% 406$.

3. Weinberger MH, Muler JZ, Luft FC, Grim CE, Fineberg NS. Defuntions and characteristics of sodiun sersitivity and blood pressure registance. Hypertension 1986:8(supplI):II127. II 134.

4. Campese VM, Parise M, Bigazzi R, Karubian F. Abmormal renal hemodynamic adaptation to high sodium intake in salt-sensitive patients with essental hypertension. J Am Soc Nephrol 1990;1:506.

5. Rydeted LL, Williams $\mathrm{GH}$.Hollenberg NK. Renal and endocrine response to saline infusion in essental lipypertension. Hypertension $1986: 8: 217-222$.

6. Konno $M$, Yasunary $K$, Murakawa $K$, Kanayama $Y$. Matsuira $T$, Takeda $T$. Effects of high sodiun and How sodium intake on circulating atrial natriuretic peptides in salt-sensitive patients with systemic hypertension. Am I Cardiol 1987;59:1212:1213.

7. Perkins CM, Casson IF, Cope GF, Lee MR. Lailure of salt to mobilize renal dopamine in essential bypertension. Lancet 1980; dedember20/27:1370.

8. Gill JR, Grossman $\mathbb{E}$, Goldstein DS. High thimary dopa and low urinary dopamine-to-dopa ratio in saltsensilive hypertension. Hypertension 1991;18:614-621.

9. Kagedal B. Goldstein DS. Carecholamines and their metabolites. J Chromatogr 1988;429:177-234.

10. Donker AJM, van der Hem GK, Sluiter WJ, Beekhuis H. A radio-isotope method for simultaneous determination of the glomerular filtration rate and the effective renal plasma flow. Neth $J$ Med $1977,20,97$.

11. Haber E, Kourner T, Page LB, Kliman B, Purnode A. Application of radioimmunoassay for angiotensin It the physiologic measurements of plasma renin activity in nomal human subjects. I Clin Endocr $1969 \cdot 29: 1349-1355$

12. Kubasik NP. Warten K, Sine HE. Evaluation of a new commercial radioussay kit for aldosterone using iodinated rricer. Clin Biochern 1979:12(2):59-61.

13. Rosmaten FMA, Tan A, Tan HS, Benrad TI. A sensitive radioimmunoassay of atrial natriuretic pepuide in human plasma using a tracer with an immobilized glycoril agent. Clin Chem Actu 1987; 165:331-340.

14. Bland JM, Alman DG. Statstical methods for assessing agreement between two methods of clinical measurement. Lancet 1986 tebrary 8:307-310.

15. Sharma AM. Schatentroh S. Kribben A. Distler A. Rellability of saltamensitivity testing in nomotensiwe subjects. Klin Wochensehr 1989:67:632-634.

16. Dranier P, Kool M. Matssen J, van Bortel L, de Leeuw P, wan Hooff J, Leunissen K. Artenal distensibjlity and complance in saltresistant and salt-sensitive borderline hypertensive patients. J Hypertems $1993: 11: 1199-1207$ 
17. Fugha $\mathbb{T}$, Henry W, Barter FC, Lake CR, Deleat CS. Fators influencing blood pressure in snlt-sensitive patients with hypertension. Am J Med $1980 ; 69 \times 334-344$.

18. Rocchini AP, Key J, Bondie D, Chico R, Moorehead C, Katch V, Martin M. The effect of weight loss on the sensitivity of blood pressure to sodium in obese adolescents. N Engl J Med 1989.321:580-585.

19. Williams GH, Hollenberg NK. Non-modulating bypertension. A subset of sodium-sensitive hypertension. Hypertension 1991;17(suppli) $181-185$.

20. Sullivan JM, Ratts TE. Sodium sensitivity in human subjects. Hemodymamic and hormonal correlates. Hypertension 1988;11:717-723.

21. Fujita T, Andro K, Ogata E. Systemic and regional hemodyramics in patients with salt-sensitiwe typertension. Hypertension $1990,16: 235-244$

22. Takeshita A, Ashihara T, Yamamoto $K$, Imaizumi T, Hoka S, to N, Nakamura M. Venous responses to salt loading in trypertensive subjects, Circulation 1984,69, no 1:50-56. 



\section{CHAPTER 4}

\section{VASCULAR DISTENSIBILITY AND COMPLIANCE IN SALT- SENSITIVE AND SALT-RESISTANT BORDERLINE HYPER- TENSION}

P Draajjer, MJF Kool", IMC Maessen", LMAB van Bortel", PW de Leeuw, JP van Hooff, KML Leunissen.

Departments of medicine, clinical pharmacology" and dietetics" of the university hospital in Maastricht, The Netherlands.

(Journal of Hypertension 1993;11:1199-1207) 


\section{Abstract}

In order to gain insight into the relationship between vascular compliance and sodium-sensitivity, arterial and venous compliance was determined in 17 sodiumsensitive and 28 sodium-resistant young borderline hypertensive males as well as in 10 matched normotensive controls, during regular sodium intake. The carotid, femoral and brachial arteries were studied using a non-invasive ultrasound vessel wall movement detector system, while venous compliance was determined using forearm strain gauge plethysmography. Furthermore, cardiac output, plasma volume and hormonal factors such as plasma renin activity were measured to assess their possible influence on vascular compliance.

Large artery compliance was significantly smaller in sodium-sensitive than in sodium-resistant subjects in all the arteries under study. In comparison with controls, arterial compliance was significantly reduced in the sodium-sensitive group, while the sodium-resistant group did not differ significantly from the controls. Venous compliance was equally reduced in the two hypertensive groups as compared to the controls, although the differences did not reach statistical significance. Cardiac output, blood pressure, plasma volume and hormonal factors did not differ between sodium-sensitive and sodium-resistant subjects and could not underlie the observed differences in arterial compliance.

In conclusion, the results of this study suggest that sodium-sensitive borderline hypertensives have reduced large artery compliance relative to sodium-resistant ones. Since this finding could not be explained by differences in hemodynamic or hormonal factors between the groups, this result points towards alterations in viscoelastic properties of the arterial wails in sodium-sensitive subjects.

\section{Introduction}

Although epidemiological and intervention studies suggest a relation between dietary sodium intake and blood pressure ', there is controversy about the role of salt in the pathogenesis of hypertension ${ }^{2}$. Several investigators have demonstrated a marked interindividual variability in the blood pressure responses to a sodium load ${ }^{34}$. This diversity in blood pressure responses, which occurs both in patients with essential hypertension ${ }^{3}$ and in normotensive controls ${ }^{5}$, has led to the concept of sodiumsensitivity ${ }^{4}$.

Many studies have addressed the question whether sodium-sensitive subjects have certain hernodynamic or vascular characteristics that distinguish them from sodiumresistant ones. Indeed, it has been shown that the increase in cardiac output during high sodium intake is paralleled by a decrease in forearm vascular resistance in sodium-resistant, but not in sodium-sensitive hypertensive subjects. In the latter 
group a rise in forearm resistance during high sodium diet has even been found " Moreover, sodium-sensitive essential hypertensive subjects on a high sodium intake display a decrease in maximal vasodilator capacity of the forearm vascular bed, whereas sodium-resistant hypertensive patients do not ${ }^{\gamma}$. These experiments suggest a disturbance in the control of vascular resistance in sodium-sensitive subjects. A possible mechanism for this disturbance could be that high sodium intake produces functional or structural changes in the arterial wall.

Alterations in the vascular wall do not only contribute to the static component of pressure and flow, i.e. vascular resistance, but might also influence the dynamic component, viz. vascular compliance. Compliance is defined as the change in intravascular volume for a given change in blood pressure and is determined by intravascular pressure, vascular dimensions and by the visco-elastic properties of the vascular wall. In hypertensive patients arterial compliance is reduced in comparison with normotensive controls \&. This reduction in compliance occurs more frequently in patients with left ventricular hypertrophy ${ }^{9}$, systolic hypertension ${ }^{10}$, impairment of myocardial perfusion ", reduced baroreceptor sensitivity" Not only arterial, but also venous compliance is reduced in essential hypertensives 12. Moreover, in sodium-sensitive subjects the capacitance of the forearm venous system is reduced in comparison with sodium-resistant ones ${ }^{6}$.

High sodium intake seems to impair vascular tone and/or structure predominantly in sodium-sensitive subjects. We were interested to know whether under conditions of regular sodium intake functional or structural differences between sodium-sensitive and sodium-resistant subjects are also present, since these may well be related to future cardiovascular morbidity ${ }^{13}$. Therefore, we studied arterial and venous compliance in sodium-sensitive and sodium-resistant borderline hypertensive subjects consuming $120 \mathrm{mmol}$ of sodium per day. Since the increased resistance in sodium-sensitive subjects during high salt intake might be caused by a reduced 1.4 or delayed is suppression of the renin-angiotensin-aldosterone system, plasma renin activity and aldosterone concentration were measured as well. Furthermore, to assess whether a difference in intravascular volume exists beween sodium-resistant and sodium-sensitive subjects, plasma volume and atrial natriuretic peptide were also measured. Finally, stroke volume was measured, because of its impact on arterial distension and thereby on arterial compliance.

\section{Patients and methods}

Forty-five previously untreated borderline hypertensive patients, as well as 10 agematched healthy normotensive controls were studied. Details on these subjects are provided in chapter 2. Moreover, detailed descriptions of the sodium-sensitivity test and of haemodynamic and laboratory techniques used in the present study are given 
in this chapter.

The sodium-sensitivity status of the borderline hypertensives was determined 5 weeks before the onset of this study by means of a diet method. At the end of each diet week ( $20 \mathrm{mmols} /$ day versus $220 \mathrm{mmols} /$ day), blood pressure and body weight were measured. An arbitrarily chosen cut-off point of $8 \mathrm{mmHg}$ difference in mean arterial pressure between the end of the high sodium and the end of the low sodium diet, was taken as an index of sodium-sensitivity. The reproducibility of this approach was excellent as was described in chapter 3 .

During the week preceding the investigation of vascular compliance, all subjects used a diet containing $120 \mathrm{mmol}$ sodium and $70 \mathrm{mmol}$ potassium per day, again guided by a dietician in an outpatient setting, while 24-hour urine samples were used to estimate diet-compliance.

\section{Arterial distensibility and compliance}

All subjects were studied at $8.00 \mathrm{am}$ after at least 15 minutes of supine rest in a room with a constant temperature of approximately $24^{\circ} \mathrm{c}$. A light breakfast had been consumed at approximately $7.00 \mathrm{am}$. The measurements were performed on the carotid, the femoral and the brachial arteries using a non-invasive ultrasound wall movement detector system. This system enables accurate measurements of arterial diastolic diameter (Dd) and arterial wall distension upon the pressure wave ( $\Delta D$ ). Simultaneously with the vessel movement registration, blood pressure was measured every 2 minutes with an automated device (Dinamap, Tampa, USA). The averages of these blood pressures and pulse pressures $(\Delta \mathrm{P})$ were calculated.

From the arterial diameter, the change in diameter during the heart cycle (distension), and the pulse pressure, arterial distensibility and compliance were calculated.

\section{Venous compliance}

Venous compliance was measured by strain gauge plethysmography (Periflow, Janssen Scientific Instruments, Beerse, Belgium) with direct intravenous pressure measurements. The investigation was performed at approximately $9.00 \mathrm{am}$, after the measurement of the arterial wall properties, again in supine position in a temperature controlled room $\left(24^{\circ} \mathrm{C}\right)$.

The arm cuff was inflated for three minutes at a cuff pressure of $25 \mathrm{mmHg}$. The change in arm volume and in intravenous pressure were measured following cuff deflation. Subsequently, the procedure was repeated at stepwise increasing cuff pressures, thereby obtaining 5 volume-pressure ratios, that were used in a linear regression analysis to obtain an estimate of venous compliance. 


\section{Echo-Doppler cardiography}

In order to obtain cardiac stroke volume, ascending aortic blood flow velocity was measured using a continuous wave Doppler system with a 10 megahertz transducer, positioned at the apex, while the aortic diameter was determined by means of bidimensional echocardiography ( 3.5 megahertz transducer, positioned at the third or fourth intercostal space at the left sternal edge, Hewlett Packard sonos 100 echoDoppler cardiograph). Cardiac output was calculated by multiplying stroke volune with heart rate. Cardiac index was calculated from the cardiac output and the body surface area.

\section{Plasma volume}

Plasma volume was measured in the two hypertensive groups using the radioiodinated serum albumin method (I-125 albumin) ${ }^{16}$. The measured plasma volume was compared to a theoretical plasma volume determined on the basis of age and weight ${ }^{17}$.

\section{Laboratory tests}

Blood samples were taken in order to determine plasma renin activity (GammaCoatradioimmunoassay kit, Baxter, Massuchusetts USA), plasma aldosterone (Coat-acount, DPC, Los Angeles, USA) and atrial natriuretic peptide concentration (ITSradioimmunoassay kit, Wijchen, The Netherlands), with the patient in sitting position.

\section{Data analysis}

Data are presented as mean \pm standard deviation. The Kolmogorov-Smimow goodness of fit test was used to verify whether variables were normally distributed. Whether variables follow the same distribution in the salt-sensitive and the saltresistant subgroups was evaluated using the Kolmogorov-Smirnow test for 2 independent samples. In case of normally distributed data, statistical analysis of the differences between the two hypertensive groups was performed with Student's unpaired T-test, whilst the differences between the hypertensive groups and the normotensives were further analysed by means of multiple regression analysis. Otherwise non-parametric tests for 2 (Kruskall-Wallis) or 3 (Mann-Whitney) independent samples were used. The level of significance was $p<0.05$. 


\section{Results}

Table 1 shows the used abbreviations.

Table 1

\begin{tabular}{|c|c|}
\hline \multicolumn{2}{|c|}{ USED ABBREVIATIOHS } \\
\hline NT & Normotensive contrals \\
\hline $8 \mathrm{~s}$ & Sodlum-sensitive borderline hypertensive patients \\
\hline SR & Sodum-resistant borderline hypertemsive patients \\
\hline BSA & Bodly surface area \\
\hline MAP & Mean arteriall pressiure \\
\hline HR & Heart rate \\
\hline SI & Stroke index \\
\hline $\mathrm{CI}$ & Cardiac index \\
\hline PRA & Plasma renin activity \\
\hline Ald & Aldosterone \\
\hline ANP & Atrial natriuretic peptiace \\
\hline
\end{tabular}

\section{Characteristics of the investigated groups}

According to the defintion used in this study, 17 borderline hypertensive patients were called salt-sensitive and 28 salt-resistant. Table 2 shows characteristics of the three investigated groups; the normotensive control group (NT), the sodium-sensitive borderline hypertensives (SS) and the sodium-resistant borderline hypertensives (SR). There were no significant differences in age or body surface area between the groups. The estimated duration of hypertension was 7 years in both groups.

The systolic and diastolic pressure, as well as the mean arterial pressure were comparable in the two hypertensive groups, while both these groups exhibited significantly increased blood pressure when compared to the controls $(p \leq 0.005$ ). Heart rate tended to be smaller in the normotensive group as compared to the sodium-sensitive hypertensive group.

Sodium excretion in the 24-hr urine sample collected on the day before the investigations was $129 \pm 28$ (median 138, range $71-160$ ), $112 \pm 44$ (median 117 , range 18 204) and 104 21 (median 105, range 69-132) mmol sodium in the sodium-sensitive, the sodium-resistant and the normotensive group respectively, while the potassium excretion was $73 \pm 13$ (median 70 , range 51-96), $70 \pm 32$ (median 67 , range 18-174) and $68 \pm 25$ (median 61, range 47-114) mmol per 24 hours. There were no significant differences in electrolyte excretion between the groups. 


\section{Table 2}

CHARACTERISTICS OF THE GROUPS. $P^{\prime}$ : PWALUE OF THE ANALTSIS OF NT VERSUS SS. $\mathrm{P}^{2}$ : SS VERSUS SR, $\mathrm{P}^{3}$ : NT VERSLS SR. (MEANISD)

\begin{tabular}{|c|c|c|c|c|c|c|}
\hline & $N T$ & $\boldsymbol{p}^{\prime}$ & $s S$ & $p^{2}$ & $S R$ & $P^{b}$ \\
\hline $\mathrm{N}$ & 10 & & 17 & & 28 & \\
\hline $\mathrm{AGE}(\mathrm{yrs})$ & $37 \pm 6$ & .06 & $41 \pm 6$ & .41 & $40 \pm 6$ & 19 \\
\hline$B S A\left(m^{2}\right)$ & $1.9 \pm 0.1$ & .11 & $2 \pm 0.2$ & .74 & $2 \pm 0.2$ & .09 \\
\hline Syst (mmHg) & $127 \pm 10$ & .005 & $155 \pm 13$ & .43 & $153+16$ & .005 \\
\hline Dias (mrihg & $76 \pm 7$ & .005 & $87 \pm 6$ & .42 & $85 \pm 8$ & .005 \\
\hline MAP (mmHg) & $93 \pm 7$ & .005 & $110 \pm 7$ & .48 & $108 \pm 10$ & .005 \\
\hline HR (bpm) & $59 \pm 8$ & .08 & $67 \pm 13$ & 20 & $63 \pm 10$ & .28 \\
\hline $\mathrm{SI}\left(\mathrm{ml} \mathrm{m}^{2}\right)$ & $39 \pm 15$ & .38 & $35 \pm 10$ & .07 & $4 ! \pm 11$ & .71 \\
\hline $\mathrm{CI}\left(1 \mathrm{~min} \mathrm{n}^{-1} \mathrm{~m}^{-2}\right)$ & $2.3 \pm 0.8$ & .82 & $2.3 \pm 0.9$ & .19 & $2.6 \pm 0.8$ & .40 \\
\hline PRA (ng.ml $\left.{ }^{-1} \cdot \mathrm{hr}^{-1}\right)$ & $1.43 \pm 0.9$ & .26 & $1.07 \pm 0.7$ & 39 & $1.46 \pm 1.7$ & .96 \\
\hline Ald (ng. $\left.\right|^{-1}$ ) & $0.41 \pm 0.2$ & .39 & $0.5 \pm 0.3$ & .17 & $0.41 \pm 0.1$ & .99 \\
\hline ANP (pg.mlis) & $30.1 \pm 11$ & .08 & $40.2 \pm 14$ & 93 & $40.7 \pm 23$ & .22 \\
\hline
\end{tabular}

\section{Echocardiography}

Cardiac index was comparable in all three groups. The stroke index tended to be smaller in the sodium-sensitive group as compared to the sodium-resistant one, but the difference did not reach statistical significance (SS: $35 \pm 10, \mathrm{SR}: 41 \pm 11 \mathrm{ml} . \mathrm{m}^{-2}$, $\mathrm{p}=0.07$, Table 2).

\section{Plasma volume}

Plasma volume was not different between the two hypertensive groups (SS: $35 \pm 4$, SR: $37 \pm 5 \mathrm{ml} . \mathrm{kg}^{-1}$ ). Theoretical values, based on age and weight were significantly higher than the actual values in approximately all the borderline hypertensive subjects (SS: $42 \pm 3, \mathrm{SR}: 43 \pm 2 \mathrm{ml} . \mathrm{kg}^{-1}, \mathrm{p}<0.001$ ).

\section{Laboratory tests}

Table 2 shows the values for plasma renin activity, aldosterone concentration and atrial natriuretic peptide level. There were no significant differences in these plasma factors between the sodium-sensitive and the sodium-resistant borderline hypertensive groups. Neither were these significantly different from the control group. 


\section{Arterial compliance and distensibility}

The results on arterial diastolic diameters are depicted in figure 1. Vascular diameters tended to be somewhat smaller in the control group than in the sodium-resistant and the sodium-sensitive borderline hypertensives.

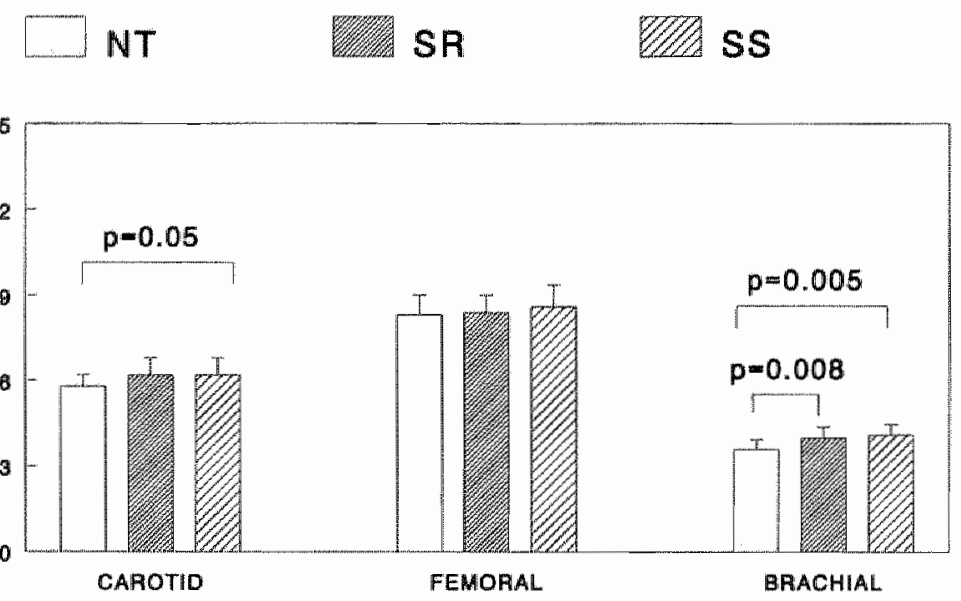

Figure 1. Diastolice diameters of the carotid, femoral and brachial arteries.

In the two hypertensive groups the vascular diameters were similar. This is in contrast with the values for distension (fig. 2), that were significantly smaller in the sodium-sensitive than in the sodium-resistant group in all investigated vessets. Also in comparison with the normotensive group, sodium-sensitive subjects had significantly reduced arterial distension. The distension in the sodium-resistant group, however, was comparable to that of the normotensive group.

The pulse pressure, measured during the investigation of the arterial dimensions was significantly higher in the two hypertensive groups (SR: $53 \pm 7, \mathrm{SS}: 54 \pm 8, \mathrm{mmHg}$ ) as compared to the controls $(46 \pm 5 \mathrm{mmHg}, \mathrm{p} \leq 0.02)$, but was not different between the two bypertensive groups. 


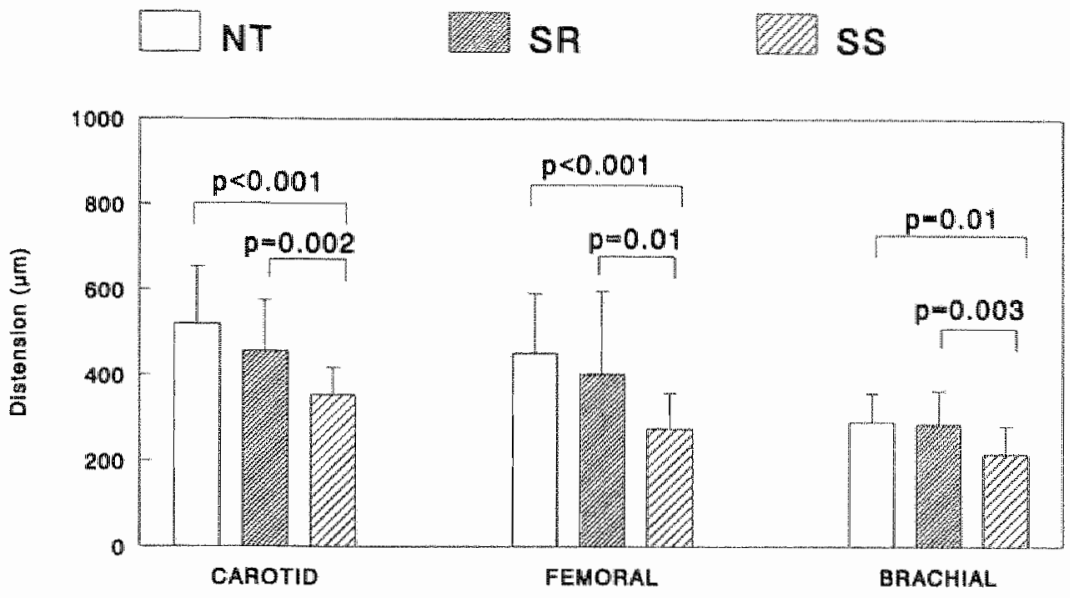

Figure 2. Distension of the carotid, femoral and brachial arteries.

Vessel diastolic diameter $(\mathrm{Dd})$, distension $(\Delta \mathrm{D})$ and pulse pressure $(\Delta \mathrm{P})$ were used to calculate the arterial wall distensibility according to the following equation.

$$
\mathrm{DC} \text { (distensibility coefficient) }=(2 \Delta \mathrm{D} / \mathrm{Dd}) / \Delta \mathrm{P} \quad 10^{-3} / \mathrm{kPa}
$$

The calculated values of the vascular clistensibility are presented in figure 3. The distensibility coefficients of all investigated arteries were significantly smaller in the sodium-sensitive group as compared to the sodium-resistant group. The difference in distensibility coefficient between the sodium-sensitive group and the controls was also highly significant in the three investigated vessels. Regarding the distensibility coefficient, the sodium-resistant borderline hypertensives tended to take an intermediate position between the sodium-sensitives and the controls. However, the reduction in distensibility coefficient in the sodium-resistant group reached statistical significance for the carotid artery only.

Compliance coefficients were calculated according to the following equation.

$$
\mathrm{CC}(\text { compliance coefficient })=(\pi \mathrm{Ddx} \Delta \mathrm{D}) / 2 \Delta \mathrm{P} \quad \mathrm{mm}^{2} / \mathrm{kPa}
$$

The calculated compliance coefficients are given in figure 4 . The compliance coefficient was significantly smaller in the sodium-sensitive group than in the resistant and the control group in all investigated arteries. The sodium-resistant borderline hypertensives on the other hand, had compliance coefficients comparable to controls in the investigated vessels. 
$[N T$

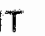

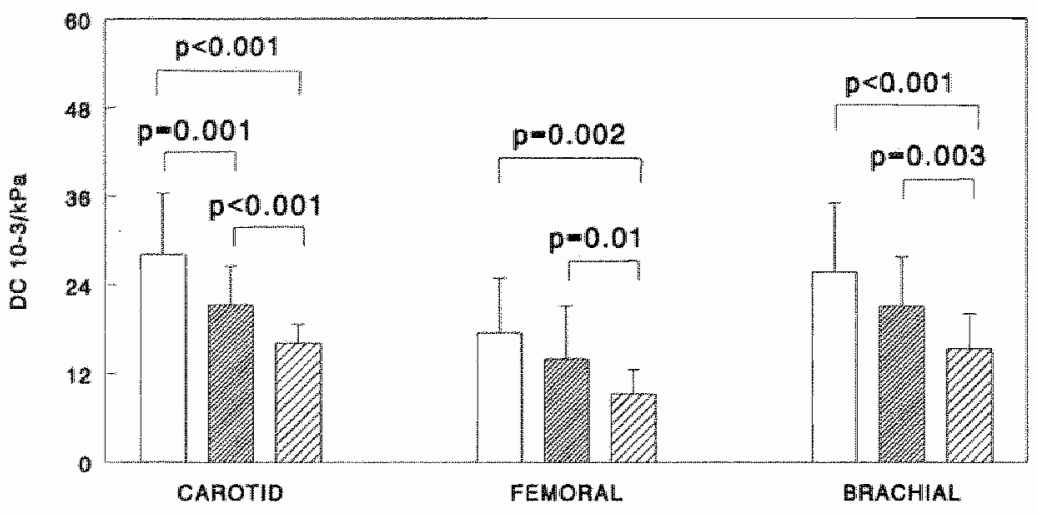

Figure 3. Disttensibillity coefficients of the carotid, femoral and brachialarteries.

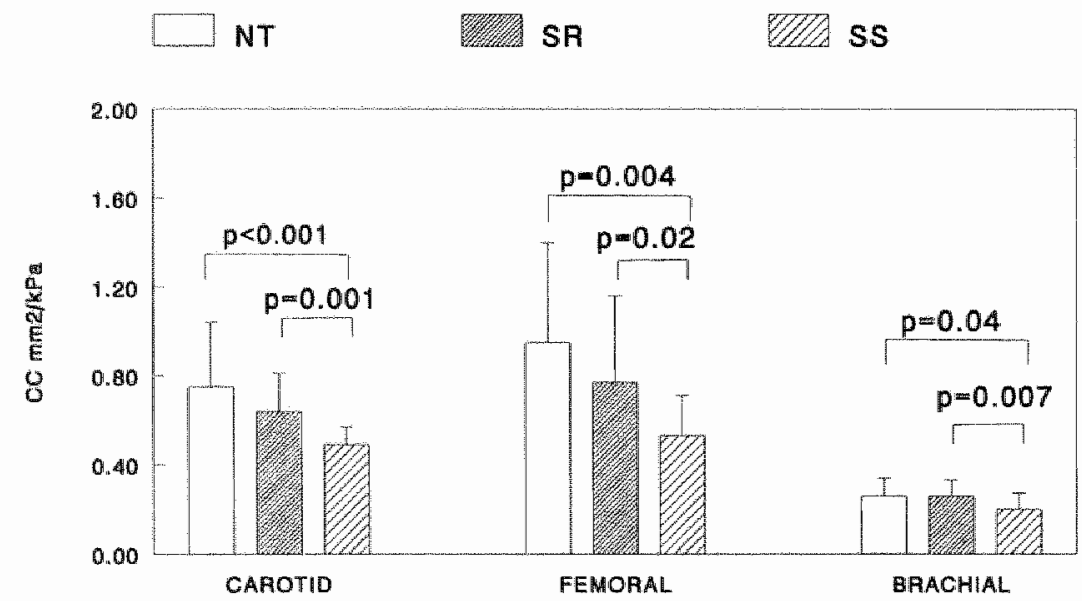

Figure 4. Compliance coefficients of the carotid, femorall and brachial arteries. 


\section{Venous compliance}

Venous compliance was $0.052 \pm 0.019 \mathrm{ml} .100 \mathrm{ml}^{-1} . \mathrm{mmHg}^{-1}$ in the sodium-sensitive group and $0.055 \pm 0.016$ in the sodium-resistant group $(p=0.9)$. Venous compliance was $0.062 \pm 0.012 \mathrm{ml} .100 \mathrm{ml}^{-1} \mathrm{mmHg}^{-1}$ in the normotensive control subjects. Despite some reduction, venous compliance in the sodium-sensitive $(p=0.14)$ and the sodium-resistant hypertensive group $(p=0.24)$ was not significantly different from normal.

\section{Discussion}

In order to avoid bias caused by the consequences of longstanding established hypertension or advanced age on the vascular wall, this study was performed in relatively young persons with only mildly elevated blood pressures ". Furthermore, only males were studied to exclude possible variations in vascular properties due to the menstrual cycle.

The borderline hypertensive subjects were divided in a sodium-sensitive group and a sodium-resistant group. There is much controversy about the concept of sodiumsensitivity. This is probably due to the lack of uniform definition and methodology. In this study, low and high salt diets of one week duration, were used to assess sodium-sensitivity and the discriminating criterion was arbitrarily chosen to be 8 mmHg difference in mean arterial pressure between the two regimens. The investigators were not aware of the order of the low salt and high salt diets in a particular subject. Furthermore, in 10 subjects our method proved to be highly reproducible (see chapter 3).

Although there was no difference between the two borderline hypertensive groups in the estimated duration of hypertension or in the level of the blood pressure at the first visit, when all subjects used their regular diet, the results of this study indicate that the distensibility and compliance of 3 large arteries, namely the carotid, femoral and brachial artery were significantly reduced in sodium-sensitive borderline hypertensive patients as compared to sodium-resistant ones. However, this result was obtained during a sodium intake of approximately $120 \mathrm{mmol}$ sodium per day and does not necessarily reflect a vascular reaction on sodium loading.

We found that the arterial diameters in the sodium-sensitive and the sodium-resistant group were similar. On the other hand, distension was significantly reduced in the sodium-sensitive group. Although the stroke index was somewhat, but not significantly smaller in the sodium-sensitive group, the pulse pressure, which accounts for the distension, was comparable in the 2 hypertensive groups. Therefore, the difference in distensibility and compliance between the sodium-sensitive and the sodium- 
resistant borderline hypertensive subjects may be related to differences in viscoelastic properties of the arterial wall

Comparing the sodium-sensitive group with the normotensive controls, it appeared that the arterial diameter tended to be larger in the sodum-sensitive group, reaching statistical significance for the carotid- and brachial artery. Although distending pressure was higher in the sodium-sensitive group, the distension was significantly smaller as compared to the normotensive controls. This may point to increased arterial vascular stiffness in the sodium-sensitive group. Indeed, both arterial distensibility and arterial compliance were significantly reduced in the sodiumsensitive group as compared to the nomotensive control group.

The sodium-resistant group also tended to increased vascular diameters as compared to the normotensive control group, although this was statistically significant for the brachial artery only. Likewise, distension tended to be diminished in the sodiumresistant group, but this did not differ significantly from normal, despite an increased distending pressure. This suggests that there is also some impairment of the vascular elastic properties in the sodium-resistant borderline hypertensive group, but apparently, this group deviates less from normal than the sodium-sensitive group. Arterial distensibility in the sodium-resistant group seems to be intermediate between control and sodium-sensitive, but the difference from normal reached statistical significance only in the carotid artery. Similarly, arterial compliance did not differ significantly from control in the sodium-resistant group. It would seem that in the sodium-resistant subjects, the increased diameter compensates for the slight decrease in distensibility, thereby maintaining approximately normal large artery compliance.

Any comparison of arterial compliance between hypertensive subjects and normotensive controls is hampered by the fact that one cannot discriminate between a reduction in elasticity due to the increased pressure per se and to other factors that may play a role in the hypertensive process, but that could exert an adverse effect on vascular elastic properties independently from blood pressure. Thus, in theory the observed reduction in distensibility and compliance could be accounted for by the elevated blood pressure. However, in this study, despite the fact that the two hypertensive groups had comparable mean arterial pressure, pulse pressure and vascular diameters, the vessel wall properties in the sodium-Sensitive group were significantly different from those in the sodium-resistant group. Therefore, there must be other factors that explain the decreased distensibility and compliance, at least in the sodium-sensitive group.

Most studies have demonstrated reduced venous distensibility in borderline and established hypertension ${ }^{12}{ }^{18}$, although some, using small numbers of subjects, have been inconclusive " The venous compliance of the borderline hypertensive subjects in this study was reduced compared with the normotensive controls, but the difference did not reach statistical significance. Furthermore, both hypertensive 
groups showed an approximately equal reduction in venous compliance relative to the nomotensive control group. Sullivan and co-workers demonstrated, under similar conditions, a smaller forearm venous capacitance in sodium sensitivesubjects than in sodium-resistant ones ${ }^{6}$. However, a reduced venous capacitance does not necessarily imply a reduced venous compliance, since capacitance is determined by both venous compliance and unstressed volume. For instance, venoconstriction induced by norepinephrine can lead to a reduction in unstressed volume and thus to a reduction in capacitance, without altering the compliance ${ }^{22}$.

In sodium-sensitive subjects increased activity or impaired suppression of the sympathetic ${ }^{20}$ or the renin-angiotensin-aldosterone ${ }^{14}$ system may explain the increased arterial stiffness, not only through the mechanism of vasoconstriction but also through a trophic effect on the vascular wall 2122.3. Moreover, a decreased concentration of atrial natriuretic peptide in sodium-sensitive subjects ${ }^{24}$ could contribute to the impaired arterial compliance, since ANP has a direct dilatory effect on arteries 25 . However, the importance of these mechanisms cannot be derived from the present study, since no plasma catecholamines were measured, while the sodium-sensitive and resistant groups did not differ in plasma renin activity, aldosterone concentration or plasma atrial natriuretic peptide level.

In conclusion, in this study we demonstrated that arterial compliance and distensibility are reduced in sodium-sensitive borderline hypertensive subjects as compared to sodium-resistant borderline hypertensive ones under conditions of regular sodiumintake and that the sodium-sensitive borderline hypertensive subjects exhibit arterial elastic properties that are more deviant from normal than sodium-resistant subjects. In the venous system a small but non-significant reduction in compliance was found in the borderline hypertensive groups as compared to the normotensive controls, while the two borderline hypertensive groups exhibited similar compliance. The mechanisms underlying these findings, however, remain to be determined.

\section{References}

1. Freis ED. Salt, volume and the prevention of hyperhension. Circulation 1976; 53 No.4:589-595.

2. Watt GCM, Foy CIW. Dietary sodium and arterial pressure: problems of studies within a single population. J Epidemiol Community Health 1982;36:197-201.

3. Sullivan IM, Ratis TE. Sodium sensitivity in human subjects. Hemodynamic and hormonal correlates. Hypertension 1988;11:717-723.

4. Weinberger MH. Milier JZ, Luft FC, Grim CE, Fineberg NS. Definitions and characteristics of sodium sensitivity and blood pressure resistance. Hypertension 1986,8(suppl II): III27-III34. 
5. Sharma AM, Schatufroh $S$, Kubben A, Dister A. Reliability of salt sensitivity testing in normotiensive subjects. Klin Wochensch 1989,67:632-634.

6. Sullivan JM, Prewitt RL, Ratts TE, Josephs JA, Connor MU. Hemodynamic characteristics of sodium sensitixe human subjects. Hypertension 1987,9:398-406.

7. Takeshita A. Mark AL. Decreased vasodilator capacily of forearm resistance vessels in borderline hypertensilon. Hypertension $1980,2,610-616$

8. London GM, Marchais SI, Safar ME. Arterial complance in hypertension. I Human Hypert 1989:3.53-56.

9. Bouthier JD, De Luca $M$, Safar ME Simon A. Cardiac hypertrophy and arterial distensibility in essential hypertension. An Heart ] 1985;109:1345-1352.

10. Orourke MF. Basic concepts for the understanding of large arteries in hypertension. I Cardiov Phamacol 1985;7.S14-\$21.

11. Rowe JW. Clinical consequences of agerelated impaiments in vascular compliance. Am $\mathrm{J}$ Cardiol $1987 ; 60: 680-71 \mathrm{G}$

12. Takeshita A, Mark AL. Decreased venous distensibility in borderline hypertension. Hypertension $1979: 1: 202-206$

13. O'Rourke M. Arteriat stiffness, systolic blood pressure and logical treatment of arterial hypertension. Hypertension 1990; $115: 339-347$

14. Oshima T, Matsura $\mathrm{H}$, Kido $\mathrm{K}$ et al. Factors determining sodium chloride sensitivity of patients with essential thypertension: Evaluation by multiwariate analysis. J Hypert 1989;7:223-227.

15. Rabinowe SL, Redgrave JE, Shoback DM. Podolsky S, Hollenberg NK, Williams GH. Renin suppression is blunted in ron-modulating essential hypertension. Hypertension $1987 ; 8: 217-222$.

16. Keyes J, Carey J, Mosses D, Beierwaltes W. Manual of nuclear medicine procedures. 2nd Edition CRS Press Cleveland 1973:95-98.

17. Dagher FI, Lyons JH, Finlayson DC, Shamsai J, Moore FD. Blood Volume Measurements: A critical shludy. Prediction of nomal values: Controlled measurements of sequential changes: Choice of a bedside method. Advanc Surg 1965;1:69-109.

18. Simon $G_{*}$ Franciosia JA. Cohn JN. Decreased verous distensibility in essential hypertension. Angiology $1979 ; 30: 147-159$

19. Brown WJ, Brown FK, Krishnan I. Stabilized venous distensibility of normotensive and hypertensive humans on thigh and low sodium intake. Angiology $1976.27: 433-442$.

20. Koolen MI. Van Brummelen P. Adrenergic activity and peripheral hemodynamics in relation to sodium sensitivity in patients with essemtial hypertension. Hypertension 1984;6:820-825.

21. Plunkett WC, Owerbeck HW. Increased arteriolar wall-to-lumen ratio in a normotensive vascular bed in coaratation hypertension. Am J Physiol 1985;249:H859-H866.

22. Sachinidis A. Ko Y. Nettekoven W, Wieczorek J, Dusing R, Vetter H. The effect of angiotensin II on DNA-synthesis varies considerably in vascular smooth muscle cells from different Wistar Kyoto rats. J Hypertens $1992 ; 10: 1159-1164$. 
23. Wang DH, Prewit RL. Captopril raduces aoric and microwasular growith hypertewsie and mormotensive rats. Hypertension 1990;15:68-77.

24. Dahl LK, Knudsen KD, Iwai J. Humoral transmission of hypertension. Evidence from parabiosis. Cire Res 1969:(Suppl1), 14 and 15:1/21-1127.

25. Doorenbos Cl. Blaww GJ. Van Brummelen P. Anterial and venous effects of atriai natriuretic peptido in the human forearm. Am J Hypertens 1991;4:333-340. 



\section{CHAPTER 5}

NAILFOLD CAPILLARY DENSITY IN SALT-SENSITIVE AND SALT-RESISTANT BORDERLINE HYPERTENSION

P Draaijer, PW de Leeuw, JP van Hooff, KML Leunissen.

Department of medicine of the university hospital of Maastricht, The Netherlands.

(Journal of Hypertension 1993;11:1195-1198) 


\section{Abstract}

In order to investigate the relationship between sodium-sensitive hypertension and microvessel density, nailfold capillary density was studied, at rest as well as after 4 minutes of circulatory arrest, using intravital video-microscopy in 17 sodiumsensitive and 28 sodium-resistant young borderline hypertensive males and in 10 normotensive controls. All subjects consumed a diet containing $120 \mathrm{mmol} /$ day. Blood pressure, cardiac index, plasma volume and humoral factors such as plasma renin activity, plasma aldosteron and atrial natriuretic peptide were determined as well.

No differences in capillary density were found under basal conditions. During hyperaemia, however, sodium-resistant subjects recruited silgnificantly less capillaries than the sodium-sensitive ones and the controls, while apart from the blood pressure, macrocirculatory parameters and humoral factors did not differ between these three groups.

We conclude that sodium-resistant borderline hypertensives seem to be characterized by a (possibly structural) reduction in nailfold capillarity, a phenomenon that yet needs to be explained.

\section{Introduction}

Although subject of many investigations, the mechanisms underlying sodiumsensitivity are not completely understood. Differences in renal sodium handling and in humoral factors ${ }^{2}$ between sodium-sensitive and sodium-resistant subjects may play a role. However, a disturbance in the regulation of vascular resistance in sodium-sensitive subjects ${ }^{3}$ could also be involved. Since a considerable part of total vascular resistance is determined at microvascular level (vessels with a diameter of $100 \mu \mathrm{m}$ or less) ${ }^{4}$, there may be differences in microvascular function or architecture between sodium-sensitive and sodium-resistant subjects. Apart from a study by Sullivan and co-workers on conjunctival microvessels in essential hypertensive subjects ${ }^{3}$, little is known about the microcirculation in relation to sodiumsensitivity. Therefore, we decided to evaluate whether there are differences between sodium-resistant and sodium-sensitive subjects, in capillary density of the nailfold skin, either at rest or after a vasodilation achieved by 4 minutes of circulatory arrest. Since microcirculatory characteristics of pressure and flow directly depend on macrocirculatory dynamics, cardiac output, plasma volume and humoral factors such as plasma renin activity, aldosterone and atrial natriuretic peptide, were also assessed. 


\section{Subject and methods}

Seventeen sodium-sensitive and 28 sodium-resistant untreated borderline hypertensive subjects as well as 10 age-matched healthy normotensive controls were studied. All subjects were 20 to 45 years of age and non-smoker. Details on the subjects are described in chapter 2.

During the week preceding this investigation of nailfold capillary density, all subjects used a diet containing $120 \mathrm{mmol}$ sodium and $70 \mathrm{mmol}$ potassium per day.

Nailfold capillary density was studied using an incident light intravital videomicroscope as was detailed in chapter 2. Investigations took place in a temperature controlled room of approximately $24^{\circ} \mathrm{C}$ and was started only after an acclimatisation period of at least one hour. The subjects were in sitting position with the investigated hand at heart level. The $4 \mathrm{th}$ finger of the left hand was studied. The number of capillaries in 3 microscopic fields $\left(0.54 \mathrm{~mm}^{2}\right)$ was studied before and after an arterial occlusion test, performed by applying a suprasystolic pressure of 4 minutes duration to the finger by inflating a finger cuff. A period of 4 minutes arterial occlusion was chosen to obtain vasodilation not only through the mechanism of myogenic vasodilation, but also through an additional metabolic vasodilatory simulus. Hence, to obtain a situation in which local factors prevail the regulation of flow, thereby recruiting the capillaries that were closed for flow during basal conditions ${ }^{5}$. Capillary density was defined as the number of capillaries per microscopic field $\left(0.54 \mathrm{~mm}^{2}\right)$. The mean number of capillaries per field before and after arterial occlusion was subsequently calculated.

Cardiac stroke output was determined using echo-Doppler cardiography (Hewlett Packard, Sonos 100) "6 plasma volume was measured using the radio-iodinated serum albumin method (I-125 albumin) ${ }^{7}$ and plasma renin activity, plasma aldoste rone and atrial natriuretic peptide were determined by radioimmunoassay 840.

\section{Data analysis}

Data are presented as mean \pm standard deviation. The Kolmogorov-Sminow goodness of fit test was used to verify whether variables were normally distributed. In case of normally distributed data, differences between the three investigated groups were analysed by means of multivariate analysis of variance (MANOVA). Otherwise, a non-parametric test for 3 independent samples was used (Mann-Whitney). The level of significance was $p<0.05$. 


\section{Results}

Table 1 shows the used abbreviations.

Table 1

\begin{tabular}{ll}
\hline USED ABBREVIATIONS & \\
\hline $\mathrm{NT}$ & Normotensive controls \\
SS & Sodium-sensitive borderline hypertensive patients \\
SR & Sodium-resistant borderline hypertensive patients \\
$\mathrm{BSA}$ & Body surface area \\
$\mathrm{HR}$ & Heart rate \\
$\mathrm{CI}$ & Cardiac index \\
$\mathbb{P V}$ & Plasmat volume \\
$U_{\mathrm{Na}}$ & Urinary sodium excretion in 24 hours \\
$U_{\mathrm{K}}$ & Urinary potassium excretion in 24 hours \\
$\mathbb{P R A}$ & Plasma renin activity \\
Ald & Aldosterone \\
ANP & Atrial natriuretic peptide \\
\hline
\end{tabular}

Table 2

CHARACTERISTICS OF THE GROUPS. $P^{1}$ : P-WALUE OF THE ANALYSIS OF NT VERSUS SS, $\mathrm{P}^{2}:$ SS VERSUS SR, $\mathrm{P}^{3}:$ NT VERSUS SR. (MEAN \pm SD)

\begin{tabular}{|c|c|c|c|c|c|c|}
\hline & $N T$ & $p^{\prime}$ & SS & $P^{y}$ & $S R$ & $p^{b}$ \\
\hline $\mathrm{N}$ & 10 & & 17 & & 28 & \\
\hline AGE (yrs) & $37 \pm 6$ & .06 & $41 \pm 6$ & .41 & $40 \pm 6$ & .19 \\
\hline$B S A\left(m^{2}\right)$ & $1.9 \pm 0.1$ & .11 & $2 \pm 0.2$ & .74 & $2 \pm 0.2$ & .09 \\
\hline Syst (mmHg) & $127 \pm 10$ & .005 & $155 \pm 13$ & 43 & $153 \pm 16$ & .005 \\
\hline Dias $(\mathrm{mmHg})$ & $76 \pm 7$ & .005 & $87 \pm 6$ & .42 & $85 \pm 8$ & .005 \\
\hline HR (bpm) & $59 \pm 8$ & .08 & $67 \pm 13$ & .20 & $63 \pm 10$ & .28 \\
\hline $\mathrm{Cl}\left(1 . \min ^{-4} \cdot \mathrm{m}^{-2}\right)$ & $2.3 \pm 0.8$ & .82 & $2.3 \pm 0.9$ & .19 & $2.6 \pm 0.8$ & .40 \\
\hline $\mathrm{PV}\left(\mathrm{ml}, \mathrm{kg} \mathrm{g}^{\mathrm{l}}\right)$ & $43 \pm 2$ & .001 & $35 \pm 4$ & .31 & $37 \pm 5$ & $.00 \|$ \\
\hline $\mathrm{U}_{\mathrm{Na}}$ (nnmol.24hr & $104 \pm 21$ & .08 & $129 \pm 28$ & .30 & $112 \pm 44$ & .42 \\
\hline$U_{K}\left(\right.$ mmol $\left.^{2}, 4 \mathrm{har}^{-1}\right)$ & $68 \pm 25$ & .56 & $73 \pm 13$ & .74 & $70 \pm 32$ & .90 \\
\hline PRA (ng $\left.\mathrm{ml}^{-1} \mathrm{hr}^{-1}\right)$ & $1.43 \pm 0.9$ & .26 & $1.07 \pm 0.7$ & .39 & $1.46 \pm 1.7$ & .96 \\
\hline Ald $\left(\mathrm{mg} .\left.\mathrm{mm}\right|^{-1}\right)$ & $0.41 \pm 0.2$ & .39 & $0.5 \pm 0.29$ & .17 & $0.41 \pm 0.2$ & .99 \\
\hline $\mathrm{ANP}\left(\mathrm{pg} \mathrm{ml}^{\prime}\right)$ & $30.1 \pm 11$ & .08 & $40.2 \pm 14$ & .93 & $40.7 \pm 23$ & .22 \\
\hline
\end{tabular}


Table 2 shows characteristics of the two borderline hypertensive and the normotensive (NT) groups during the study. The estimated duration of bypertension was approximately 7 years in the two hypertensive groups. There were no significant differences in haemodynamics, electrolyte excretion or humoral factors between the three groups.

The mean number of capillaries per microscopic field before and after 4 minutes of arterial occlusion is depicted in figure 1. During the investigations skin temperature did not differ between the three groups (SS: $29.6 \pm 1.5$, SR: $29.7 \pm 1.7$, NT: $30.2 \pm 1.4$ $\left.{ }^{\circ} \mathrm{C}\right)$.

At rest, there were no significant differences in capillary density between the groups (SS: $22 \pm 5$, SR: $20 \pm 5$, and NT: $22 \pm 5$ capillaries per field (cpf).

During hyperaemia, there was a significant increase in the mean number of capillaries per field in all three groups (SS: $26 \pm 7$, SR: $22 \pm 6$ and NT: $25 \pm 5$ cpf. As indicated in figure 1 , in the hyperaemic phase, there tended to be more perfused capillaries in the sodium-sensitive group than in the sodium-resistant group ( $\mathrm{p}=0.07$ ). Sodium-sensitive borderline hypertensive patients recruited approximately as many capillaries as the normotensive controls upon the vasodilatory stimulus of 4 minutes of ischaemia (SS: $3.5 \pm 2.8 \mathrm{cpf}$ or $16 \%$, NT: $3.3 \pm 1.1 \mathrm{cpf}$ or $15 \%$ ). However, the recruitment of capillaries in response to the same stimulus was significantly smaller in the sodium-resistant group than in the sodium-sensitive or control group (SR: $1.7 \pm 1.8 \mathrm{cpf}$ or $8 \%$, fig. 2 ).

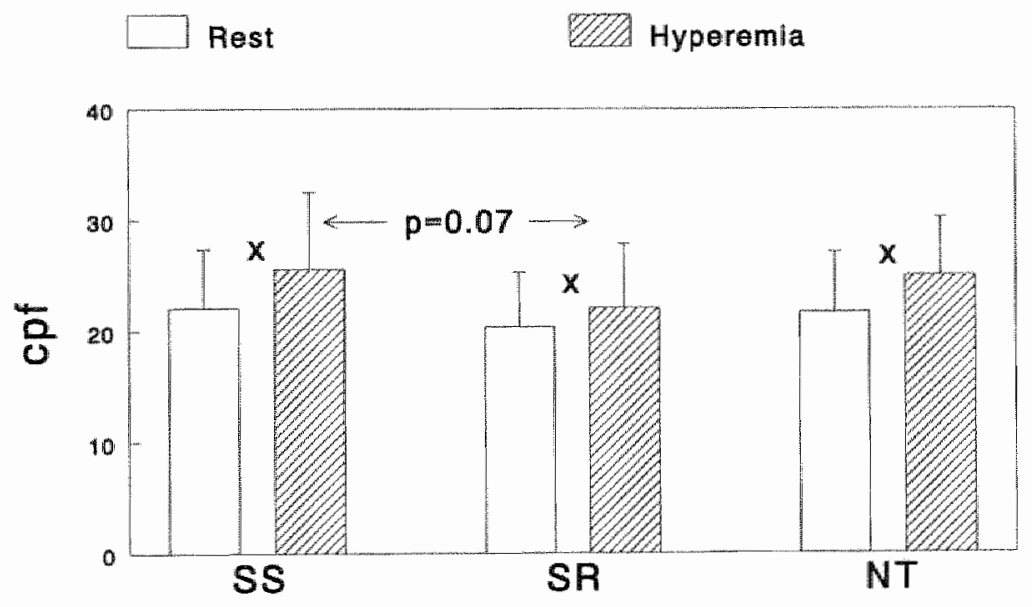

Figure 1. Nailfold capillary density. Nailfold capillary denshty before (rest) and after 4 milnutes of arterial acclusion (hyperaemia) in the three investigated gromps. Cpf $=$ capillaries per field, $x: p<0.05$. 


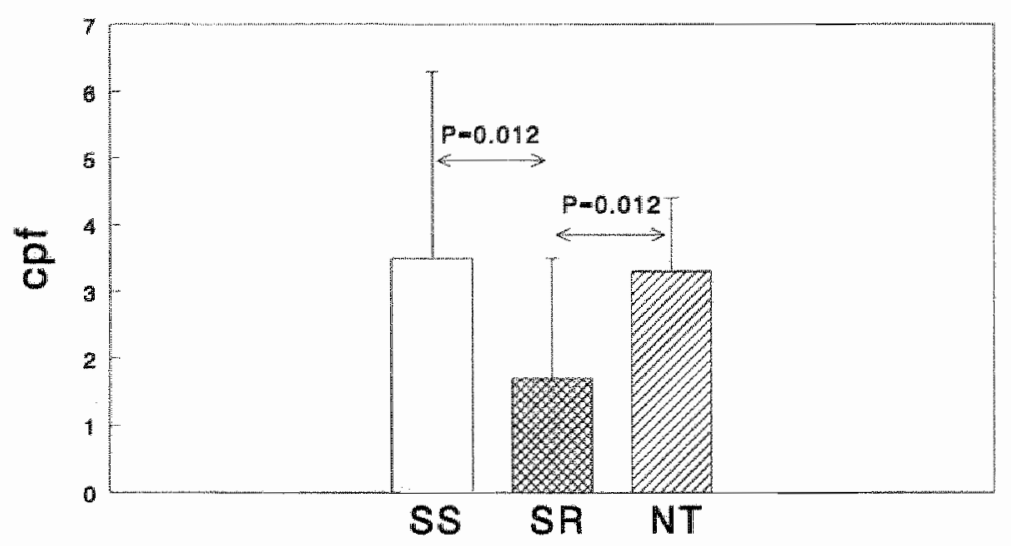

Figure 2. Capillary Recruitment. Nallfold capillary recruitment upon 4 minutes of arterial occlusion in the three investigated groups. Cpf: capillaries per field.

\section{Discussion}

A decrease in microvessel density, also called rarefaction, has been repeatedly demonstrated in the spontaneously hypertensive rat ${ }^{11} 12{ }^{13}$. Also in human hypertensives a reduced number of capillaries has been found, for instance in biopsies of the pectoralis and quadriceps muscles ${ }^{14}$. Both degree and duration of the blood pressure elevation may influence microvessel density. In order to avoid bias caused by the consequences of longstanding established hypertension or advanced age on the microcirculation ${ }^{15}$, the present study was performed in relatively young persons with only mildly elevated blood pressures. Furthermore, only males were used to exclude possible variations in microvascular properties due to the menstrual cycle. In humans, microcirculatory measurements can only be obtained in a non-invasive way, which restricts the evaluation to superficial tissues. Thus, we chose to investigate the nailfold skin, although we acknowledge the fact that this may not be a vascular bed that is of major importance in the regulation of total peripheral vascular resistance.

Under basal conditions, there were no significant differences in nailfold capillary density between the three groups under study, despite a significant difference in blood pressure between the normotensive group on one hand and the two borderline hypertensive groups on the other hand. Recently, Duprez and co-workers, also 
reported normal capillary density in the nailfold of mildly hyperiensive subjects, using comparable techniques "In contrast, Sullivan at al. reported a reduction in conjunctival capillary density in high output borderline hypertensive subjects " Moreover, they found a reduced conjunctival capillary density in sodium-sensitive subjects as compared to sodium-resistant ones " This reduction in capillary density was significantly correlated to cardiac output, but not to arterial pressure. Yet, one has to keep in mind that in the present study, comparable numbers of capillaries in the sodium-sensitive and resistant groups were found during a sodium intake of 120 mmolday. It may well be that at higher levels of sodium intake, a decrease in capillarity would have been found, similar as to what has been described for conjunctival capillary density $" 8$.

Four minutes of arterial occlusion results in a situation in which local myogenic and metabolic mechanisms account for the regulation of flow and the restoration of oxygen deficit ${ }^{5}$, by means of maximal vasodilation. Pre-capillary arterioles are then assumed to be maximally dilated, with subsequent recruitment of all capillaries that arise from these arterioles ${ }^{15}$. The lesser capillary density duning hyperaemia, that was found in sodium-resistant subjects as compared to sensitive ones, may therefore implicate a structural reduction in the number of capillaries in the former group.

Alternatively, if $4^{\prime \prime}$ of ischaemia would not be enough to obtain total arteriolar dilation, the observed differences in capillary density during hyperaemia may also be reflections of functional differences at the level of the precapillary arterioles. A vasospastic tendency in finger microcirculation has indeed been demonstrated in essential hypertension ${ }^{19}$.

The mechanisms that are responsible for our findings remain elusive. It is unlikely that macrocirculatory parameters such as blood pressure, cardiac output or plasma volume could account for the difference between the two hypertensive groups as these variables were similar in these groups. Likewise, we failed to find support for a role of the renin-angiotensin-aldosteron system or plasma atrial natriuretic peptide.

In conclusion, in sodium-resistant borderline hypertensive subjects, there seems to be a reduction in the number of nailfold capillaries as compared to sodium-sensitive borderline hypertensives. Since this reduction in capillarity appeared only after a stimulus of which we assume that it induces total vasodilation, structural microvascular differences may be present between sodium-sensitive and sodium-resistant subjects. However, the underlying mechanisms as well as the pathophysiologic implications of this finding remain to be established. 


\section{References}

1. Kaw pressure and other related variables in humat subjects with ideopathic hypartension. Am J Med 1978:64:193198

2. Fijlta $T$, Batter FC, Lake CR, Delea CS. Factors influencing blood pressure in salt sensitive patients with hypertension. Am J Med 1980,69:334-344.

3. Sullivan JM, Prewitt RL, Ratts TE, Josephs JA, Connor MJ. Hemodyramic characteristics of sodium sensive tham subjects. Hypertention $1987,9,398-406$.

4. Draijijer P, Le Noble JLML, Leuniseen KML, Strayker Boudier HAJ. The microcirculation and essential hypertension. Neth J Med 1991;39:158.169

5. Johnson $\mathrm{PC}$, Burton $\mathrm{KS}$, Henrich $\mathrm{H}$, Herrich U. Effect of occlusion duration on reactive hyperemia in sartonius nuscle capillaries. Am J Physiol 1976; vol230 mo3:715-719.

6. Schuster AH, Nanda NC. Doppler echocardiographic measurements of cardiac output: Comparison with a mon-golden standard. Am J Cardiol 1984:53:257-259.

7. Keyes $I_{\text {, Carey }} J_{*}$ Mosses $D_{*}$ Beierwaltes $W$. Manual of nuclear medicine procedures. 2 nd Edition, CRS Press, Cleveland 1973:95-98.

8. Haber E, Koerner T, Page LB, Kliman B, Purnode A. Application of a radioimmunoassay for angiotensin I to the physiologic measurements of plasma renin activity in nomal human subjects. $J$ Clin Endocr $1969 ; 29: 1349,1355$.

9. Kubasilk MP, Warten K, Sine HE. Evaluation of a new commercial radioassiay kit for aldosterone using iodinated tracer. Clin Biochem 1979,12(2)"59.61.

10. Rosmalen FMA. Tan A. Tan HS, Benraad TJ. A sensitive radioimmunoassay of atrial natriuretic peptide in thuman plastian using a tracer whin an mmobilized glyconil agent. Clin Chem Acta 1987; $65: 331-340$.

11. Huthine PM, Darnel AE. Obserwation of a decreased number of small arterioles in spontaneousty hypertensive rats. Circ Res 1974:34(supil)161-165.

12. Prewitt RL, Chen IIH, Dowell RE. Development of microvascular rarefaction in the spontaneously hypertensive ratt. Am J Physiol 1982:243:H243-H253.

13. Le Noble JLML, Tangelder GI, Slataf DW, van Esser H, Reneman RS, Struyker-Boudier HAJ. A functional morphometric study of the cremaster muscle microcitculation in young spontaneously thypertensive rats. 5 Hypertens $1990 ; 8.741-748$.

14. Henrich HA, Romen W. Heimgarer W, Harting E, Bamer F. Capillary rarefaction characteristics of ethe skeletal musele of hypertersive palients. Klin Wochenschar 1988:66:54-60.

15. Bollinger $A_{n}$ Fagrell B. Clinical capillaroscopy. A guide to its use in clinical research and practice. Chapter $4:$ techniques and nomal fundings. Hogrefe and Huber Publishers 1990.

16. Duprez D, de Buyzere M, de Backer T, Vercammen J, Arusselmans F, Clement DL. Impaired microcircuIation in mild. to-moderate essential hypertension. I Hypertens 1992;10.251-254. 
17. Sullivan JM, Prewitt RL. Josephs JA. Attenuation of the microcirculation in young patients with highoutput borderline hypertension. Hypertension 1983;5:844-851.

18. Ghione $S$, Bertuglia $S$, Colantuoni A, Genovesi Ebert F, Fonmei E, Rosa C. Mezzasalma L, Gazzeni P. Genovesi Ebert A, Marabotti C. Meconi P, Palombo C. Hemodynamic and microviscular changes after shoriterm increase in sodium intake in young normal volunteers. 3 Hypertens 1986:4(suppl5):S195-S 197.

19. Gasser P, Buhler FR. Nailfold microcirculation in normotensive and essential hypertensive sybjects, as assessed by video-microscopy. IHypertens 1992;10:83-86. 



\section{CHAPTER 6}

\section{VASCULAR COMPLIANCE IN SALT-SENSITIVE AND SALT-RESISTANT BORDERLINE HYPERTENSIVE PATIENTS}

Effect of treatment with enalapril or felodipine

P Draaijer, MJF Kool", LMAB van Bortel", F Nieman, PW de Leeuw, JP van Hooff, KML Leunissen.

Departments of medicine and clinical pharmacology* of the university hospital of Maastricht, The Netherlands.

(submitted for publication) 


\section{Abstract}

Recently, we demonstrated a reduction in the compliance of the carotid, femoral and brachial artery in sodium-sensitive subjects consuming a regular sodium intake of approximately 120 mmols per day, as compared to both sodium-resistant borderline hypertensive subjects and normotensive controls. Venous compliance was not different in the two borderline hypertensive groups and was only slightly lower than in controls. Large artery compliance was studied using a non-invasive ultrasound vessel wall movement detector system, while venous compliance was determined by means of strain gauge plethysmography.

The borderline hypertensive subjects were subsequently treated with enalapril 10 mg/day, felodipine $5 \mathrm{mg} /$ day or placebo during six months. Despite similar reductions in blood pressure, enalapril induced a significant increase of the muscular femoral and brachial artery compliance, but not of the elastic carotid artery, while felodipine did not influence large artery compliance at all in the sodium-sensitive group. The effect of enalapril on muscular artery compliance was established through a dose-dependent increase in distension and not through a change in arterial diameter. Arterial compliance was not influenced by either of the drugs in the resistant group. Venous compliance was also not altered by the medication.

In conclusion, femoral and brachial artery compliance in sodium-sensitive borderline hypertensive subjects, that was found to be lower than that of sodium-resistant subjects, improved by antihypertensive treatment with enalapril, but not with felodipine, despite the similar reductions in blood pressure induced by both drugs. This finding may imply that firstly, reduced arterial compliance is caused by more than just blood pressure elevation, and secondly, the renin-angiotensin system may play a role in the reduced arterial compliance of sodium-sensitive subjects.

\section{Introduction}

Recently, it was found that under conditions of a regular sodium intake of approximately 120 mmol sodium per day', sodium-sensitive borderline bypertensive subjects display a reduced compliance of the carotid, femoral and brachial arteries as compared to sodiumresistant ones and normotensive controls. Furthermore, despite the slight increase in blood pressure, arterial compliance in resistant subjects did not differ appreciably from normal. The diminished compliance in the sensitive group was the consequence of reduced arterial wall distension upon the pulse wave since arterial diameter, blood pressure and pulse pressure were similar in the sensitive and resistant group.

The mechanisms underlying the difference in large artery compliance remain elusive. It could be argued that differences in the activity of the renin-angiotensin system between sodium-sensitive and sodium-resistant subjects play a role as sodium-sensitivity has been linked to inadequate suppression of the renin system after a sodium load ${ }^{2}$. In this respect, 
sodium-sensitive hypertensive subjects are thought to exhibit an inappropriately high intrarenal production of angiotensin II, while sodium-resistant subjects do not " Thus, it may be hypothesized that by virtue of its vasoconstrictor and/or growth promoting effects ${ }^{4}$, angiotensin II could be responsible for decreased arterial compliance in sodium-sensitive subjects.

On the other hand, a disturbance in intracellular calcium metabolism may induce stiffer arteries in sodium-sensitive subjects. Indeed, in vascular smooth muscle cells a raised level of free calcium may increase muscular tone, thereby contributing not only to the pressor action of sodium, but also to increased vascular stiffness. In this respect, it is relevant to note that in essential hypertensive patients the pressure response to high sodium intake correlates positively with the increase in lymphocytic intracellular free calcium concentration ${ }^{5}$.

Part of the above mentioned pathophysiologic considerations may also apply to venous compliance. Takeshita and co-workers described a reduced venous compliance in sodiumsensitive hypertensive subjects as compared to sodium-resistant ones on a high sodium diet of 345 mmols per day "In our study population, venous compliance tended to be decreased in the sodium-sensitive and resistant borderline hypertensive subjects as compared to normotensive controls!

Based upon these considerations, treatment with either an ACE-inhibitor or a calcium entry blocker may improve vascular compliance. Therefore the aim of this study was to investigate the effect of 6 months treatment with either enalapril or felodipine on the compliance of carotid, femoral and brachial arteries in sodium-sensitive and resistant borderline hypertensive subjects. In addition, we measured venous compliance during enalapril and felodipine treatment to investigate whether these agents conferred any benefit on this variable.

Large artery compliance may be a major determinant of left ventricular hypertrophy in hypertension ${ }^{7}$. The reduced large artery compliance that was found in sodium-sensilive borderline hypertensives may well be related to increased left ventricular mass. Finally, we performed echo-Doppler cardiographic measurements, not only to study whether there are differences in left ventricular mass between the groups and how pharmacological intervention interferes, but also to study stroke volume, since arterial distension and thus compliance depends on stroke volume.

\section{Patients and methods}

\section{Patient characteristics}

Seventeen untreated sodium-sensitive and 28 sodium-resistant borderline hypertensive subjects were included in the study. All subjects were 20 to 45 year old males and non-smoker. Detailed information on the subjects and the sodium-sensitivity assessment is given in chapter 2 . 


\section{Protocol}

After the initial study, that revealed the above mentioned difference in arterial compliance between the groups, the subjects were randomly and in a double blind manner assigned to three treatment strategies, viz. enalapril $10 \mathrm{mg} /$ day, felodipine $5 \mathrm{mg} / \mathrm{day}$ or placebo. Before and again after three months of therapy, at the end of the treatment period at six months and three months after stopping treatment, the subjects were investigated. During the week preceding the day at which the investigations took place, they consumed a diet containing 120 mmol sodium and 70 mmol potassium per day, while 24-hour urines were collected in order to estimate adherence to the diet.

The subjects used a light breakfast and entered the hospital at 8.00 am, at the days of the investigations. At first, body weight was measured. All subsequent investigations were performed in supine position, in a temperature controlled room of approximately $24^{\circ} \mathrm{C}$. Blood pressure was measured after at least 15 minutes of rest. Systolic and diastolic pressure were measured every 5 minutes for half an hour and the average of these blood pressure values was determined. Mean arterial pressure was calculated as the sum of diastolic pressure and one third of the pulse pressure. Simultaneously, heart rate was determined. Subsequently, arterial and venous compliance were measured. Finally, echo-Doppler cardiographic measurements were performed.

\section{Arterial distensibility and compliance}

The carotid, femoral and brachial arteries were studied using a non-invasive ultrasound wall movement detector system. This system, developed by Hoeks et al. has been described in detail in chapter 2 .

\section{Venous compliance}

Venous compliance was measured, as previously described, by strain gauge plethysmography (Periflow, Janssen Scientific Instruments, Beerse, Belgium) with direct intravenous pressure measurements.

\section{Echo-Doppler cardiography}

The measurements were performed using a Hewlett Packard sonos 100 echoDoppler cardiograph, with the subjects in the partial left lateral decubitus position. Parasternal B-mode short and long axis images were obtained to provide reference points for subsequent $\mathrm{M}$-mode investigation (3,5 $\mathrm{MHz}$ transducer). Left ventricular 
internal diameter (LVID), interventricular septum (IVS) and left ventricular posterior wall thickness (LVPW) were measured distally to the tips of the mitral valve at the onset of the QRS complex on the ECG, during three consecutive cardiac cycles. Average values were determined. Left ventricular mass (LVM) was calculated according to the formula of Devereux. Left ventricular hypertrophy was considered to be present when the left ventricular mass index exceeded $125 \mathrm{~g} / \mathrm{m}^{2}$.

In order to obtain cardiac stroke volume, ascending aortic blood flow velocity was measured using a continuous wave Doppler system, while the aortic diameter was determined by means of B-mode echocardiography. Cardiac output was calculated by multiplying stroke volume with heart rate. Cardiac output, stroke volume and left ventricular mass were normalized for body surface area.

\section{Data analysis}

Data were at first checked for normality. Because no great skewness was found in the data, differences in characteristics of the investigated groups were tested by means of independent Student t-tests. Repeated measurement multivariate analysis of variance was used to analyse possible treatment effects.

Doubly multivariate analysis of variance was done to ascertain the elimination of blood pressure as confounding factor in the relation between type of treatment and arterial measurements ${ }^{9}$. Correlations between variables were evaluated by linear regression analysis. All data analysis was done using programmes of SPSS-pct; pvalues $\leq 0.05$ were regarded as statistically significant.

\section{Results}

Table 1 shows the used abbreviations.

\section{Table 1}

\begin{tabular}{ll}
\hline USED ABBREVIATIONS & \\
\hline SS & Sodium-sensitive borderline hypertensives \\
SR & Sodium-resistant borderline hypertensives \\
BSA & Body surface area \\
HR & Heart rate \\
MA.P & Mean arterial pressure \\
DC & Distensibility coefficient \\
CC & Compliance coefficient \\
\hline
\end{tabular}




\section{Characteristics of the investigated groups}

Table 2 shows characteristics of the sodium-sensitive borderline hypertensive (SS) and the sodium-resistant borderline hypertensive groups (SR) at the start of the study. There were no significant differences in age or body surface area between the groups. The estimated duration of hypertension was 7 years in both groups. Systolic and diastolic pressures, as well as mean arterial pressure were comparable in the groups. Likewise, heart rate did not differ between the groups.

Table 2

\begin{tabular}{llll}
\hline GENERAL CHARACTERUSTICS. (MEAN \pm SD) & & & \\
\hline & $S S$ & $P$ & $S R$ \\
N & 17 & & 28 \\
Age (yrs) & $41 \pm 6$ & .41 & $40 \pm 6$ \\
BSA (m) & $2 \pm 0.2$ & .74 & $2 \pm 0.2$ \\
Syst (mmHg) & $155 \pm 13$ & .43 & $153 \pm 16$ \\
Dias (mmHg) & $87 \pm 6$ & .42 & $85 \pm 8$ \\
MAP (mmHg) & $110 \pm 7$ & .48 & $108 \pm 10$ \\
HR (bpm) & $67 \pm 13$ & .20 & $63 \pm 10$ \\
& & & \\
\hline
\end{tabular}

Five sodium-sensitive borderline hypertensives were treated with enalapril (SS-E), 5 with felodipine (SS-F) and 7 with placebo (SS-P), while 11 sodium-resistant subjects had enalapril (SR-E), 10 felodipine (SR-F) and 7 placebo (SR-P) during the treatment period. The two excluded subjects were initially grouped as SR-P. The average decrease in mean arterial pressure after six months of treatment was SSE: $14(2 \leftrightarrow 28) \mathrm{mmHg}$, SS-F: $11(1 \leftrightarrow 25) \mathrm{mmHg}$, SS-P:3(-6↔16) mmHg in the sodiumsensitive group and SR-E:12(-5↔33) mmHg, SR-F:6(-7↔21) mmHg, SR-P:5($25 \leftrightarrow 24) \mathrm{mmHg}$ in the resistant group (NS).

\section{Arterial distensibility and compliance}

Treatment with enalapril, felodipine or placebo did not significantly influence arterial diameter and distension of the three investigated arteries of the sodium-resistant group. Pulse pressure was not significantly altered during the treatment period. As a consequence arterial compliance was not improved by the pharmaca in the resistant group (fig. $1^{\mathrm{a}, \mathrm{b}, \mathrm{c}}$ ). 


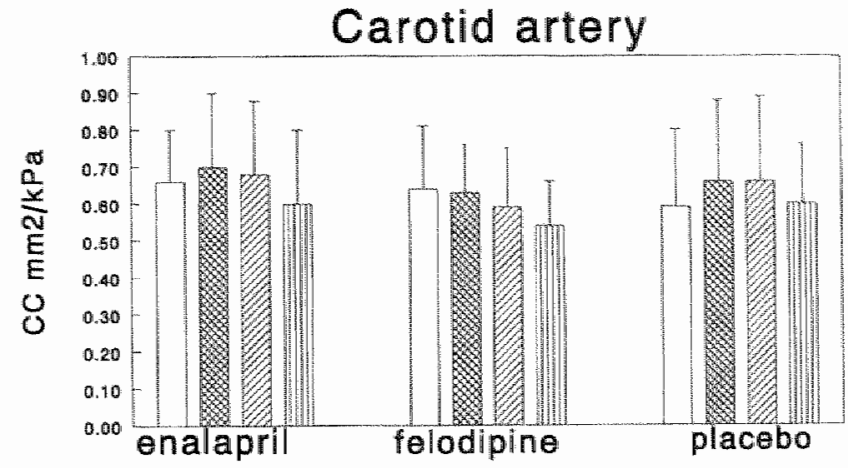

Femoral artery

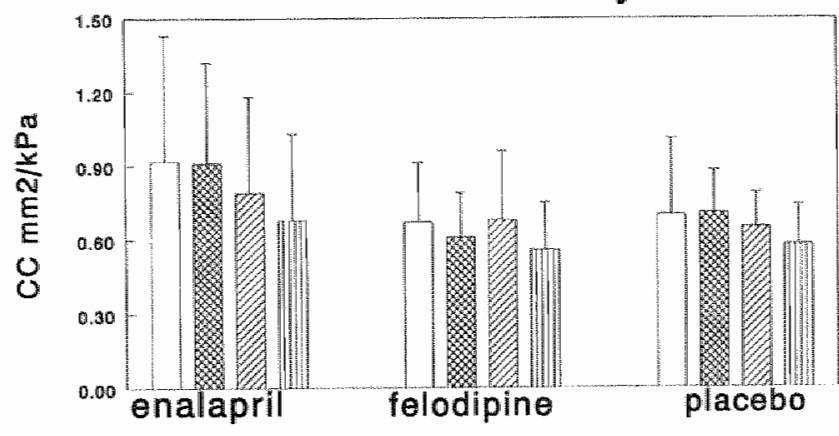

\section{Brachial artery}

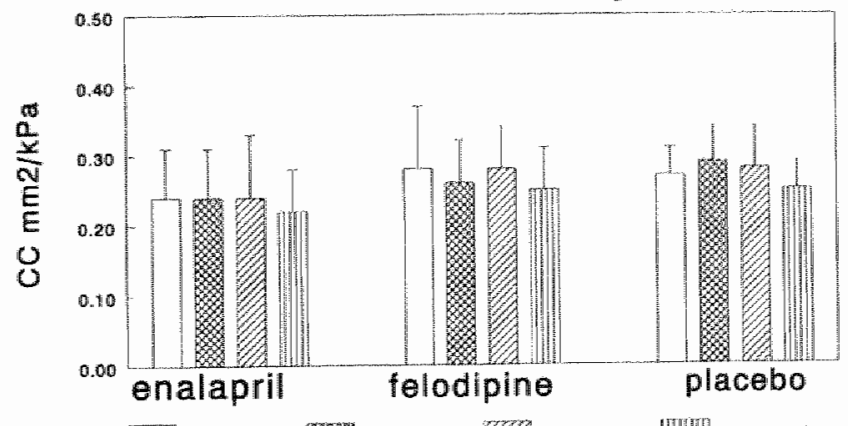

Effects of treatment in the sodium-resistant group :

Figure $1^{\text {\# }}$. Carotid Artery Compliance.

Figure $I^{\text {th }}$ Femoral Artery Compliance.

Figure 1c. Brachial Artery Compliance. 
Carotid artery compliance did not change significantly in the enalapril or felodipine treated sodium-sensitive subjects (fig. 2).

[D months 3 months 6 months $[1] I I I) 9$ months

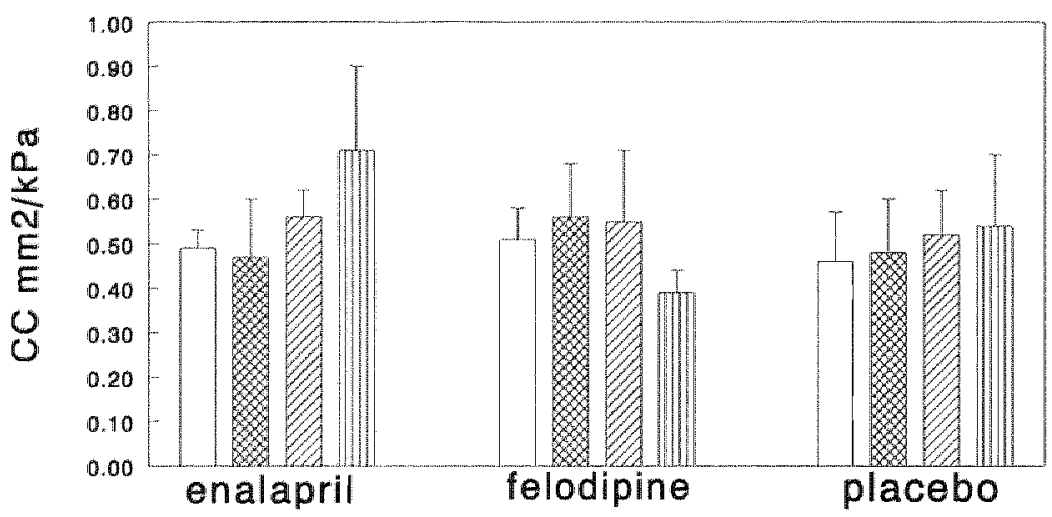

Figure 2. Carotid Artery Compliance. Effects of treatment in the sodium-sensitive group.

In contrast, femoral and brachial artery compliance improved significantly in the enalapril treated sodium-sensitive subjects, due to increased distension rather than increased diameter. The improvement of the elastic properties of the femoral and brachial artery reached a maximum after six months of treatment and fell towards baseline values in the wash-out period. Felodipine did not induce such an improvement (figures $3^{a, b, c, d}$ and $4^{a, b, c, d}$ ). Since pulse pressure was not significantly influenced by either enalapril or felodipine (mean decrease in pulse pressure after 6 months: SS-E:2 (range $-7 \leftrightarrow 10$ ) mmHg, SS-F:3 (range $-4 \leftrightarrow 15$ ) $\mathrm{mmHg}$, SS-P:3 (range $-6 \leftrightarrow 9$ ) $\mathrm{mmHg}$ ) and was not significantly different between the groups, a higher pulse pressure can not be held responsible for the increased distension of the femoral and brachial arteries upon enalapril. 
D 0 months 3 months W 6 months IIIIII 9 months

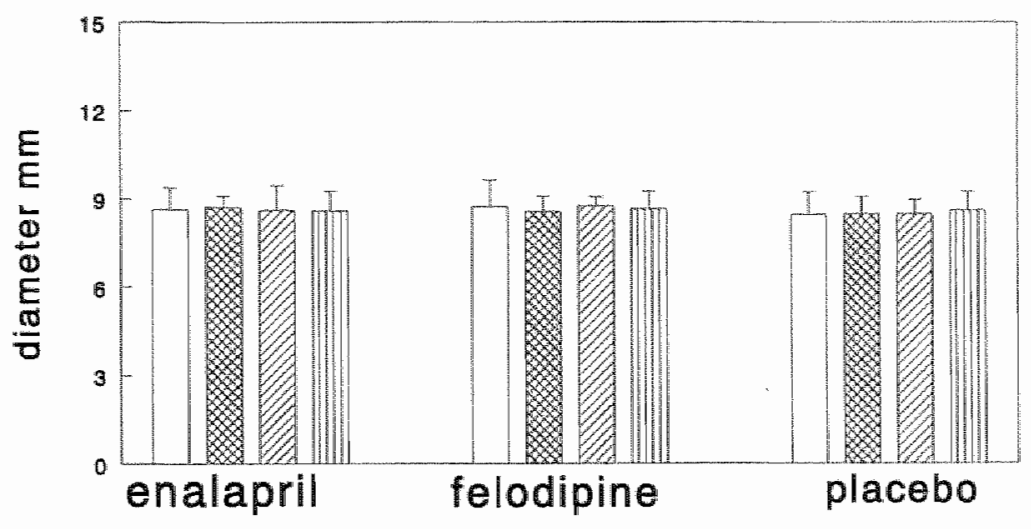

Figure $3^{\mathrm{a}}$. Femoral Artery Diameter. Effects of treatment.

$\square 0$ months 3 months $\bigcup \mathbb{Z} 6$ months [III]I] 9 months

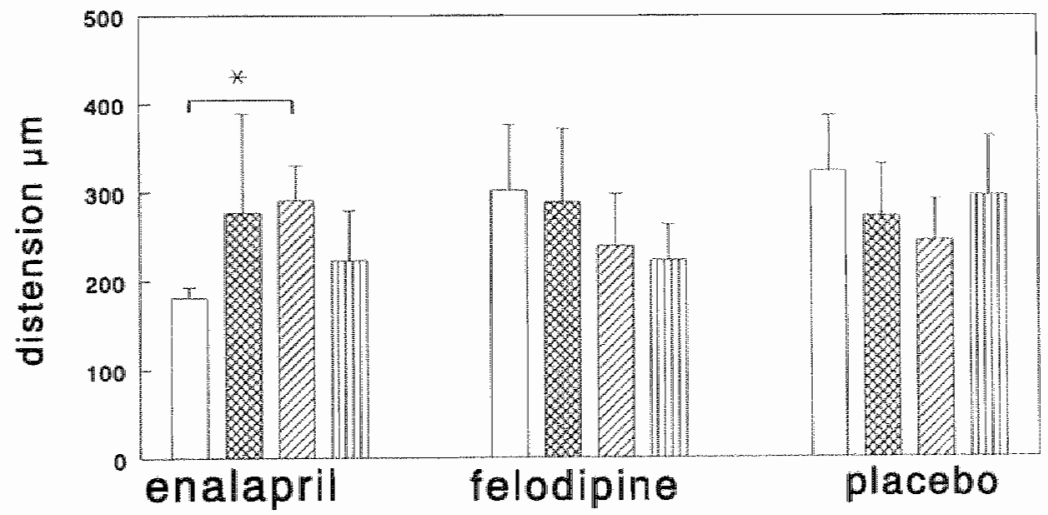

Figure $3^{\text {b }}$. Femoral Artery Distension. Effects of treatment, ${ }^{*} \mathrm{p}=0.001$. 
$\square$ months 86 months 3 WIIA 6 months [IIIII 9 months

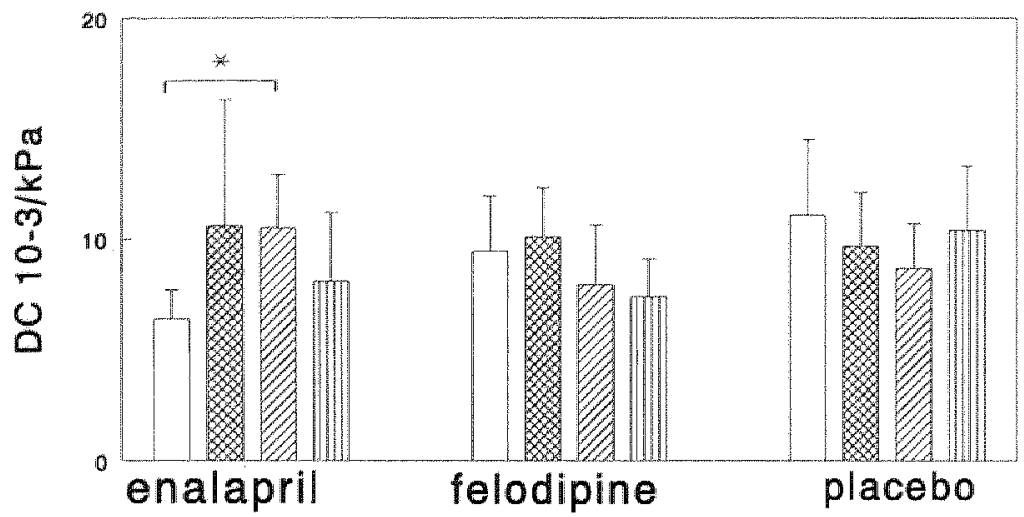

Migure 3c. Femoral Artery Distensibility. Cffects of treatment, $*: p=0.001$.

0 months 3 months $\mathbb{Z Z Z} 6$ months [IIIII 9 months

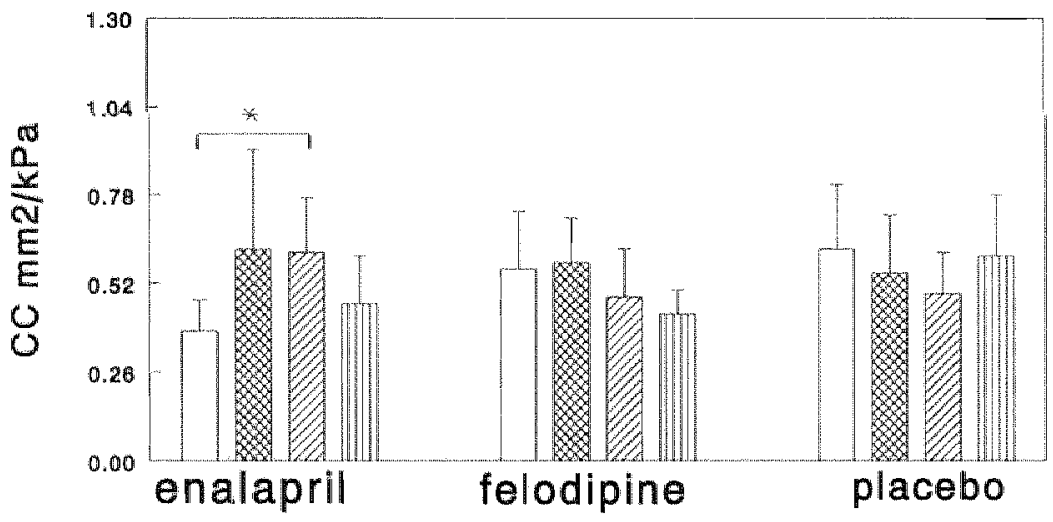

Figure $3^{\text {th }}$. Femoral Artery Compliance. Effects of treatment, ${ }^{*}: p=0.009$. 


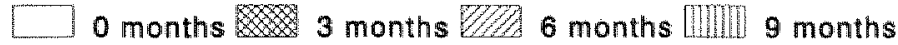

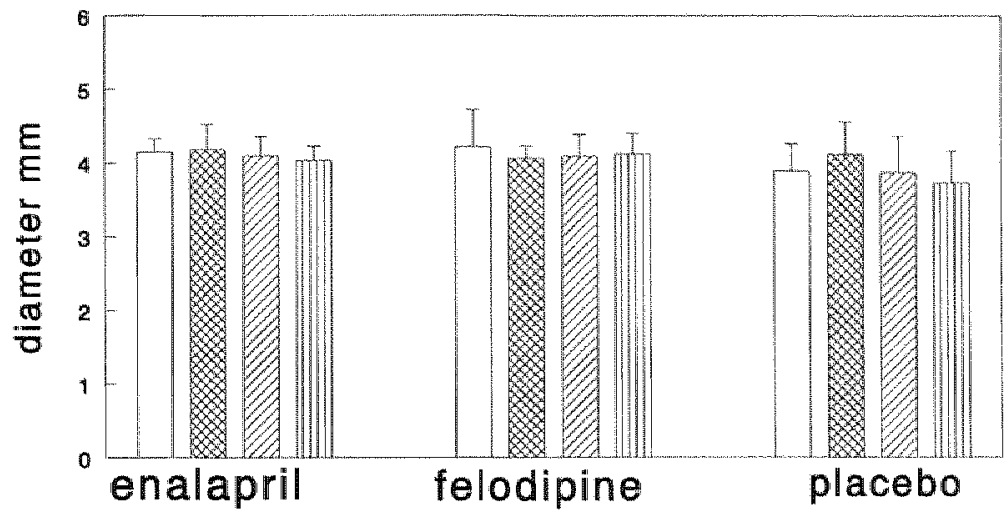

Figure $4^{\text {n }}$. Brachial Artery Diameter. Cffects of treatment.

$\square 0$ months 3 months $Q \mathbb{Z} 6$ months [IIIII] 9 months

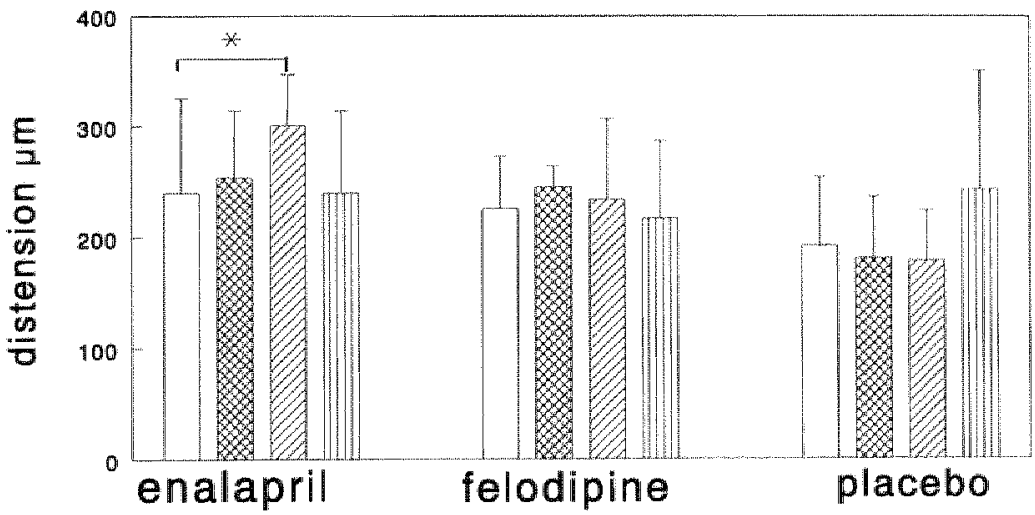

Figure $4^{\mathrm{b}}$. Brachial Artery Distension. Effects of treatment, $*_{*} p=0.01$. 
D 0 months 3 months 6 months IIIIII 9 months

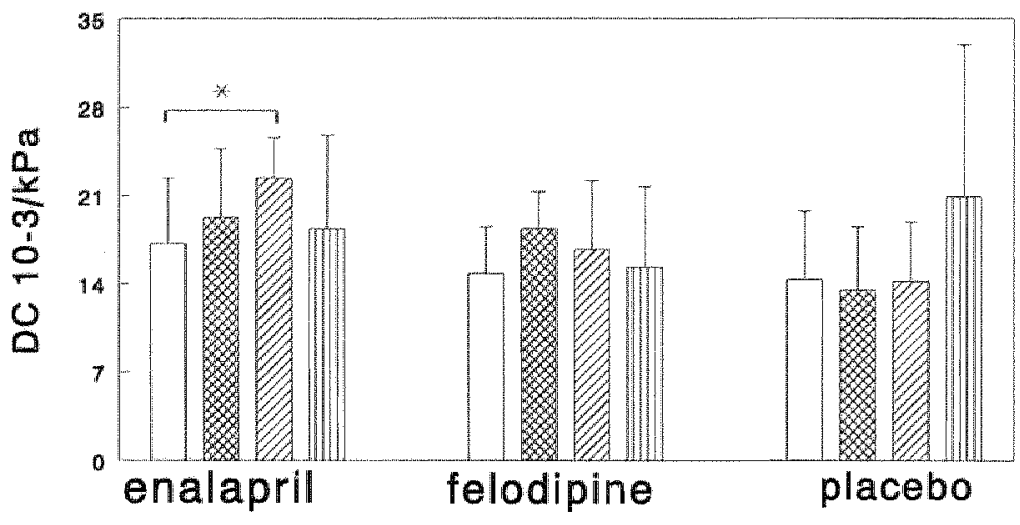

Figure $4^{c}$. Brachial Artery Distensibility. Effects of treatment, *: $p=0.02$.

D months 3 months $\square / Z 6$ months IIIIIII 9 months

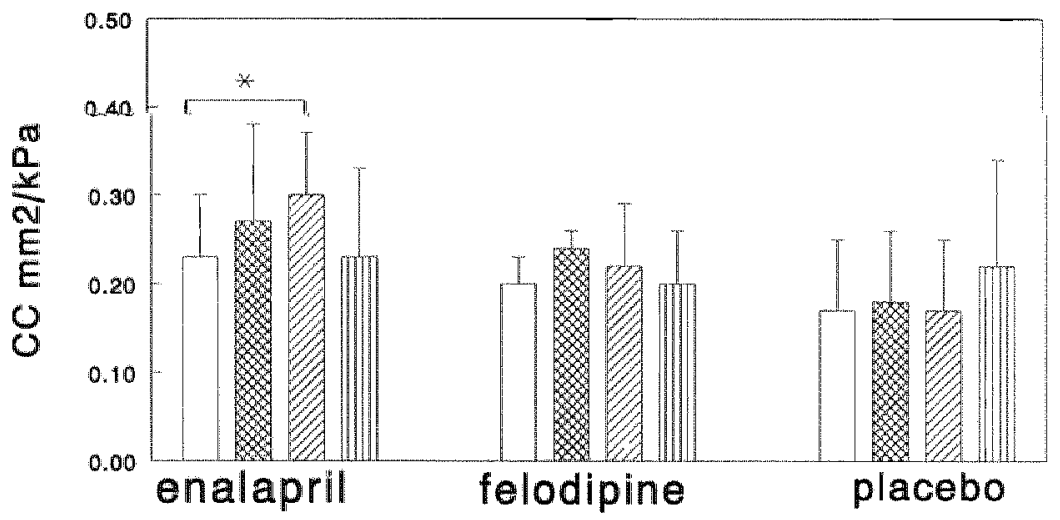

Figure $4^{\mathrm{d}}$. Brachial Artery Compliance. Effects of treatment, *: $p=0.03$. 
Since the enalapril induced reduction in blood pressure per se may induce improvement of distensibility of the arteries, a doubly multivariate analysis of variance was performed in order to evaluate whether the improvement of femoral distension was entirely achieved through a decrease in blood pressure, or whether enalapril exerts additional effects independently of blood pressure. This analysis indicated that the treatment effect of enalapril on both femoral and brachial distension remained significant when mean blood pressure values were taken into account, suggesting an effect of enalapril on arterial distension independent from its blood pressure lowering action (femoral artery $\mathrm{p}=0.01$, brachial artery $\mathrm{p}=0.02$ ).

\section{Venous compliance}

Venous compliance was comparable and only slightly below normal in the sodiumsensitive and sodium-resistant groups at the start of the study. Pharmacological intervention with either enalapril or felodipine, did not induce changes that were significantly different from placebo.

\section{Echo-Doppler cardiography}

Although left ventricular mass index tended to be somewhat larger in the sodiumsensitive group than in the resistant one after the initial investigation (SS: 109 \pm 25 $\mathrm{g} / \mathrm{m}^{2}, \mathrm{SR}: 95 \pm 37 \mathrm{~g} / \mathrm{m}^{2}, \mathrm{p}=0.2$ ), the slightly elevated blood pressure in the investigated groups has not yet led to left ventricular hypertrophy. In the entire group of borderline hypertensive subjects, significant inverse correlations were found between untreated large artery distension and left ventricular mass index (carotid: $r=-0.64$, $p<0.0001$, femoral: $r=-0.43, p=0.013$, brachial $r=-0.31, p=0.022$ ). Pharmacological intervention did not significantly influence left ventricular mass, stroke index or cardiac index.

\section{Discussion}

Six months of enalapril treatment induced a significant improvement of the femoral and brachial artery distensibility and compliance in the sodium-sensitive, but not in the sodium-resistant borderline hypertensive group. This improvement was achieved by an effect of enalapril on the vascular distension rather than by enlargement of the vascular diameter. The effect of enalapril on the distension of the two arteries reached a maximum after six months of treatment and returned towards baseline levels at the end of the wash-out period. Furthermore, doubly multivariate analysis 
suggested that the improvement of femoral and brachial artery distension could not be explained by the decrease in blood pressure only. Thus, these data suggest that enalapril chronically modulates the visco-elastic properties of the femoral and brachial artery wall in sodium-sensitive subjects. Furthermore, the fact that enalapril did not appreciably influence large artery compliance in the sodium-resistant group may favour the hypothesis that the renin-angiotensin system is involved in determining the difference between sodium-sensitive and sodium-resistant borderline hypertensive subjects as far as large artery compliance is concerned.

The compliance of the carotid artery was not significantly altered in the sodiumsensitive group. It may be expected that enalapril, through its relaxant effect on vascular smooth muscle, has a more pronounced effect on muscular arteries such as the femoral and brachial arteries than on elastic arteries such as the carotid.

In established and experimental hypertension ace-inhibitors are known to exert a beneficial effect on arterial compliance $1011 / 2$. Information on effects of aceinhibition on large arteries in borderline hypertensive subjects is not widely available. Unlike the arterial dilatory effect of both enalapril ${ }^{26}$ and felodipine ${ }^{13}$ in essential hypertensives, no such effect was present in our borderline hypertensive population. The positive effect on compliance was entirely achieved through an increase in arterial distension.

Apart from a vasodilatory effect, ace-inhibitors are known to interfere with growth factors ${ }^{1 / 4}$ and may induce regression of hypertrophy of arterial walls.

Although blood pressure, pulse pressure, stroke and cardiac index were equally influenced by enalapril and felodipine treatment in all investigated groups, felodipine did not alter large artery compliance in the sodium-sensitive group. This suggests that the positive effect of enalapril and the lack of effect of felodipine on femoral and brachial distension is not related to changes in haemodynamics.

Previously, we found that despite a slight, but similar reduction in venous compliance in sodium-sensitive and resistant borderline hypertensive subjects, the differences were not statistically significant from normal. As a consequence, no major effects of treatment on venous compliance were expected in the present study. Indeed, venous compliance was not appreciably modified by antihypertensive treatment in our subjects. No effect of enalapril or felodipine treatment on left ventricular mass was found. In this respect, one has to keep in mind that no left ventricular hypertrophy was present in the subjects under study at the start of the treatment period.

In conclusion, six months of enalapril treatment induced a significant dose-dependent improvement of femoral and brachial artery distension and compliance in sodium-sensitive borderline hypertensive subjects, that could not be explained by changes in blood pressure, pulse pressure or cardiac index.

No effects of enalapril were seen in the carotid artery of the sodium-sensitive 
subjects, suggesting inhomogeneity in the response of large arteries to enalapril treatment. Felodipine did not induce significant changes in the arterial compliance of sodium-sensitive subjects. Moreover, neither drug modified arterial compliance in sodium-resistant subjects or venous compliance in the sensitive and the resistant groups.

\section{References}

1. P. Draaijer, M. Kool, I. Maessen, P. de Leeuw, J wan Hooff, K. Leunissen. Arterial distansibility and compliance in salt-resistant and saltwsensitive borderline hypertension. J Hypertens 1993;11:1199-12017.

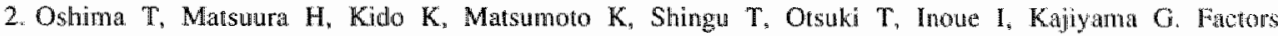
determining sodium chloride sensitivity of patients with essential hypertension: wahution by multivariate analysis, J Hypertens 1989;7:223-227.

3. Hollenberg NK. Williams GH. The renal response to converting enzyme inhbition and the reatment of sodium-sensitive hypertenston. Clin and Exper Theory and practice 1987;A9(28 3):53:-541.

4. Wang DH, Prewitt RL. Captopril reduces aortic and microvascular growth in hypertensiwe and notmotensiwe rats. Hypertension 1990;15:68-77.

5. Oshima T, Massura H, Matsumoto K, Kiclo K, Kajiysma G. Role of cellular calcitum in salt-sensitivity of patients with essential typertension. Hypertension 1988;11:703-707.

6. Takeshita A, Ashihara $T$ Yamamoto $K_{n}$ Imaizumi T, Hoka S, Ito N, Nakamura M. Venous responses lo salt loading in hypertensive subjects. Circulation 1984;69, nol:50-56.

7. Bouther JD, De Luca $N$, Safar ME, Simon AC. Cardiac hypertrophy and arterial distensibiliby in essential hypertansion. Am Heart I 1985;109:1345-1352.

8. Casalle PN, Deverenx RB, Mitner M. Value of echocardiographic lett ventricular mass in predicting cardiowascular morbid events in hypertensive men. Ann lntern Med 1988; 105:173-178.

9. Stevens and Jannes. Applied multivarate statistics for social seiences. Second athition, 1902, Lawrence Erlbaum associates, Publishers, Hillsdale, New Jersey.

10. Simor AC, Levenson J, Bonther JD, Safar ME. Effects of ahonic administration of enaltapril and propanolol on the large arteries in essental hypertension. J Cardiowasc Pharmacol 1985:7:856-861.

11. Asmar RG, Pannier B, Latrent T, Benetos A, Daou J, Safar ME. Haemodynamic effects of perindopril in essential hypertension. J Human Hypertens 1990;4(suppi4):35-44.

12. Levi BI, Benessiano J poitevin $P$, Safar ME. Angiotensir-converting enzyme inhibition and compliance of the carotid atery in normotensive and hypertensive rats. J Human Hypertens 1989;3:57-62.

13. Sallar ME, Asmar RG, Benetos A, London GM, Levy BI. Sodium, large arteries and diuretic compounds in hypertension. J Hypertens 1992;10(suppl6) \$133-\$136. 
14. Wang DH, Prewit RL. Captopril reduces atortic and microvasular growth in hypertensive and normotensiwe rats. Hypertension 1990; $15: 68-77$. 


\section{CHAPTER 7}

CAPILLARY DENSITY IN SALT-SENSITIVE AND SALTRESISTANT BORDERLING HYPERTENSIVE PATIENTS

Effect of treatment with enalapril or felodipine.

P Draaijer, PW de Leeuw, JP wan Hooff, KML Leunissen.

Department of medicine of the university hospital of Maastricht.

(submitted for publication) 


\section{Abstract}

Previously, a reduced number of perfused capillaries was demonstrated in the finger naiffold skin of sodium-resistant borderline hypertensive males during the hyperaemic phase induced by 4 minutes of circulatory arrest, in comparison with sodium sensitive borderline hypertensive subjects and nomotensive controls. The present study was initiated to explore whether antihypertensive treatment with the aceinhibitor enalapril and the calcium-antagonist fellodipine would improve the reduced capillary recruitment upon the vasodilatory stimulus in the resistant subjects.

Therefore, 17 sodium-sensitive and 28 sodium-resistant borderline hypertensive subjects were randomized into three treatment stategies, viz enalapril ( $10 \mathrm{mg} / \mathrm{day}$ ), felodipine (5mg/day) or placebo for six months. Nailfold capillary density was studied by means of intravital video microscopy, at rest as well as after a vasodilatory stimulus.

A slight decrease in blood pressure was seen in the enalapril and felodipine treated groups. However, neither enalapril, nor felodipine had a detectable influence on nailfold capillary density at rest or during hyperaemia in the borderline hypertensive subjects. Moreover, the lesser recruitment in sodium-resistant subjects upon a vasodilatory stimulus of 4 minutes of arterial occlusion as compared to sodiumsensitive ones was maintained throughout the study.

It was concluded that nailfold capillary density was not influenced by six months of antihypertensive treatment with enalapril or felodipine.

\section{Introduction}

A decrease in microvessel density, also called microvessel rarefaction, is considered as a potent contributor to the increased resistance in hypertension '. It appeared, in studies performed at our lab, that in comparison with the normotensive Wistar Kyoto rat, the spontaneously hypertensive rat, a strain that is relatively sodiuminsensitive ${ }^{2}$, displayed a decreased capillary and small arteriolar density in the cremaster muscle at the age of 5-6 weeks, the age at which the pressure starts to rise, suggesting impaired microvascular growth in the latter strain ${ }^{3}$. On the analogy of these experiments, we investigated finger nailfold capillary density in young borderline sodium-sensitive and sodium-resistant hypertensive subjects as well as in a normotensive control group. No differences were found in capillary density under resting conditions between the three investigated groups. However, after a vasodilatory stimulus, sodium-resistant subjects recruited significantly less capillaries than sodium-sensitive and control subjects, suggesting structural rarefaction in the former group.

Limited information is avallable on the effects of antihypertensive drugs on microvessel rarefaction and angiogenesis. Since capillary growth seems to be induced by increased shear stress and blood/endothelial cell interaction or by increased capillary 
wall tension ${ }^{4}$, it may be expected that drugs inducing profound haemodynamic changes at microvascular level, may also influence capillary growth. The calciumantagonist felodipine may alter microvessel dynamics, since increased small arteriolar and, to a lesser extent, large arteriolar diameter was demonstrated in a study in striated muscle in the conscious spontaneously hypertensive rat by Messing and coworkers in our institute ${ }^{5}$. In contrast, the ace-inhibitor enalapril did not influence arteriolar diameter in the above mentioned experimental model. Furthermore a negative effect of ace-inhibitors on microvascular growth has been demonstrated in the one-kidney, one-clip hypertensive rats ${ }^{6}$.

The aim of the present studly was to evaluate the effects of long-term treatment with either felodipine or enalapril on capillary density of the finger nailfold skin in sodium-sensitive and sodium-resistant borderline hypertensive patients. We were especially eager to learn whether or not the decreased capillary reserve that was found in the resistant subjects would alter during antihypertensive treatment.

\section{Patients and methods}

\section{Patient characteristics}

Seventeen untreated sodium-sensitive and 28 sodium-resistant borderline hypertensive patients were included in the study. Patients characteristics and the method used to define sodium-sensitivity are given in detail in chapter 2 . All subjects were 20 to 45 year old males and non-smoker.

\section{Protocol}

After the initial study, that revealed the above mentioned difference in nailfold capillary density between the groups, the subjects were randomly and in a double blind manner assigned to three treatment stategies, viz enalapril $10 \mathrm{mg} / \mathrm{day}$, felodipine $5 \mathrm{mg} / \mathrm{day}$ or placebo. Three months after starting therapy, at the end of the treatment period at six months, and three months after stopping treatment, the measurements were repeated. During the week preceding the day at which the investigations took place, a diet containing $120 \mathrm{mmol}$ sodium and $70 \mathrm{mmol}$ potassium per day was used, while 24-hour urine samples were collected in order to estimate diet compliance.

The subjects entered the hospital at 8.00 am at the days of the investigations. A light breakfast had been used at home. Blood pressure was measured after at least 15 minutes of rest. Systolic and diastolic pressure were measured every five minutes for half an hour and the average of these blood pressure values was determined. 
Mean arterial pressure was calculated as the sum of diastolic pressure and one third of the pulse pressure. Simultaneously, heart rate was determined. Subsequently, nailfold capillary density was studied using an incident light intravital videomicroscope as is described in chapter 2 . The investigation took place in a temperature controlled room $\left(24^{\circ} \mathrm{C}\right)$. Capillary density in three microscopic fields was measured, at rest as well as after a vasodilatory stimulus in an artempt to recruite capillaries that were closed for flow during basal conditions?

\section{Data analysis}

Data are presented as mean \pm standard deviation. Treatment effect was assessed by means of multivariate analysis of variance for repeated measurements. The level of significance was $\mathrm{p}<0.05$.

\section{Results}

\section{Characteristics of the investigated groups}

Table 1 shows characteristics of the sodium-sensitive borderline hypertensive (SS) and the sodium-resistant borderline hypertensive groups (SR) at the initial measurement. There were no significant differences in age or body surface area between the groups. The estimated duration of hypertension was 7 years in both groups. Systolic and diastolic pressures, as well as mean arterial pressure were similar in the groups. Likewise, heart rate did not differ between the groups.

Table 2

\begin{tabular}{llll}
\hline GENERAL CHARACTERISTICS. (MEAN & & & \\
\hline & $S S$ & $P$ & $S R$ \\
N & 17 & & 28 \\
Age (yrs) & $41 \pm 6$ & .41 & $40 \pm 6$ \\
BSA (m²) & $2 \pm 0.2$ & .74 & $2 \pm 0.2$ \\
Syst (mmHg) & $155 \pm 13$ & .43 & $153 \pm 16$ \\
Ditus (mmHg) & $87 \pm 6$ & .42 & $85 \pm 8$ \\
MAP (mmHg) & $110 \pm 7$ & .48 & $108 \pm 10$ \\
HR (bpm) & $67 \pm 13$ & .20 & $63 \pm 10$ \\
\hline
\end{tabular}


Five sodium-sensitive borderline hypertensives were treated with enalapril (SS-E), 5 with felodipine (SS-F) and 7 with placebo (SS-P), while 11 sodium-resistant subjects had enalapril (SR-E), 10 felodipine (SR-F) and 7 placebo (SR-P) during the treatment period. Mean arterial pressures of the groups before ( 0 months) during ( 3 and 6 months) and after treatment ( 9 months) are depicted in figure $\mathbb{1}$.

$\square 0$ months 3 months 60 months 9 months

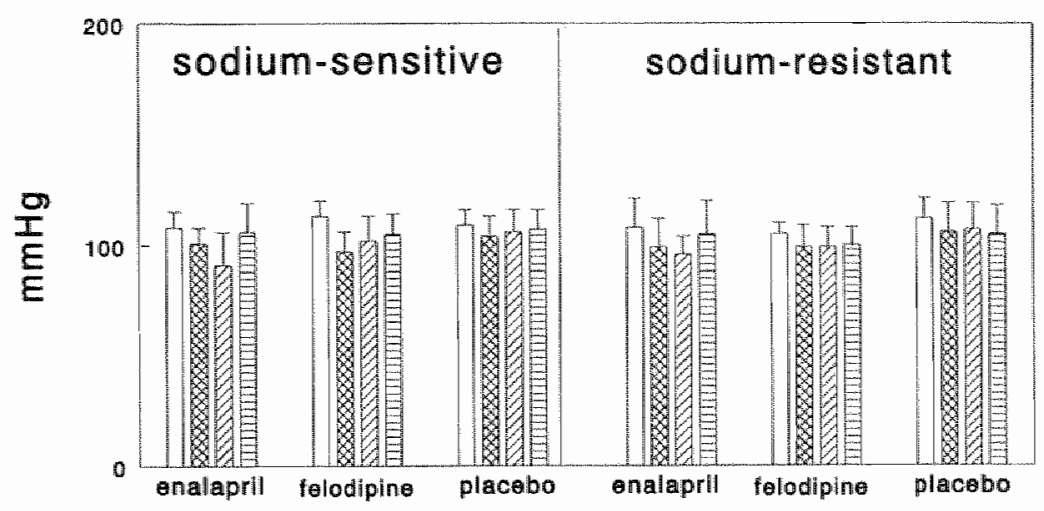

Figure 1. Mean arteriall pressure; effects of treatment

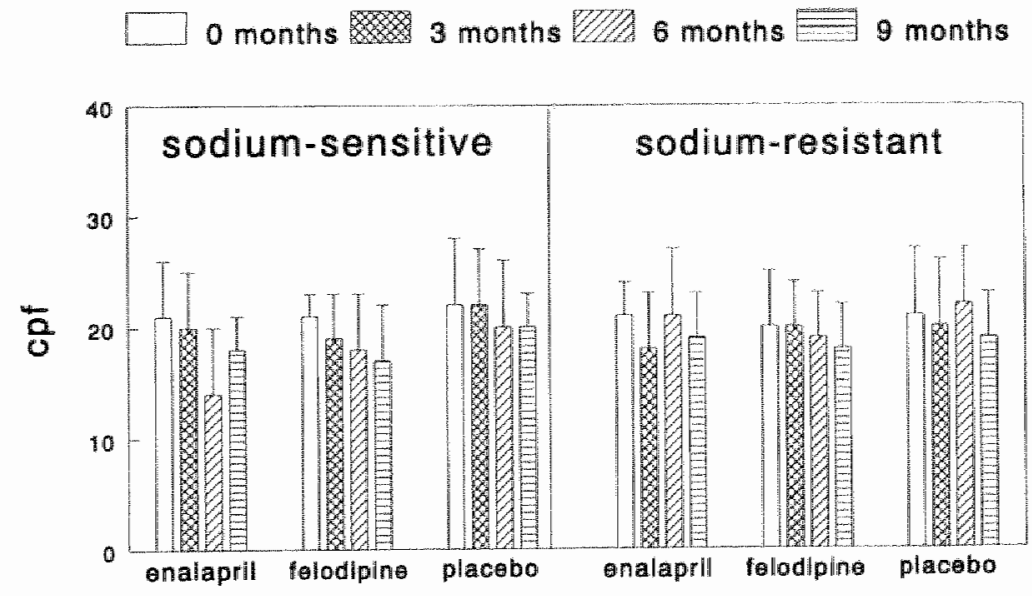

Figure 2. Nailfold capillary density, rest condition 


\section{0 months 3 months $\mathbb{Z} 20$ months 69 months}

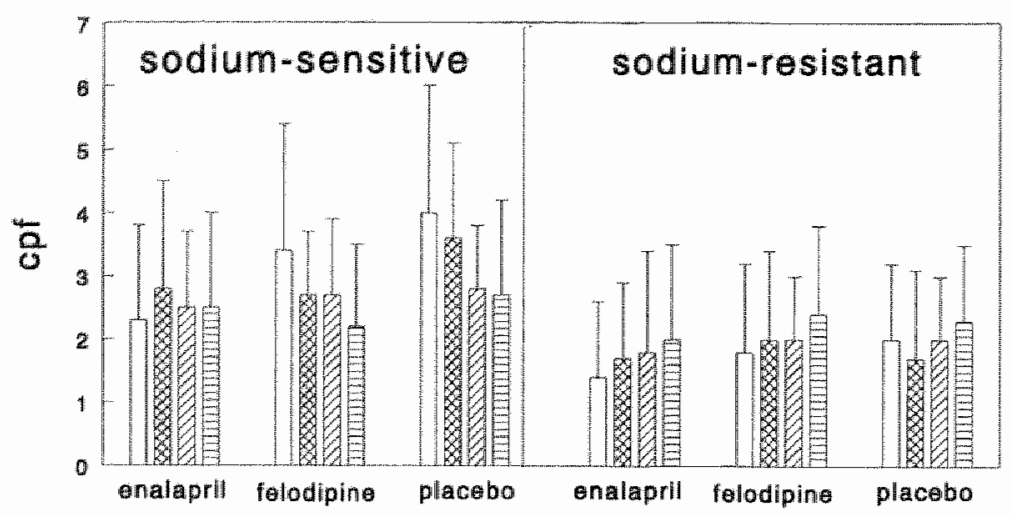

Figure 3. Capillary recruitment due to 4 minutes of circulatory arrest

Neither enalapril, nor felodipine induced significant changes in nailfold capillary density in the sodium-resistant group or the sodium-sensitive group (fig. 2). Also capillary recruitment was not significantly altered by the antihypertensive treatment (fig. 3). Sodium-sensitive subjects recruited significantly more capillaries upon the stimulus of 4 minutes arterial occlusion than sodium-resistant ones during the initial. investigation. As can be seen in figure 3, this tendency was maintained throughout the study, although no statistical significance was reached due to small treatment groups and considerable variation.

\section{Discussion}

Sodium-resistant borderline hypertensive subjects differed from sodium-sensitive ones by a lesser recruitment of capillaries upon a vasodilatory stimulus as was found in a previous study. In this respect, we speculated that in resistant subjects a microvascullar growth deficit may underlie the increased resistance of essential hypertension. Furthermore, we wondered whether conventional antihypertensive treatment was able to improve the reduced capillary reserve of the resistant subjects. Therefore, two agents were tested, felodipine with a clear microvessel dilatory action and an unknown action on microvessel density and enalapril with no detectable arteriolar dilatation and a possibly negative effect on microvascular growth ${ }^{5}$, as was revealed in hypertensive rats.

It was shown, in the present study, that nailfold capillary density was not detectably 
influenced by long term treatment with felodipine or enalapril, neither in sodium-resistant subjects, nor sodium-sensitive ones. Moreover, the lesser recruilment in sodium-resistant subjects upon a vasodilatory stimulus was maintained throughout the study.

Although some studies performed in experimental models demonstrate a clear positive effect of long-term treatment with antihypertensive agents $\&$ \& microvascular growth, we were not able to demonstrate such an effect on nailfold density in borderline hypertensives with felodipine or enalapril. However, this finding does not imply that other microvascular beds would not be affected by these agents, since a considerable heterogeneity in microvascular morphometrical and functional characteristics has been described in different tissues (for review see ref. ${ }^{9}$ ). Furthermore, the nailfold bed may not be a vascular bed of major importance in the regulation of peripheral vascular resistance and thereby not a major target for antihypertensive therapy.

In recent years, it was revealed that a considerable part of the increased resistance in hypertension is located in the microcirculation and that, in addition to microvascular diameter changes, microvessel rarefaction contributes importantly to this increased resistance. Therefore, future research may aim at acquiring insight into the mechanisms leading to angiogenesis as well. as into the effects of pharmacological agents on microvessel growth.

In conclusion, six months of treatment with the ace-inhibitor enalapril or the calcium antagonist felodipine did not significantly influence nailfold capillary density in rest or after a vasodilatory stimulus in sodium-sensitive and sodium-resistant borderline hypertensive males.

\section{References}

1. Green AS, Tonellato PJ, Lui J. Lombard JH, Cowlay A W jr. Microvascular rarefaction and tissue vascular resistance in hypertension. Am I Physiol 1989;256:H126-HII31.

2. Leenen FHH. Toal CB. Detary sodium restriction and the renin-angonensin system in young portaneousfy hypertensive rats. I Hypertens 1989:7:57-61.

3. Le Noble JLML, Tangelder G. Slataf DW, var Essen H, Rememan RS, Struyker Botwer HA. A functional morphometrie study of the cremaster muscle microcilculation in young spontancously trypertensive rats. J Hypertens $1990 ; 8: 741-748$.

4. Dawson JM. Hudlicka $O$. The affects of long term administration of prazosin on the microcirculation in sketetal muscles. Cardiovascular researci $1989,23: 913,920$.

5. Messing MWJ, van Essen H. Struker Boudier HAJ. Inhibition of angiotensin convering enzyme does nol influence arteriolar tone in striated muscle of conscious spontaneously hypertensive rats Acta Clin Belg $1991 ; 46: 252-253$ 
6. Wang DH, Prewin RL. Captopmil reduces aortic and microvascular growth in hypertensive and nomptens:we rats. Hyperiension 1990; 15:68-77.

7. Johmon PC, Burfon KS, Honich H. Henrich U. Effect of occlusion duration on reactive byperemian in sirtorius muscle capillaries. Am J Physiol 1976; vol230ino3:715-719.

8. Huthims PM, Marshbum TH, Maultsby SJ, Lynch CD, Smith TL, Dusseau JW. Lomgterm microvascular responsa to hydratazine in spontaneously hypertensiwe sats. Hypertension $1988 ; 12 ; 74-79$.

9. Suryker Bouder HA, Le Nobie JLML, Messing MWJ, Hubents MSP. Le Noble FAC, van Essen H. The mitcrocirculation and hypartengion. I Hypertens 1992; 10(suppl 7):SH47-\$156. 
CHAPTER 8

SUMMARY AND CONCLUDING REMARKS 


\section{Summary}

Controversy exists about the sodium-sensitivity concept. Indeed, since blood pressure resporises to high sodium intake are highly variable, it is difficult to assess which part of the blood pressure response is due to normal variation and which part represents a salt retaining trait. Moreover, very little attention has been paid to the reproducibility of sodium-sensitivity. However, sodium-sensitivity appeared to be a highly reproducible phenomenon in the borderline hypertensive group under study in the present thesis, as was described in Chapter 3. Furthermore, it was found that sodium-resistant subjects displayed a significant increase in urinary dihydroxyphenylalanine (dopa) excretion and a significant decrease in dopamine-to-dopa ratio when sodium intake was changed from low into high in the first but also in the repeated study. The latter finding suggests that more dopa is available during high sodiumintake than is actually transformed into dopamine, which subsequently acts as a local natriuretic substance. These salt induced changes in the renal dopaminergic system, however, were consistently absent in both the initial and the second experiment in sensitive subjects. It appeared as if the latter subjects already had a supernormal dopa excretion during low sodium intake and were not capable of a further elevation of the dopa levels when sodium intake was increased. This suggests that, to compensate for a decreased renal excretory capacity, sodium sensitive subjects need supernormal dopa levels in order to establish sodium homeostasis. A significant correlation between urinary dopa excretion during low sodium intake and the pressor response induced by high salt intake in sodiumsensitive subjects, but not in resistant ones, may strengthen the above mentioned assumption. Higher levels of atrial natriuretic peptide (ANP) were found during both low and high salt intake as well as a steeper increase upon high sodium intake in the sodium-sensitive group compared to the sodium-resistant subjects. Higher ANP levels during high salt intake as well as the steeper increase suggest sodium and volume retention. However, the exact role of significantly higher levels of ANP during low salt intake in the sensitive group remains to be established. The nett alterations in renal blood flow, glomerular filtration rate, plasma renin activity and plasma aldosterone levels when sodium intake was increased showed no difference from one group to the other, not in the first experiment, neither in the repeated one. Thus, although in the literature sodium-sensitivity has been linked to maladaptations of renal haemodynamics or of the renin-angiotensin system to increases in sodium intake, the present data do not support overt maladaptations. However, one has to keep in mind that plasma renin activity should be related to the cumulative sodium balance. In this respect PRA and aldosterone levels may be inappropriately high in the sensitive group.

Many studies have been performed to unravel the haemodynamics behind the sodium induced pressor response. Less attention has been paid to the question whether cardiovascular characteristics of sodium-sensitive and sodium-resistant subjects differ during regular normal day sodium intake. Since sodium-sensitivity has been linked to a more serious course of the hypertensive process, it may be 
expected that such differences exist. Indeed, it has been demonstrated that during regular sodium intake, salt-sensitive hypertensives have higher fore-arm vascular resistance than sodium-resistant ones. Moreover, as described in Chapter 4, sodiumsensitive borderline hypertensive subjects displayed significantly reduced distensibility and compliance of three large arteries, namely the carotid, femoral and brachial artery, as compared to sodium-resistant borderline hypentensive subjects. This reduction could not be explained by a higher blood pressure level, higher levels of pressure regulating hormones or longer duration of hypertension in the sensitive group. It has been stated that stiff arteries, since they are subject to high intramural stresses, tend to age faster than flexible ones. Also a link between atherosclerosis and reduced arterial compliance has been suggested. Moreover, significant inverse correlations were found beween large artery compliance and left ventricular mass in the borderline hypertensive subjects under study. Therefore, reduced arterial compliance may well be an explanation for the more serious course of the hypertensive disease in sodium-sensitive subjects.

In this respect, it is of interest to know whether reduction of the blood pressure towards normotensive values by means of antihypertensive therapy will improve the reduced large artery compliance in sodium-sensitive subjects. As described in Chapter 6, long-term treatment with enalapril $10 \mathrm{mg} /$ day induced a significant improvement of the arterial distension, and thereby of the distensibility and compliance of the muscular femoral and brachial arteries, but not of the elastic carotid artery. Treatment with the calcium-antagonist felodipine ( $5 \mathrm{mg} / \mathrm{day}$ ), on the contrary, did not influence large artery compliance in the sodium-sensitive group, despite of a similar reduction in blood pressure. Neither enalapril, nor felodipine influenced large artery compliance in the resistant group. The dose dependent improvement of femoral and brachial compliance during enalapril therapy and the regression of compliance towards baseline values after stopping treatment which was encountered in the sodium-sensitive group, may implicate a pathophysiologic role of (local) angiotensin II.

Venous compliance was only marginally reduced in the borderline hypertensive subjects as compared to controls during regular sodium intake. Moreover, venous compliance did not differ between sensitive and resistant subjects, while it has been demonstrated that during high sodium intake a decrease in venous compliance in sodium-sensitive subjects may contribute to the pressor response. Six months of treatment with enalapril or felodipine did not alter venous compliance.

Predominantly experimental studies, performed in skeletal muscle of spontaneously hypertensive rats, indicate that a large part of the increased resistance in hypertension is determined at microcirculatory level and that two mechanisms seem to be responsible for this increase, namely enhanced large arteriolar tone and decreased small arteriolar and capillary density. In humans, studies of the microcirculation are restricted to superficial tissues such as the nailfold skin or the conjunctiva. A reduction in conjunctival capillary density has been found in sodium-sensitive subjects during a high sodium intake. However, under conditions of nomal sodium 
intake, capillary density in the nailfold skin of the sodium-sensitive borderline hypertensive subjects, sodium-resistant borderline hypertensives and normotensive controls under study in the present thesis were not significantly different, as described in Chapter 5 . In contrast to this, sodium-resistant subjects recruited less capillaries upon a vasodilatory stimulus induced by 4 minutes of circulatory arrest than sodium-sensitive borderline hypertensives and controls, suggesting a structural diminishment of the number of capillaries in the resistant group. Whether this finding may be generalized to other tissues is unknown. But, future research may aim at testing the hypothesis of a microvascular growth deficit as a blood pressure elevating mechanism in sodium-resistant subjects.

At present, pharmacodesign is directed towards the development of agents that primarily influence microvascular growth. Awaiting such agents, it is of interest to know how existing antihypertensive drugs interfere with the microcirculation. According to experimental studies, some antihypertensive drugs had a negative influence on microvascular growth, while others acted as growth promotors. Longterm treatment with the ace-inhibitor enalapril or the calcium-antagonist felodipine, however, did not influence the reduced capillary density during vasodilation in the sodium-resistant borderline hypertensive subjects under study, as described in Chapter 7. Nailfold capillary density appeared to be continually stable regardless of the type of antihypertensive treatment.

\section{Concluding remarks}

Summarizing, it may be concluded that the assessment of the individual sodium susceptibility of a borderline hypertensive subject may have important implications. At first, sodium-sensitivity may be related to reduced large artery compliance. The reduction in large artery compliance may contribute to the detrimental effects of the hypertensive process such as the eventual development of atherosclerosis and left ventricular hypertrophy. Secondly, the sodium-sensitivity status may have implications for the choice of antihypertensive therapy since for a similar reduction in blood pressure, the ace-inhibitor enalapril significantly improved large artery compliance, while the calcium-antagonist felodipine did not.

Whether the reduced number of capillaries during reactive hyperaemia in sodiumresistant subjects is a result of microcirculatory adaptations to the increased blood pressure or a reflection of impaired microvascular outgrowth can not be derived from the present study. Extended research, preferably in vascular beds that are relevant to the regulation of peripheral resistance, is necessary to value the pathophysiological implications of the finding. Moreover, treatment with enalapril or felodipine did not alter capillary density. 
Future research will aim at longitudinal investigation of arterial, venous and capillary properties of the borderline hypertensive group. The relation between reduced large artery compliance, future development of left ventricular hypertrophy and ace-inhibitor therapy will deserve utmost attention. The development of a convenient and valid test for the determination of sodium-sensitivity may also be an important aim in future research. 



\section{CHAPTER 9}

SAMENVATTING 


\section{Samenvatting}

Zoutgevoeligheid is een controversieel concept. Na een zoutbelasting is er een grote variatie in bloeddrukrespons. Het moeilijk te bepalen welk deel van de bloeddrukverandering het gevolg is van normale variatie en welk deel toegeschreven kan worden aan een daarop gesuperponeerde zoutgevoeligheid. Daar komt nog bij dat er weinig gegevens beschikbaar zijn aangaande de reproduceerbaarheid van zoutgevoeligheid. In Hoofdstuk 3 werd de reproduceerbaarheid van bloeddrukveranderingen volgend op de overgang van een laag zout dieet naar een hoog zout dieet, getest. Zoutgevoeligheid, bepaald middels een dieetmethode, bleek een zeer reproduceerbaar fenomeen te zijn in de groep borderline hypertensieve mannen die bestudeerd werd in het huidige onderzoek. Verder bleek tijdens dit experiment dat zoutresistente proefpersonen een significante toename toonden van de dihydroxyphenylalanine (DOPA)-uitscheiding in de urine en een significante afname van de dopamine/DOPA ratio wanneer de zoutinname veranderde van laag naar hoog. Dit gebeurde in de eerste maar ook in de herhaalde studie. Deze bevinding geeft aan dat er meer DOPA beschikbaar is tijdens de periode van hoge zoutinname dan dat door het renale tubulusepitheel omgezet wordt in dopamine. Dopamine zou vervolgens werken als een lokaal natriuretische substantie. Deze door zout geinduceercle veranderingen in het renale dopaminerge systeem bleken zowel in het eerste als in het tweede experiment afwezig in de zoutgevoelige groep. Deze laatste groep toonde al tijdens laag zout dieet hoge DOPA concentraties in de urine, terwijl verdere toename van de DOPA-excretie als reactie op verhoging van de zoutinname uitbleef. Dit gegeven zou kunnen suggereren dat zoutgevoelige proefpersonen, mogelijk ter compensering van een vermindering in het renale natrium-excretie vermogen, reeds tijdens lage zoutinname een hoge DOPA-concentratie nodig hebben voor zouthomeostase. Deze assumptie wordt gesteund door een significante correlatie tussen de DOPA-spiegel in de urine tijdens laag zout dieet en de door hoog zout geinduceerde bloeddrukverandering, die werd gevonden in zoutgevoelige-, maar niet in zoutresistente proefpersonen. Ook werden hogere plasma atriaal natriuretisch peptide (ANP)-spiegels gevonden in de zoutgevoelige groep, zowel tijdens laag zout dieet als tijdens hoog zout dieet, alsmede een sterkere stijging bij de overgang van laag naar hoog zout. Hogere ANP-spiegels tijdlens hoog zout dieet alsmede de sterkere stijging suggereren natrium- en volumeretentie. De betekenis van de hogere ANP-concentratie tijdens de lage zoutinname is minder duidelijk. De door het hoog zout dieet geinduceerde veranderingen in de renale doorbloeding, de glomerulaire filtratie snelheid, de plasma renine activiteit en de plasma aldosteron concentratie waren vergelijkbaar in de zoutgevoelige- en zoutresistente groep, zowel in het eerste als in het herhaalde experiment. In de literatuur wordt zoutgevoeligheid gerelateerd aan maladaptaties van de renale haemodynamiek of het renine-angiotensine-aldosteron systeem (RAAS) aan een hoge zoutinname. De data uit deze studie ondersteunen deze hypothesen niet, echter men dient zich aangaande het RAAS te realiseren dat de plasma renine activiteit geinterpreteerd moet worden in het kader van de cumulatieve zoutbalans. In dit kader zouden de plasma renine activiteit en het aldosteron 
gehalte relatief gezien te hoog kunnen zijn in de zoutgevoelige groep.

Zoutgevoelige hypertensie zou cen ernstiger beloop hebben dan zoutresistente hoge bloeddruk. De reden hiervan is niet bekend. Het is daarom interessant te weten of zoutgevoelige proefpersonen tijdens een gemiddelde dagelijkse zoutinname afwijken in bepaalde cardiovasculaire karakteristieken van zoutresistente. Een hogere vaatweerstand is in de literatuur beschreven in de onderarm van zoutgevoelige proefpersonen tijdens een normale zoutinname. Uit de in Hoofstuk 4 beschreven studie blijkt, dat zoutgevoelige borderline hypertensieven een significante vermindering vertoonden van de distensibiliteit en de compliantie van grote slagaders als de a. carotis, de a. femoralis en de a. brachialis in vergelijking met zout-resistente en gezonde controles. Deze vermindering in de zoutgevoelige groep tav de resistente groep, kon niet verklaard worden door een hogere bloeddruk, verschillende concentraties wan bloeddruk-regulerende hormonen of een langduriger bestaan van de bloeddrukverhoging. Uit de literatuur is bekend dat stijvere slagaders aan hogere intramurale stress onderhevig zijn en daardoor mogelijk sneller verouderen. Er is ook een relatie beschreven tussen atherosclerose en verminderde arteriële compliantie. Verder bleek er in de groep borderline hypertensieven een significante inverse relatie te bestaan tussen de distensibiliteit van de onderzochte slagaders en de linker ventrikel massa, zoals reeds eerder beschreven voor hypertensie patienten. Dit alies kan impliceren dat de verminderde arteriële compliantie een verklaring zou kunnen zijn voor het ivm zoutresistente hypertensie, ernstiger ziektebeloop van zoutgevoelige hypertensie.

In dit kader is het van belang te weten of antihypertensieve therapie een positieve invloed uitoefent op de verminderde arteriële compliantie van de zoutgevoelige proefpersonen. Zoals beschreven in Hoofdstuk 6 bleek zes maanden behandeling met de angiotensine-converting-enzyme inhibitor enalapril in een dosering van 10 $\mathrm{mg} / \mathrm{dag}$ een significante verbetering te induceren in de distensibiliteit en compliantie van de musculaire aa. femoralis en brachialis in de zoutgevoelige groep. Een dergelijk effect werd niet bereikt in de elastische a. carotis. De calcium-antagonist felodipine in een dosering van $5 \mathrm{mg} / \mathrm{dag}$ had geen effect op de compliantie van de onderzochte arterieën in de zout-gevoelige groep. In de zoutresistente groep werd de compliantie van de drie arterieên niet significant beinvloed door de 6 maanden durende behandeling met enalapril of felodipine. De dosis afhankelijke verbetering van de compliantie van de aa. femoralis en brachialis in de zoutgevoelige groep, alsmede de regressie van de compliantiewaarden naar het uitgangsniveau na staken van de enalapril behandeling, suggereren dat (lokaal) angiotensine II mogelijk van pathofysiologische betekenis is bij de verminderde arteriële compliantic van de zoutgevoelige proefpersonen.

De veneuze compliantie gemeten tijdens gemiddelde zoutinname bleek sllechts marginaal verminderd tov de controles. Tevens was er geen verschil in veneuze compliantie tussen zoutgevoelige en zoutresistente proefpersonen. Eerder werd echter aangetoond dat tijdens een zoutbelasting de veneuze compiantie van zoulgevoelige hypertensieven lager is dan die van zoutresistente hypertensieven. Zes maanden behandeling met enalapril en felodipine had geen effect op cle veneuze 
compliantie.

Dierexperimentele studies, met name verricht in skeletspier van spontaan hypertensive ratten, toonden dat een groot deel van de verhoogde vaatweerstand, zoals die gevonden wordt bij hypertensic, bepaald wordt op microcirculatoir niveau. Twee mechanismen zouden met name voor deze weerstandsverhoging verantwoordelijk zijn. Ten eerste een toegenomen arteriolaire tonus en ten tweede een verminderde arteriolaire en capillaire densiteit. Humane microcirculatoire studies zijn schaars en minder informatief van opzet omdat deze studies zich beperken tot superficiele weefsels zoals de huid of de conjunctiva, hetgeen vaatbedden zijn die niet van prominent belang zijn in de regulatie van de vaatweerstand. Een verminderde capillaire densiteit tijdens hoog zout dieet werd reeds beschreven in de conjunctiva van borderline hypertensive mannen. Gedurende de gemiddelde zoutinname werd echter een vergelijkbare capillaire densiteit gevonden in de nagelriem van nomotensieve controles, zoutgevoelige en zoutongevoelige borderline hypertensieven, zoals beschreven in Hoofstuk 5 . Tijdens de hyperaemische fase na 4 minuten circulatoir arrest in de vinger, bleek echter dat de zoutresistente proefpersonen significant minder capillairen recruiteerden dan de zoutgevoeligen en de controles. Dit zou kunnen duiden op een structureel verschil in aantal capillairen tussen zoutgevoelige en zoutresistente borderline hypertensieven. Deze bevinding kan echter niet zondermeer geëxtrapoleerd worden naar andere weefsels. Meer onderzoek is nodig, liefst in verschillende vaatbedden, om na te gaan of een microvasculair groei deficit een bloeddruk werhogend mechanisme zou kunnen zijn in zoutresistente hypertensieven.

Op het moment wordt onderzoek verricht naar nieuwe farmacologische substanties waarmee microvasculaire groei beinvloed kan worden. Aangaande de bestaande antihypertensiva bleek dat sommige een negatieve invloed uitoefenen op microcirculatoire groei, terwijl andere als groei-promotoren werken. Zoals beschreven in Hoofdstuk 7 bleek 6 maanden antihypertensieve therapie met enalapril en felodipine geen invloed te hebben op de capillaire densiteit in de nagelriem van borderline hypertensieve jonge mannen.

\section{E Conclusie}

Het vaststellen van de individuele zoutgevoeligheidsstatus van borderline hypertensieven kan belangrijke implicaties hebben. Ten eerste bleek zoutgevoeligheid gerelateerd te zijn aan een verminderde compliantie van grote slagaders. Deze reductie in de soepelheid van de vaten kan bijdragen aan het ontstaan van atherosclerose en linker ventrikel hypertrofie. Ten tweede bleek dat de keuze van antihypertensieve therapie mede bepaald kan worden door de zoutgevoeligheidsstatus. Behandeling met de ace-inhibitor enalapril gaf een significante verbetering van de compliantie van musculaire arterièen in de zoutgevoelige groep terwijl behandeling 
met de calcium-antagonist felodipine geen effect had op de compliantie, ondanks eenzelfde bloeddrukdaling.

Of het verminderde aantal capillairen tijdens reactieve hyperaemie in de zoutresistente borderline hypertensieve groep een gevolg is van microcirculatoire aanpassingen aan de verhoogde bloeddruk, danwel een reflectie is van een verminderde microvasculaire groei, valt uit de huidige studie niet op te maken. Verdere onderzoeken, bij voorkeur in vaatbedden die een rol spelen in de regulatie van de totale vasculaire weerstand zijn noodzakelijk om de pathofysiologische betekenis van de bevinding op waarde te schatten. Antihypertensieve therapie met enalapril of felodipine had geen invloed op de capillaire densiteit in de nagelriem.

Toekomstig onderzoek zal zich richten op het vervolgen van arteriële, veneuze en capillaire eigenschappen van de groep borderline hypertensieven. Met name de relatie tussen de arteriële compliantie en de ontwikkeling van linker ventrikel hyypertrofie en het effect van ace-inhibitie hierop verdient grote belangstelling. Verder dient een gemakkelijke en valide methode ontwikkeld te worden om zoutgevoeligheid wast te stellen. 
. 


\section{Dankwoord}

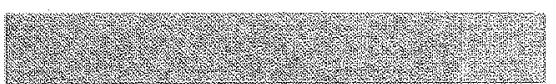




\section{Dankwoord}

Velen hebben bijgedragen aan de totstandkoming van dit proefschrift.

Zevenenveertig jonge mannen met een licht verhoogde bloeddruk participeerden in de studie. Hen wil ik zeer nadrukkelijk danken voor de vele uren vrije tijd die ze in het lab doorbrachten en de dieetweken die ze blijmoedig doorstonden.

Mijn co-promotor Dr. Karel Leunissen wil ik danken voor zijn nimmer aflatende toewijding en steun. Zijn kennis, inzet en enthousiasme wil ik mezelf tot voorbeeld stellen.

Mijn promotores Prof. Dr. J.P. van Hooff en Prof. Dr. P.W. de Leeuw hebben veel energie gestoken in respectievelijk de opzet en de afronding van de studie. Hiervoor wil ik mijn grote erkentelijkheid uitspreken.

De leden van de beoordelingscommissie, Prof. Dr. R.S. Reneman (voorzitter), Prof. Dr. H.A.J. Struyker Boudier, Prof. Dr. W.H. Birkenhäger en Prof. Dr. H.J.J. Wellens dank ik voor hun bereidwilligheid om het manuscript te beoordelen. The willingness of Prof. Dr. M.E. Safar to review the manuscript is greatfully acknowledged.

De werkgroep Nefrologie vormde een goede thuisbasis. Willi van Kuyk, Jeroen Kooman, Maarten Christiaans, Ton Luik, Carlo Gaillard, Desirée van Schoubroeck en Anke Hendriks wil ik hartelijk danken voor hun bijdragen.

Mirian Kool en Luc van Bortel wil ik bedanken voor de prettige samenwerking en de vele uren die met name Mirian besteedde aan het meten van de slagaderparameters van mijn onderzoeksgroep.

De samenwerking met Josée Maessen en Annet Op het Veld, van de afdeling dietetiek was altijd uiterst plezierig. Met zeer veel kennis van zaken hebben zij de dieten van de proefpersonen vastgesteld en geëvalueerd.

Op de afdeling nucleaire geneeskunde heb ik met zeer veel plezier gewerkt. Piet Willems, Servé Halders en Sandra Zimny dank ik voor hun grote inzet tijdens het verrichten van de nierklaringsexperimenten. Dr. G.A.K. Heydendal maakte deze samenwerking mogelijk.

Claudia den Haan wil ik danken voor de getoonde inzet tijdens het tellen van de capillairen. Zij behield telkens haar goede humeur tijdens dit toch onplezierig te noemen werk.

Dr. Fred Nieman dank ik voor de vele adviezen die hij gegeven heeft tijdens de statische bewerkingen van de data. Zonder hem zou ik zeker in het statistische moeras ten onder zijn gegaan.

De laboranten van Chemie 6 onder leiding van Dr. P.C.A. Menheere en Josée Vranken, ben ik zeer erkentelijk voor de arbeidsintensieve bepalingen die ze telkens weer deden, ondanks grote werkdruk vanuit de kliniek.

Bert Meems gaf voorafgaande aan en tijdens de studie vele nuttige methodologische adviezen. Hiervoor wil ik hem hartelijk danken.

De familie Cortenraad heeft mij in meerdere opzichten geholpen. Jo was niet alleen proefpersoon. Bij hem kon ik met allerhande vragen terecht. Leny maakte de tekening die afgebeeld staat op de omslag en René verzorgde de lay-out van het proefschrift. Ik ben hen hiervoor zeer veel dank verschuldigd.

De verpleegkundigen van de afdeling haemodialyse dank ik voor hun interesse en 
voor de gezellige koffiepauzes die tussen de bedrijven door plaatsvonden. Ook de sportieve uitstapjes met Pierre Waterval en Jean Kalders zorgden voor de nodige ontspanning.

Marleen Dresens dank ik voor alle uren die we samen, joggend door het Jekerdal, doorbrachten. Deze uren, waarin Marleen de totstandkoming van dit proefschrift letterlijk op de voet volgde, waren voor mij hoogtepunten van de dag.

Mijn ouders dank ik voor alle mogelijkheden die ze mij geboden hebben.

Erwin dank ik voor alle moeite die hij zich getroost opdat ik in Maastricht kan werken en voor de schaarse maar meer dan plezierige momenten dat we samen thuis zijn. 



\section{Curriculum Vitae}

Petra Dranjer

$28-1-1963$

geboren te Voorburg

$1975-1981$

atheneum-B Huygens Lyceum te Voorburg

$1981-1982$

studie Geneeskunde aan het Rijksuniversitair

Centrum te Antwerpen

$1982-1989$

studie Geneeskunde aan de Rijksuniversiteit te Leiden

$1989-1993$

assistent-in-opleiding aan de Rijksuniversiteit

Limburg (Cardiovascular Research Institute Maastricht, Divisie Hypertensie, begeleider: Dr KML Leunissen)

$1993 \mathrm{ev}$ assistent geneeskundige-in-opleiding tot internist (Academisch Ziekenhuis Maastricht, opleider: Prof Dr JA Flendrig) 